\title{
Operator 4.0 and Cognitive Ergonomics
}

\section{Mohamad Fallaha}

Submitted to the

Institute of Graduate Studies and Research

in partial fulfillment of the requirements for the degree of

\author{
Master of Science \\ in \\ Industrial Engineering
}

Eastern Mediterranean University

December 2019

Gazimağusa, North Cyprus 
Approval of the Institute of Graduate Studies and Research

Prof. Dr. Ali Hakan Ulusoy

Director

I certify that this thesis satisfies all the requirements as a thesis for the degree of Master of Science in Industrial Engineering.

Assoc. Prof. Dr. Gokhan Izbirak

Chair, Department of Industrial

Engineering

We certify that we have read this thesis and that in our opinion it is fully adequate in scope and quality as a thesis for the degree of Master of Science in Industrial Engineering.

Assoc. Prof. Dr. Qasim Zeeshan

Co-Supervisor
Assoc. Prof. Dr. Orhan Korhan

Supervisor

Examining Committee

1. Assoc. Prof. Dr. Huseyin Guden

2. Assoc. Prof. Dr. Orhan Korhan

3. Assoc. Prof. Dr. Qasim Zeeshan

4. Asst. Prof. Dr. Sahand Daneshvar

5. Asst. Prof. Dr. Elif Yel 


\begin{abstract}
With the dawn of industry 4.0 , a paradigm shift must occur where the traditional work environment and manufacturing proclivities must transform into a dynamic cyber-physical systems where humans and machines work together for increased productivity and flexibility. This novel and unique work relationship will require unconventional interactions between operators and machines, which will inevitably necessitate an upgrade from the traditional operator to Operator 4.0 or Smart Operator. Engineers and operators must ameliorate their cognitive skills to adapt to Industry 4.0 working environment. Also, smart operators will be required to obtain certain cognitive skills pertaining to wearable technology, sensors or virtual reality equipment as this equipment enhances cognitive capabilities of the Operator 4.0. This research thesis bestows an analysis of Industry 4.0. And provide an evaluation of the topical state of cognitive ergonomics of Smart Operator or Operator 4.0. Considering the importance of VR applications in manufacturing, this research aims to find the cognitive skills required for Operator 4.0 in future factories. The methodology used in this research is based on a factory simulation in Virtual Reality environment. The simulation is similar to Industry 4.0 factories. Participants' feedback and responses to the given task will help further emphasize how useful can VR in manufacturing be of a help to train future workers. Also, it can assist future designers to avoid any Graphical User Interface (GUI) issues (such as defaults in the 3D simulation as well as the controller software that is used to control the machines) and to improve the quality of such application for a better and more convenient experience.
\end{abstract}


Keywords: Industry 4.0, Operator 4.0, Cognitive Ergonomics, Virtual Reality, Augmented Operator, Cyber-Physical Systems (CPS), Internet of Things (IoT), Big Data, Artificial Intelligence (AI), Smart Factory 


\section{$\ddot{O} \mathbf{Z}$}

Industry 4.0 (I 4.0) doğuşu ile geleneksel iş çevresi ve üretim eğiliminin bir paradigma kayması ile dinamik, siber-fiziksel sistemlere yönelmesini gerekmektedir. Bu sayede insanlar ve makineler üretim ve esnekliğin artması için birlikte çalışmaktadır. Bu yeni ve benzersiz iş ilişkisi, uygulayıcıların ve makinelerin geleneksel olmayan etkileşimine ihtiyaç duyacaktır. $\mathrm{Bu}$ nedenle geleneksel uygulayıcıdan Operator 4.0'a veya Smart Operator 'e yükseliş kaçınılmaz bir ihtiyaçtır. Mühendisler ve uygulayıcılar Industry 4.0'ın iş ortamına ayak uydurmak için bilişsel becerilerini geliştirmelidirler. Ayrıca, Smart Operator'lerin giyilebilen teknoloji, sensörler veya sanal gerçeklik ile ilgili belirli bilişsel becerilere sahip olmaları gerekmektedir. Çünkü bu donanımlar Operator 4.0'in bilişsel işlem kabiliyetini artırmaktadır. Bu araştırma makalesi, Industry 4.0 analizini ve Smart Operator veya Operator 4.0'ın bilişsel ergonomisinin güncel durum değerlendirmesini sunmaktadır. Sanal gerçeklik uygulamalarının üretimdeki önemi düşünüldüğünde bu araştırma gelecekteki fabrikalarda Operator 4.0'ün ihtiyacı olan bilişsel becerileri tespit etmeyi amaçlamaktadır. Bu araştırmada yöntem olarak Sanal Gerçeklik (VR) ortamında bir fabrika simulasyonu kullanılmıştır. Simulasyon, Industry 4.0 fabrikalarına benzerlik göstermektedir. Katılımcıların verilen göreve geri bildirimleri ve cevapları gelecekteki işçileri eğitmede VR'ın ne kadar kullanışlı olduğunu vurgulamaya yardımcı olacaktır. Buna ek olarak, gelecekteki tasarımcılara Grafiksel Kullanıcı Arayüzü (GUI) sorunlarından (örneğin 3D simulasyon hataları ve de makineleri kontrol etmede kullanılan yazılımdaki hatalar) kaçınmada ve daha iyi ve elverişli bir deneyim için böyle bir uygulamanın kalitesini artırmaya yardımcı olabilecektir. 
Anahtar Kelimeler: Industry 4.0, Operator 4.0, Kognitif Ergonomi, Sanal Gerçeklik, Geliştirilmiş Operatör, Siber-Fiziksel Sistemler (CPS), Internet of Things (IoT), Big Data, Yapay Zeka (AI), Akıllı Fabrika 


\section{TABLE OF CONTENTS}

ABSTRACT

1.1 Aim, Research Questions and Objectives ................................................ 3

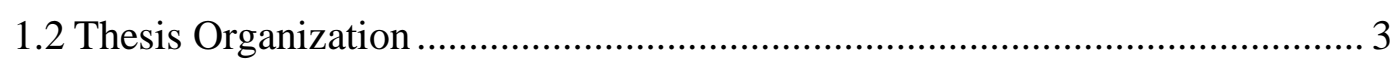

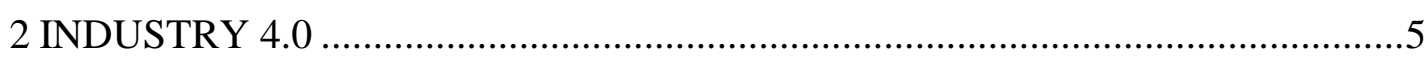

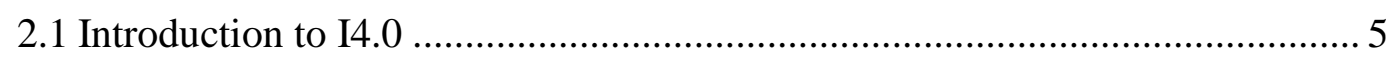

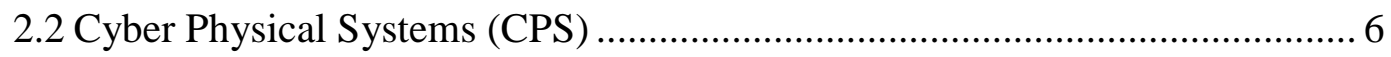

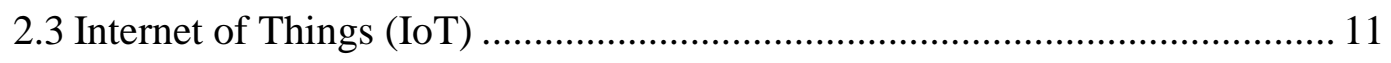

2.3.1 Intelligent Wearable Devices and IoT........................................... 13

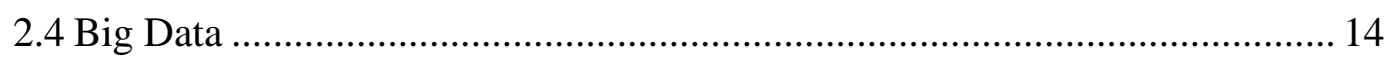

2.4.1 Infrastructures of Big Data Systems ............................................... 14

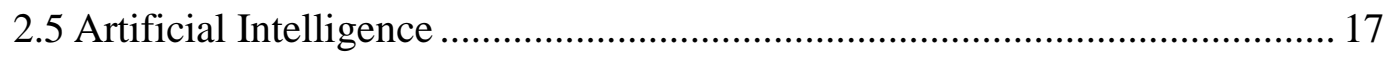

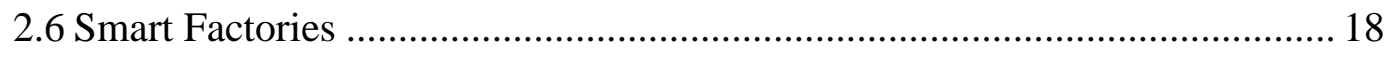

2.6.1 Smart Operators in Smart Factories ................................................. 21

3 HUMAN FACTORS IN THE INDUSTRY ................................................22

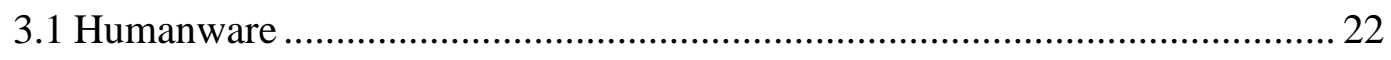

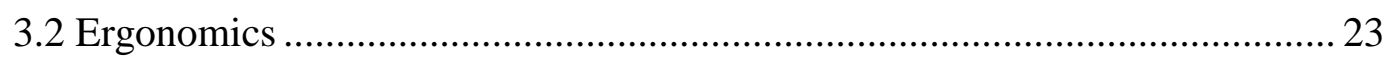

3.2.1 Physical Ergonomics ................................................................ 23

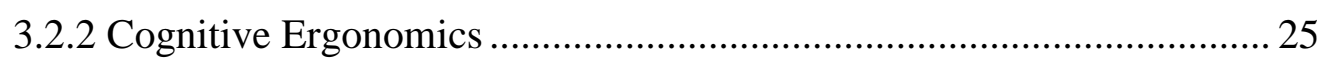

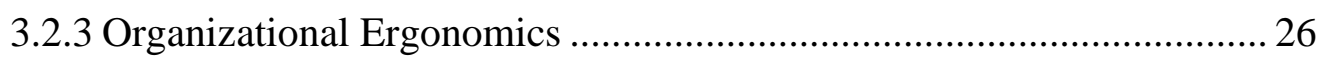


3.3 Physical Workload. 26

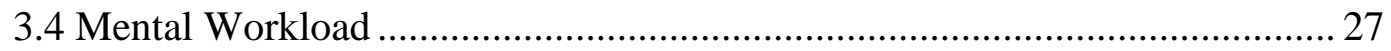

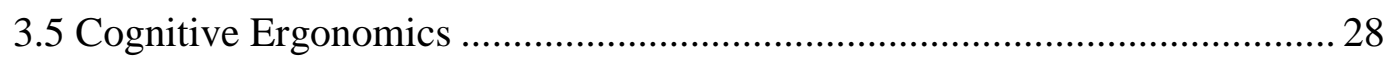

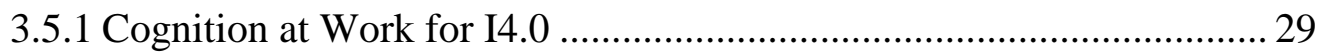

3.5.2 Perception and Attention at Work for I 4.0 ..................................... 29

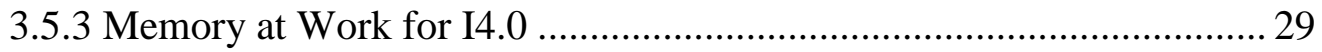

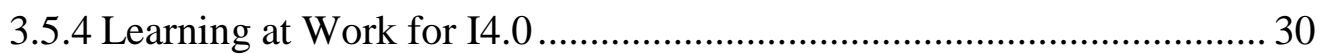

3.5.5 Cognitive Ergonomic Design for Software User Interface................... 30

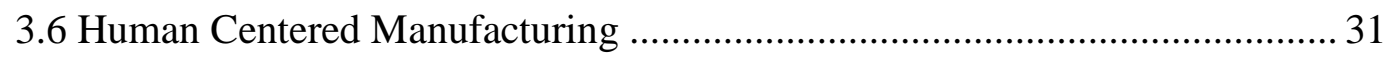

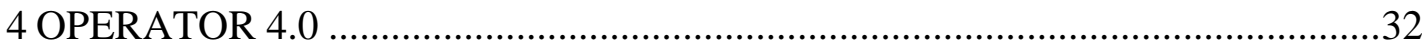

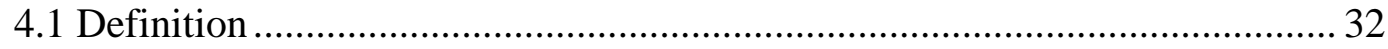

4.2 Operator 4.0 and Cognitive Ergonomics .................................................. 34

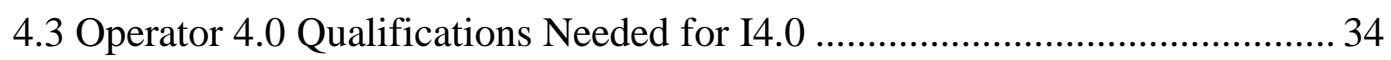

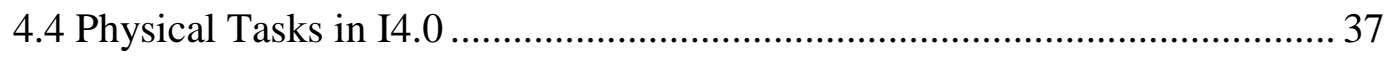

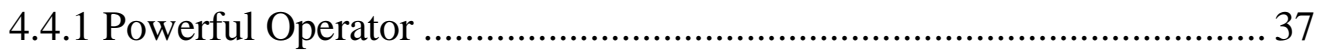

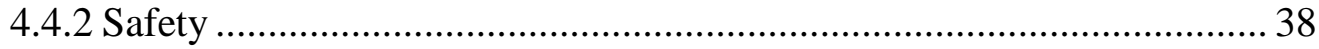

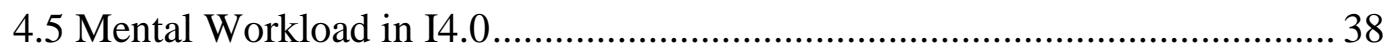

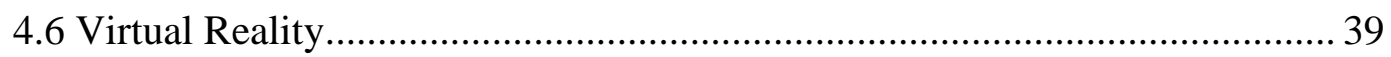

4.6.1 Applications of VR in Manufacturing ........................................... 40

4.6.2 Benefits of VR in the Modern Industrial World ................................ 43

4.6.3 VR/AR and Cognitive Ergonomics ................................................... 44

4.6.4 Cognitive Requirements for VR/AR Technologies ............................ 46

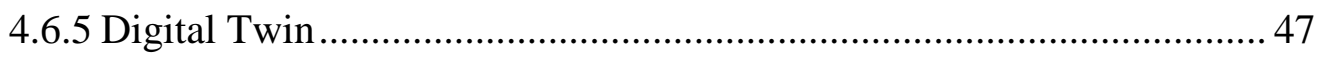

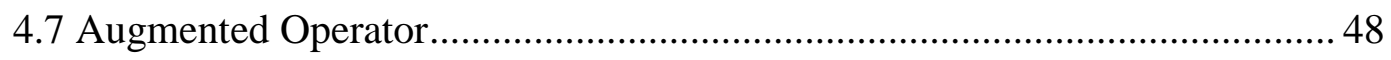

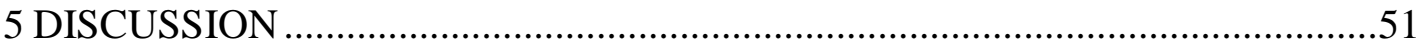


5.1 Design

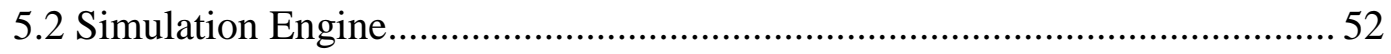

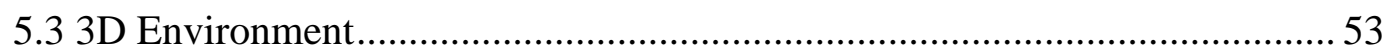

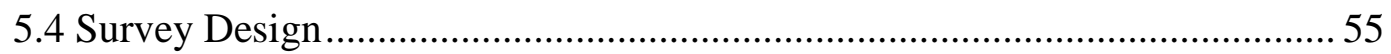

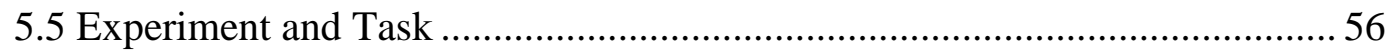

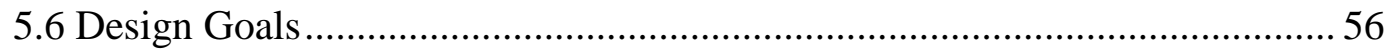

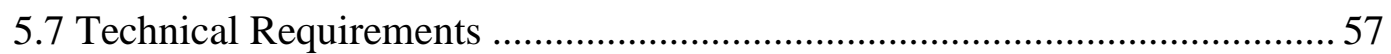

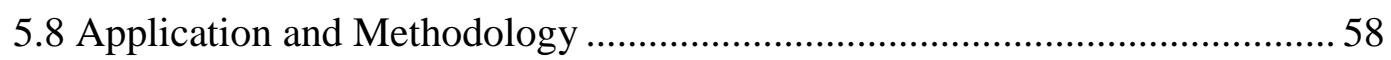

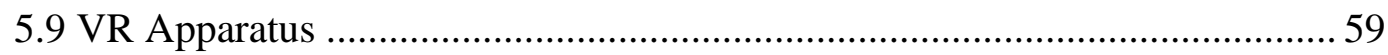

5.10 Components of HTC Vive VR System ..................................................... 59

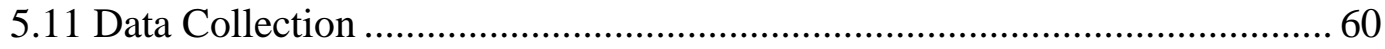

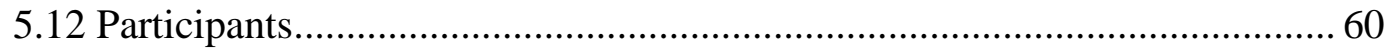

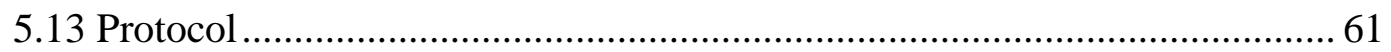

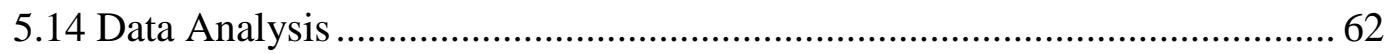

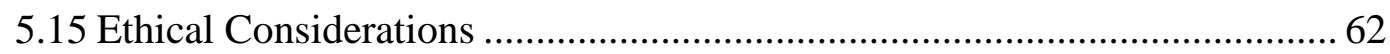

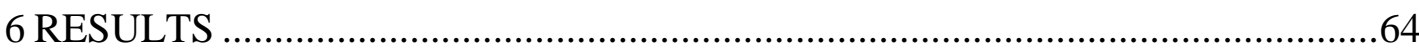

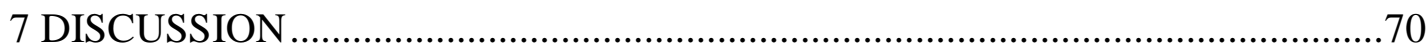

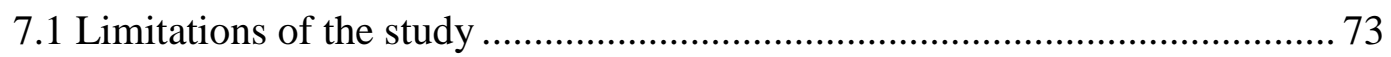

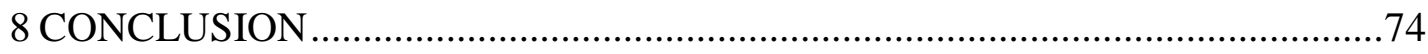

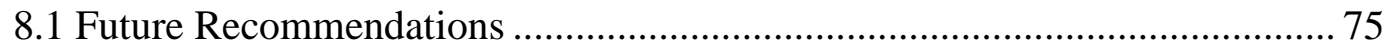

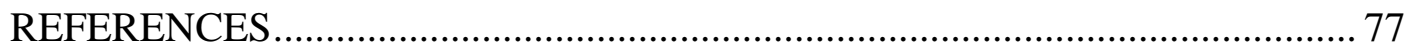

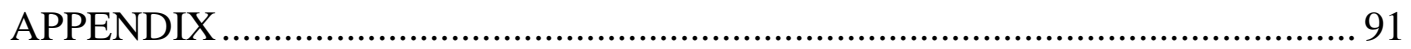




\section{LIST OF TABLES}

Table 1: Main differences between I3.0 and I4.0. Adapted from Terziyan, Gryshko,

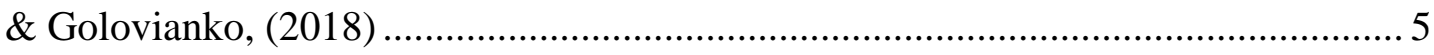

Table 2: Latest developments on Cyber-Physical Systems...................................... 10

Table 3: Technical features comparison of smart and traditional factories. .............. 20

Table 4: 10 main principles of physical ergonomics. Adapted from Macleod, (2008)

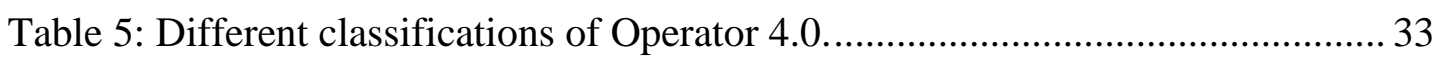

Table 6: Production related operator figuration....................................................... 35

Table 7: Information Technology related operator figuration. ................................ 36

Table 8: Current applications of VR/AR technologies. Adapted from Heinonen,

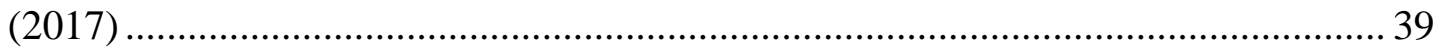

Table 9: VR applications in manufacturing systems .......................................... 40

Table 10: Main tasks of Virtual Manufacturing technique. adapted from Dépincé et

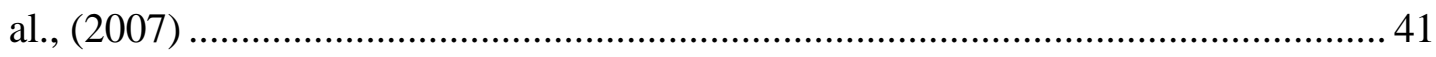

Table 11: Attention and cognitive abilities. ............................................................ 46

Table 12: Cognitive skills required by Operator 4.0 within VR ............................. 47

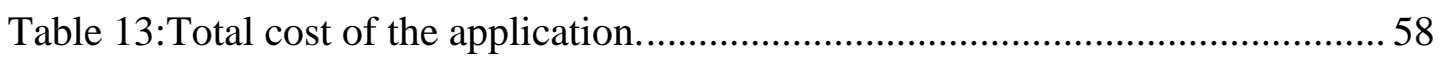

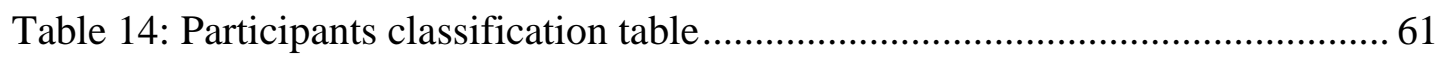




\section{LIST OF FIGURES}

Figure 1: 5C Architecture in Industry 4.0. Adapted fromLongo, Nicoletti, \&

Padovano, (2017) 2

Figure 2: Cyber-Physical Production System. Adapted from Peres, Dionisio Rocha, Leitao, \& Barata, (2018) 9

Figure 3: Social media IoT communication system. Adapted from Li et al., (2018) 14

Figure 4: Connection structure between CPS and Big Data in I4. Adapted from L. D.

Xu \& Duan, (2018) 16

Figure 5: Present CPS research in I4.0. Adapted from L. D. Xu \& Duan, (2018).... 17

Figure 6: Smart factory system design. Adapted from Terziyan et al., (2018) 19

Figure 7: Human-cantered design and Cognitive Ergonomics. Adapted from Customerinnovations.com, (2018) 26

Figure 8: Industrial revolutions and operators' role. Adapted from Zolotová, Papcun, Kajáti, Miškuf, \& Mocnej, (2018) 32

Figure 9: Adoption of AR technology in manufacturing industry. Adapted from PWC, (2015) 42

Figure 10: Adoption of VR technology in manufacturing industry. Adapted from PWC, (2015) .43

Figure 11: Main applications of VR/AR technologies in industry 44

Figure 12: How VR/AR works. Adapted from Matsas \& Vosniakos, (2017) 45

Figure 13: VR modeling inside Unity engine. Adapted from Medium.com, (2019). 53

Figure 14: Game4automation 3D simulation 54

Figure 15: Virtual Reality simulation 54

Figure 16: Unplanned change in Virtual Reality simulation 55 
Figure 17: Computer system requirement by HTC Vive VR kit. Adapted from Vive.com, (2019)

Figure 18: MSI high performance computer system. Adapted from Msi.com, (2018)

Figure 19: HTC Vive VR Kit. Adapted from Bhphotovideo.com, (2018) 60

Figure 20: RQ 1 results 64

Figure 21: RQ 2 results 65

Figure 22: RQ 3 results 66

Figure 23: RQ 4 results 66

Figure 24: RQ 5 results 67

Figure 25: Survey results for ,a) RQ 6, b) RQ7 68

Figure 26: Survey results for, a) RQ 8, b) RQ 9 69

Figure 27: Unplanned changes and stress analysis .71

Figure 28: Age analysis for participants above 25 years old 71

Figure 29: Age analysis for participants below or equal to 25 years old 72 


\section{Chapter 1}

\section{INTRODUCTION}

The aim of I4.0 concept is to integrate lots of consumers' daily life aspects to the elements of value chain process where this integration leads to one sole system Kinzel, (2017). I4.0 permits new ways of cooperation amongst software systems, machines, and humans. This phenomenon is called the Industrial Internet of Things, Services and People (IoTSP) . Improvement such as data analysis, operation optimization, raise productivity, boost accuracy, conserve energy, and produce lots of e-services for future factories can be achieved by the interconnection of things, services and people via the Internet Romero, Wuest, Stahre, \& Gorecky, (2017). All these tasks are done without depending on human assistance whereas human tasks will be limited to communicating with the machines instead of operating them.

The main elements of industry 4.0 are:

- Cyber-Physical Systems (CPS)

- Internet of Things (IoT)

- Big Data

- Artificial Intelligence (AI)

- Intelligent Factories 


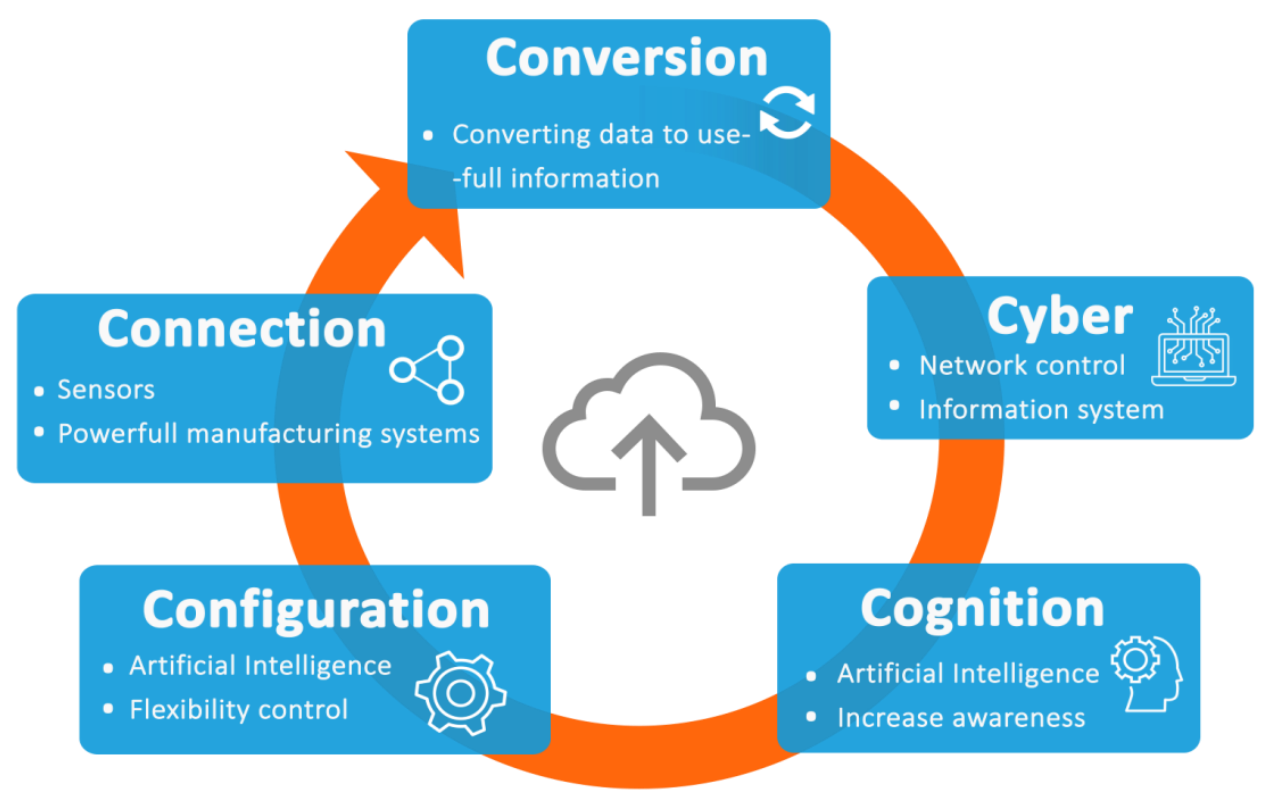

Figure 1: 5C Architecture in Industry 4.0. Adapted fromLongo, Nicoletti, \& Padovano, (2017)

The fourth industrial revolution requires lots of technological improvement and development, therefore, operators and engineers will have to upgrade their level of cognitive skills to suite the Industry 4.0 needs such as being able to process a lot of information and taking right actions. This review paper, will discuss what research have been done about the applications of cognitive ergonomics in Industry 4.0.

A manufacturing engineer can reduce needless mental workload to support operators do the job duties with better efficiency and less faults and misinterpretations only by having basic awareness of the principles of righteous cognitive design. Kaasinen et al., (2019)Illustrating what kind of human capacities and restrictions of data analysis is considered a practical aim of cognitive ergonomics in a way such that working environment, safety, operator behaviors are developed to make sure that all stresses and working loads are set aside Bligård and Osvalder, (2014). 


\subsection{Aim, Research Questions and Objectives}

The aim of this research is to look into different methods used to assist the future Operator 4.0 with his tasks in the smart factory. Furthermore, this thesis aims suggest ways to improve cognitive ergonomics skills for future workers.

To achieve this, the following three research questions must be answered:

- Research question 1: What are the required skills for Operator 4.0?

- Research question 2: How can virtual reality in manufacturing help future workers to adapt in working within a smart factory?

- Research question 3: What are the improvements that can be made to further improve the current available I4.0 methods?

The objective of research question 1 is to emphasize and classify the specific skills required for Operator 4.0 for their specific tasks. Also, identifying the cognitive ergonomics skills required for Operator 4.0.

The objective of research question 2 is to address the different Virtual Reality applications in manufacturing. Lastly, the objective of research question 3 is to suggest ways to further improve Operator 4.0 wellbeing.

\subsection{Thesis Organization}

- Industry 4.0: provides an introduction on the latest developments of I4.0 with relation to CPS, IoT, Big Data, Artificial Intelligence and Smart Factory.

- Human factors in Industry:discusses the main roles of workers in future factories and emphasizes the main required skills by Operator 4.0

- Operator 4.0: describes different methods used to assist Operator 4.0 to do his tasks. It also classifies the main skills and cognitive ergonomics skills required for Operator 4.0. 
- Design and methodology: presents the method of the research and the design process of the experiment and the survey questions. It also data collection method and ethical protocols.

- Results: states the results of the 9 survey questions.

- Discussion: discusses the results of the collected data.

- Conclusion 


\section{Chapter 2}

\section{INDUSTRY 4.0}

\subsection{Introduction to I4.0}

The expression of Industry 4.0 (or the Fourth Industrial Revolution) is related to development and improvement of the management of industrial and manufacturing facilities. The first Industrial revolution was in 1748 and was referred to as Industry 1.0, where mechanical production machines were introduced. In the beginnings of the 20th century, assembly lines were integrated in manufacturing processes and right after that in the late 20th century computer controlled production had big impact to the manufacturing industry Kinzel, (2017). Nonetheless, the expression Industry 4.0 was firstly deployed in Germany in 2011, where people representing various sections like business, legislative issues, and academics were trying to improve the industrial factories in Germany to be more competitive in the international manufacturing world with regards to improving the production time Epicor, (2019).

Table 1: Main differences between I3.0 and I4.0. Adapted from Terziyan, Gryshko, \& Golovianko, (2018)

\begin{tabular}{|l|l|l|}
\hline Feature & I3.0 & $\mathbf{I 4 . 0}$ \\
\hline Architecture & Paramedical system & $\begin{array}{l}\text { Dynamic and flexible } \\
\text { services }\end{array}$ \\
\hline Processes shape & Waterfall focused & Smart factory \\
\hline $\begin{array}{l}\text { Manufacturing } \\
\text { Technique }\end{array}$ & Automated & Virtual \\
\hline Support of & Layered automation (5 Layers & Smart manufacturing \\
\hline
\end{tabular}




\begin{tabular}{|l|l|l|}
\hline operations & architecture) & $\begin{array}{l}\text { (Artificial Intelligence, } \\
\text { Cyber-Physical systems, } \\
\text { Internet of Things, Bid } \\
\text { Data) }\end{array}$ \\
\hline $\begin{array}{l}\text { Collaboration } \\
\text { type }\end{array}$ & Operator-task & Consumer-Services \\
\hline Decisions & Operator \& Automatic system & $\begin{array}{l}\text { Operator \& Smart agents \& } \\
\text { CPS }\end{array}$ \\
\hline
\end{tabular}

\subsection{Cyber Physical Systems (CPS)}

Based on Muhuri, Shukla, \& Abraham, (2019), CPS is the main element of Industry 4.0, the element which was being developed since the 18th century by combining different technologies of communication, electrical and mechanical areas and kept on upgrading to suit the modern technologies like real time computation, networking, security and more which gives this system an importance and makes it point of interest for governments, industry and academics. To understand how CPS affects the fourth industrial revolution, a collection of articles related to this I4.0 element are reviewed. Monostori et al., (2016) agrees that CPS uses a random way of communication with discrete dynamics of computing systems and continuous dynamics of control systems. Thereby, dynamics of Cyber-Physical Systems can be complicated.

CPS is essential to systems related with medicine, energy, transportation, industry and manufacturing with the high incorporation of communicating, controlling and computing technologies.

There is still lots of research that has to be made to classify the complexity and productivity matters for the development of the design of CPS especially when focusing on the latest developments of networked control, hybrid systems, real-time 
computing, real-time networking, wireless sensor networks, security, and modeldriven improvement.

Unneeded complexity issues related to CPSs like heterogeneity and division can be abstracted by software platforms that has well defined and suitable levels of elimination and architecture. They are the key element to develop effective CPSs for different applications Kyoung-Dae \& Kumar, (2012).

The manufacturing science and technology community has opened a smooth way for CPS and CPPS to be part of the $4^{\text {th }}$ industrial revolution. Nonetheless, still, there is a considerable need for more activities to be made along with some studies of the socio-ethical sides of both CPS and CPPS Monostori et al., (2016).Combining the necessary technologies with Multi-agent systems (MAS) andservicefocusedarchitectures (SOAs) might have an effect on CPSs related to modern smart factories Leitao et al., (2016).

Decision making is essential in Industry 4.0 and using the old methods to make decisions is not enough. A strategic method is used for decision making as the technological development is heading towards achieving the fourth industrial engineering the researches are suggesting that since big companies utilize a method of triple bottom-line structure for making big decisions on a high level (e.g. setting a new production plan and altering strategies) where those bottom-lines are concentrating on three different factors (economic, social and circumferential performance), similar structure should be integrated within middle and low decision levels. The suggested structure was applied to a developing CPS. As a result of applying the system on a high level automated plant and the success of the application of this system is still not proved. However, such application has showed the relation the possibility to apply the structure for circumferential effects, valuation 
and prognosis. Sénéchal \& Trentesaux, (2019). Checking the availability and activeness of CPS and the efficiency of cost and processes is done through robustness and intelligence L. D. Xu \& Duan, (2018). Along with that, the Internet of Things comes with a big functionality of transferring data whenever needed. This property allows collecting all required data throughout product lifecycle where the collection of data can be used by machine learning systems to improve products and avoid mistakes. Different methodologies are used to collect information and data about the influence and human usage of products and uses collected data to improve product. Product Embedded Information Devices similar to radiofrequency identification (RFID) and global positioning system (GPS) are used to collect user data to investigate potential product improvement. Such approaches will facilitate the supervision of product performance for designers and manufacturers so quality can be improved on a continuous bases. This concept is beginning of self optimizing products. Voet, Altenhof, Ellerich, Schmitt, \& Linke, (2019). Big Data systems are used for data collecting, storage, retrieval, computing and analyzing. The research about the infrastructure of big data systems have great interest. However, the data analysis aspect had less concern had less concern in general and in order to suit the needs for CPSs more research on in this area is required. L. D. Xu \& Duan, (2018). Although the it is necessary to achieve Industry 4.0 to fulfill high customers service level and higher production rates to fulfill market demands, the human role in this industrial revolution will have as much impact as Artificial intelligence on the modern manufacturing techniques where there is the slight difference between human intelligence and artificial intelligence and how both can be easily operating against each other leading us back rather than forward. The advanced development of technologies and systems like artificial intelligence, big data and digital 
communication might have distracted the employment human intelligence. Therefore, the cooperation between new production and automated technologies must be in parallel with human intelligence as demonstrated in figure 2 that overcomes AI with its human worth of sympathy, human responsibility and caring Özdemir, (2019).

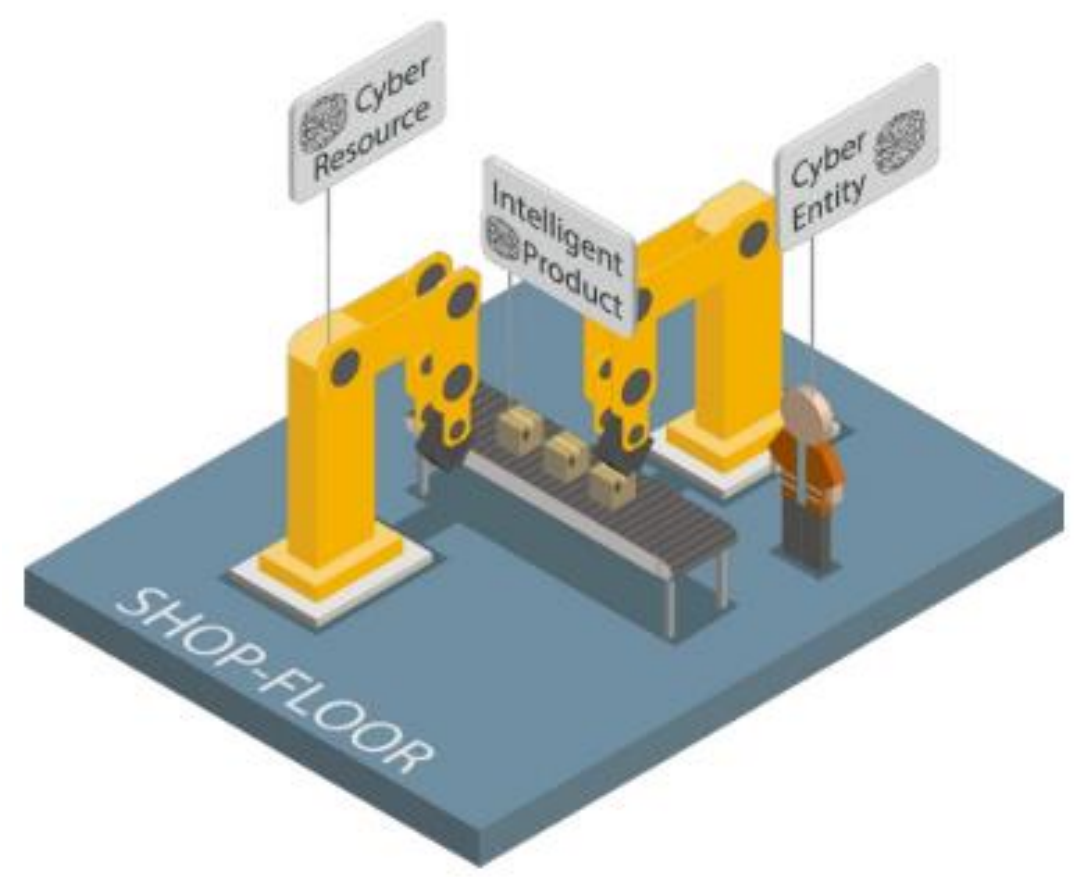

Figure 2: Cyber-Physical Production System. Adapted from Peres, Dionisio Rocha, Leitao, \& Barata, (2018)

The maintenance of CPSs for I4.0 is as important as the development of it. A study shows how much maintenance of different facilities have made a big effect on the efficiency of manufacturing and production systems and industry 4.0 systems are no different and they require as much maintenance. 
Table 2: Latest developments on Cyber-Physical Systems

\begin{tabular}{|c|c|c|}
\hline Reference & Method/s Applied & Contribution \\
\hline $\begin{array}{l}\text { (Kyoung-Dae\& } \\
\text { Kumar, 2012) }\end{array}$ & $\begin{array}{l}\text { - Mediate network between } \\
\text { computer and physical systems. } \\
\text { (NCS) } \\
\text { - Hybrid Systems for switching } \\
\text { between different operational } \\
\text { modes and Real-Time } \\
\text { Scheduling Theory. }\end{array}$ & $\begin{array}{l}\text { Needless complexity issues } \\
\text { can be reduced. }\end{array}$ \\
\hline $\begin{array}{l}\text { Leitao et al., } \\
\text { (2016) }\end{array}$ & $\begin{array}{l}\text { - Multi-agent systems } \\
\text { - Intelligent Data Analysis and } \\
\text { Real-Time Supervision } \\
\text { (IDARTS) }\end{array}$ & $\begin{array}{l}\text { Investing data through } \\
\text { merging Cyber Physical } \\
\text { System and cloud } \\
\text { computing. } \\
\text { Integration of a Cyber- } \\
\text { Physical System with cloud } \\
\text { computing. }\end{array}$ \\
\hline $\begin{array}{l}\text { Sénéchal \& } \\
\text { Trentesaux, } \\
(2019)\end{array}$ & $\begin{array}{l}\text { - Triple bottom-line structure } \\
\text { - Sustainable Condition-Based } \\
\text { Maintenance (SCBM) } \\
\text { - Remaining Sustainable Life } \\
\text { (RSL) } \\
\text { - Conditions Based } \\
\text { Maintenance (CBM) }\end{array}$ & $\begin{array}{l}\text { Methods for evaluating } \\
\text { prognosis and } \\
\text { environmental impact } \\
\text { assessment } \\
\text { Results were not proved. }\end{array}$ \\
\hline $\begin{array}{l}\text { L. D. Xu \& Duan, } \\
\text { (2018) }\end{array}$ & $\begin{array}{l}\text { Analytical role of Big Data and } \\
\text { the interaction with Big Data } \\
\text { and CPS (Survey) }\end{array}$ & $\begin{array}{l}\text { Lack of interaction with } \\
\text { cyber physical system } \\
\text { aspect and big data while } \\
\text { there are few surveys on } \\
\text { each aspect separately. }\end{array}$ \\
\hline $\begin{array}{l}\text { (Voet, Altenhof, } \\
\text { Ellerich, Schmitt, } \\
\text { \&Linke, 2019) }\end{array}$ & $\begin{array}{l}\text { product-embedded identification } \\
\text { devices (PEID) } \\
\text { Framework structure: } \\
\text { - Knowledge collection } \\
\text { - Usage characterization } \\
\text { - Knowledge discovery in } \\
\text { usage profiles }\end{array}$ & $\begin{array}{l}\text { Facilitate the supervision of } \\
\text { product performance for } \\
\text { designers and manufacturers } \\
\text { for continuous quality } \\
\text { improvement. } \\
\text { Self optimizing products } \\
\text { beginning. }\end{array}$ \\
\hline (Ozdemir, 2019) & $\begin{array}{l}\text { Artificial Intelligence and } \\
\text { Human Intelligence (Survey) }\end{array}$ & $\begin{array}{l}\text { Systems like artificial } \\
\text { intelligence, big data and } \\
\text { digital communication } \\
\text { distracted the employment } \\
\text { of human intelligence. }\end{array}$ \\
\hline $\begin{array}{l}\text { (Romero et al., } \\
\text { 2016) }\end{array}$ & $\begin{array}{l}\text { The maintenance of CPSs } \\
\text { through: Augmented Reality }\end{array}$ & $\begin{array}{l}\text { Time efficient, economic } \\
\text { and reliable. }\end{array}$ \\
\hline
\end{tabular}




\subsection{Internet of Things (IoT)}

The expression, Internet of Things (IoT) was presented by, Kevin Ashton, in 1999, while presenting for Procter and Gaamble. Afterwards, Internet of Things has become a standard in the area of wireless communication. An assortment of ordinary components, things and articles, for example, Radiofrequency Identification (RFID) labels, sensors, actuators, cell phones and numerous other cell phones, are broadened around by the idea IoTAlam, Saini, \& El Saddik, (2015). These assortments are ready to connect each to other and can be controlled by the internet Gubbi, Buyya, Marusic, \& Palaniswami, (2013) and are recognizable, reachable and lucid through different addressing patterns. IoT is predicted by few reports, as one of the technologies of higher effect until 2025 Molano, Lovelle, Montenegro, Granados, \& Crespo, (2018) as it has come to so much advancement and significance.

The Internet of Things (IoT), in light of the association between physical things and the Internet, is a developing term that consolidates various innovations and methodologies. According toKopetz, (2011), due to the connection with Internet and PCs, major technology developments were made in the course of the most recent decades. In this manner, the intelligent object is the of an IoT vision, since this new worldview comprise in providing regular items with knowledge, permitting them not to exclusively gather data and collaborate with their surroundings, yet in addition to be interconnected with different objects, trading information and activating activities through the Internet Pereira \& Romero, (2017).

In numerous framework areas like intelligent cities, and intelligent buildingsand homes, the Internet of Things has additionally been created. IoT is utilized to move forward thecharacteristics of buildings and decrease waste, in smart buildings, The term Smart Cities is consideredas a cyber-physical ecosystem with astute sensors and 
unfamiliar services across the city .In China, a new project was established "Sensing China", this project for instance, was started in June 2010. It was foreseen that everything would have a distinguishing identity tag that could communicate the data to Internet, after the completion of the project. Individuals could follow the usage of the things and screen any factors or items; the gathered information can be used to diminish wastes and costs Fielding \& Taylor, (2002). The fruitful results of applying IoT in a network as well as a city can be predicted. Li, $\mathrm{Da} \mathrm{Xu,} \mathrm{\&} \mathrm{Zhao,} \mathrm{(2018).}$

The expansion of IoT will give a few opportunities to clients, manufacturers and organizations, in industrial conditions and value chains. This will have an incredible effect in a few fields, for example, robotization, industrial assembling, logistics, business processes, process management and transportation Miorandi, Sicari, De Pellegrini, \& Chlamtac, (2012). Industrial Internet of Things (IIoT) is a term which is acquainted to explaindifferent possible applications of IoT withinindustry. The utilization of problematic innovation, for example, sensors, actuators, control frameworks, machinetomachine (M2M), data analysis, and security systems, have been inferred by Industrial Internet of Things (IIoT) to improve current industrial systems. Pereira \& Romero, (2017). New limits and numerous applications are developing, because of The Internet of Things, inside three primary pillars as follows:

- Process optimizattion

- Optimized source utilization (Consumption)

- Making of complex autonomous systems

The further improvement and propagation of IoT systems will permit the establishment of included added-value products and services by enabling things to 
end up more astute, increasingly reliable and progressively self-governing, Kyriazis \& Varvarigou, (2013).

Industry 4.0 is also referred to as Industrial Internet of Things IIoT and it is the combination of manufacturing and production with IoT. With the physical world of sensors, progressivelyexpanding the pace of businesses and exponentially improving the industry in general, Industrial Internet of Things (IIoT) is interfacing machines with each other to achieve the M2M connection. It's the network of sensors, gadgets and machines by means of the Internet. Through the arrangement of software services and its independent control in the cloud, It incorporates the association of industrialnetworksandservice systems to various information storing frameworks. The ascent in the usage of sensors, progressed information examination and decision making is causing dramatic impacts to the global world. Molano et al., (2018).

\subsubsection{Intelligent Wearable Devices and IoT}

A portion of the IoTSP model, a few smart wearable arrangements, have been intended for an assortment of purposes to be woreon a range of different human body parts, for example, head, eyes, wrist, midriff, hands, fingers, legs, or installed into various components of clothing. Perera, Liu, \& Jayawardena, (2015) so as to techaugment user physical, sensorial and mental capacities. Thus, an assorted variety of 'things' has been combined with sensors, actuators, software and network connectivity so as to enlarge their abilities. Such is the situation of intelligent machines, presently equipped for working as self-governing (intelligence), stay away from and the correct way of processing errors and blunders (security), learn and envision future occasions (management), and associate with different machines and frameworks (connectivity) Romero et al., (2017). 


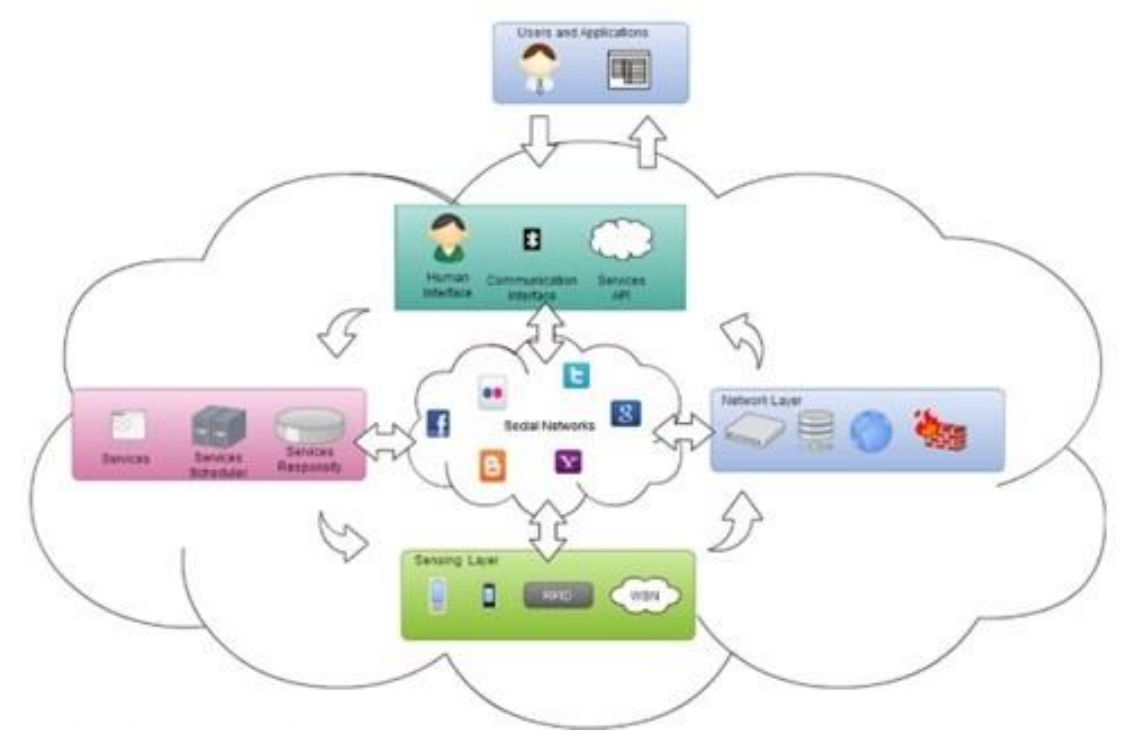

Figure 3: Social media IoT communication system. Adapted from Li et al., (2018)

\subsection{Big Data}

There exists a contiguous correlation between CPS and Big Data. This is evident in processes where cyber-physical systems consistently accumulate large amounts of data that is being organized and managed with the help of big data techniques with the sole aim of enhancing system efficiency, security, and scalability. Usually, the proper management of big data issued by the CPS in Industry 4.0 occurs due to two main functional constituents which are data analytics and system infrastructure as is depicted in Figure 4 and 5. The main function of data analytics is to ameliorate resource effectiveness and product personalization while the system foundations manage real time link between cyber instruments and facilities through a strong connectivity L. D. Xu \& Duan, (2018).

\subsubsection{Infrastructures of Big Data Systems}

L. D. Xu \& Duan, (2018)stated that the Big Data systems and most pertinent infrastructures encompassed the following: 
- Data capture: The first step of any data analysis process is to catch and storeprecise and dependable information.

- Data storage and retrieval: the three most used and advanced database systems equipped to handle data are MongoDB, Cassandra and data warehouse.

- Distributed computing: An enormous collection of data is congregated in a building that is fully equipped with computers that are provided withfast local area network (LAN) .

- According to Delen \& Demirkan, (2013) data analytical processes vary greatly and can fit into three sections: descriptive analytics, predictive analytics, and prescriptive analytics.

- Descriptive analytics: Descriptive statistical functions: s median and variance are the most commonly used descriptive analytical processes.

- Correlation analysis: here we have two categories: effectiveness direction and efficiency direction.

- Clustering: This pertains to groups holding similar records. The cluster can consist of a group of similar companies operating in the same area or a group of customers with similar likings.

- According to Jałowiecki, Kłusek, \& Skarka, (2017) a generative model describes the rules needed to generate data. İn case the described rules are similar to those in nature, the data accumulated by the described set of rules will be similar to the observed data.

- Predictive analytics: Predictive analytics is the opposite of descriptive-analytic as its main goal is to describe past occurrences. Predictive analytics utilizes past experiences to predict future happenings assuming that they will occur similarly. 
- Prescriptive analytics: This is also a method to predict occurrences that might take place in the future using the past as an example for the future. For example, using prescriptive analysis to calculate future demand of current products.

\section{Big Data of Cyber-Physical System}

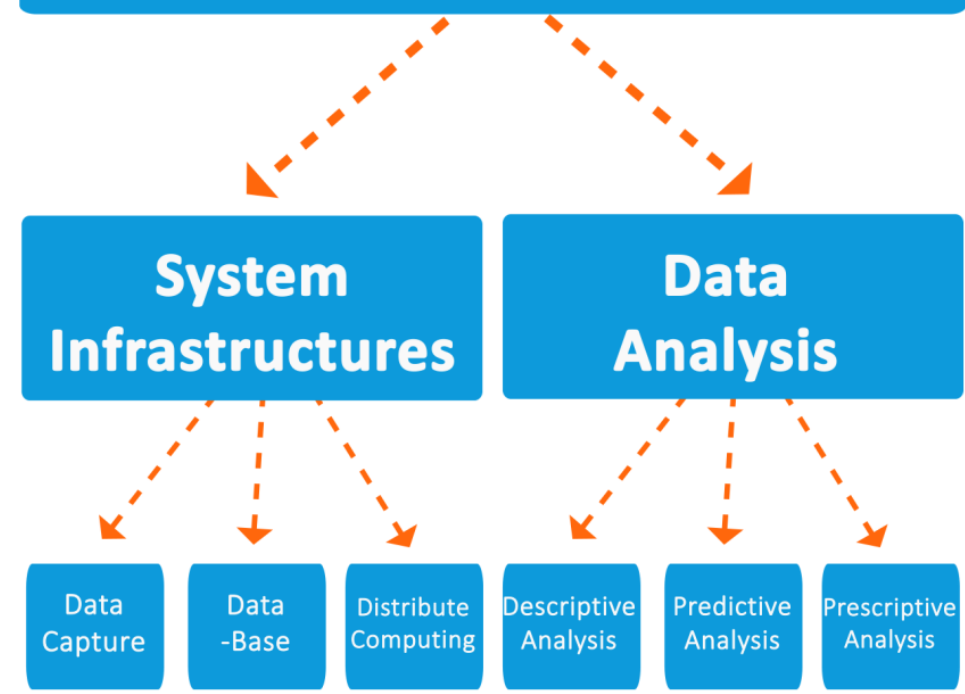

Figure 4: Connection structure between CPS and Big Data in I4. Adapted from L. D. Xu \& Duan, (2018)

Besides the frequently asked research questions on the ability of system foundations to gather and store a large amount of data, L. D. Xu \& Duan, (2018) claims that some interesting requirements for CPS systems exist. These requirements are all connected to reliability resiliency and security matters. Due to the strong relationships within CPS, the whole system might fail if one element fails. This, of course, is a constant challenge to its most prominent aim of reliability, resiliency, and security. During their research, Fawzi, Tabuada, \& Diggavi, (2014)discovered and studied a safe control loop specifically intended to aid in the reconstruction of a system by utilizing the modulo principle method to predict the status of a dynamical CPS from attacks. This could be a set-theoretic control framework on the 
communication channels to guard against False Data Injection attacks introduced and suggested by Lucia, Sinopoli, \& Franze, (2016).

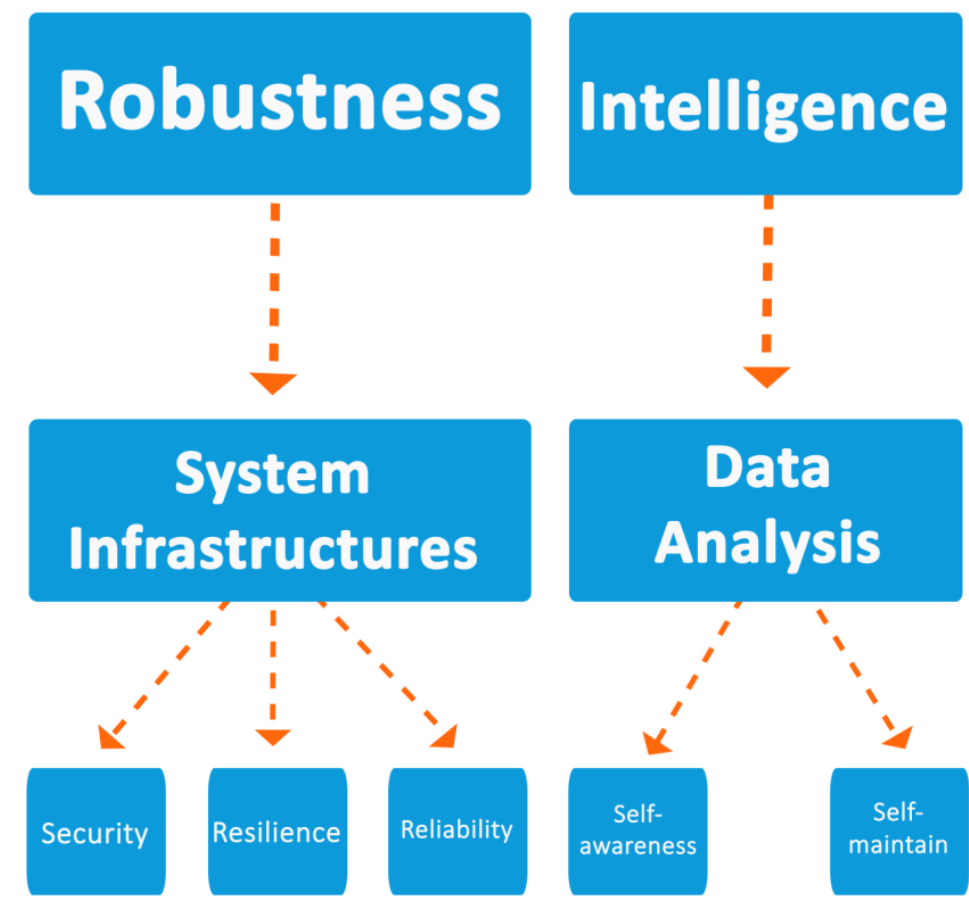

Figure 5: Present CPS research in I4.0. Adapted from L. D. Xu \& Duan, (2018)

For the CPS to function at its best, it is expected that Big data techniques will be implemented as they are crucial to this matter. Nonetheless, restrictions on the current research are also a fact because this is still the preliminary stage of Industry 4.0 L. D. Xu \& Duan, (2018).

\subsection{Artificial Intelligence}

According to Terziyan et al., (2018), Industry 4.0 will entail Artificial Intelligence that will be incorporated into different aspects of the planning, production, and management processes. This warrants important real-time decisions and responsibilities in various cases. 


\subsection{Smart Factories}

Shen, Hao, Yoon, \& Norrie, (2006)states that several enhanced industrialplans are suggested before the smart manufacturing of Industry 4.0. Among the proposed plans was the multi-agent system (MAS) which is also the most representative. However, the MAS is not able to handle the intricacies of manufacturing systems, thus it still cannot be fully implemented in the manufacturing system Wang, Wan, Li, \& Zhang, (2016). Due to this, Wang et al., (2016)suggested anintelligentfactory framework capable of integrating cloud, terminals and industrial wireless network IWN, with the smart shop floor devices including machines, conveyors and products fitting to support the smart factory.

The most crucial constituent of the smart factory is the cooperation between humans with robots and robots with robots. The early versions of the robots were very specific in their decision-making and solely focused on their task, Terziyan et al., (2018). According to Alami, (2013), robots must have clear built-in reasoning tools that enable them to see humans as a potential collaborator in different industrial processes. Nonetheless, the prominent focus of research in this field is on physical human robot interactions, such as human aware navigation and motion Ramírez, Khambhaita, Chatila, Chetouani, \& Alami, (2016). Terziyan et al., (2018)believes that cognitive aspects of Human Robot Collaboration (HRC) are extremely important. He argues that in certain contexts robots must understand and mirror human cognitive behaviour. Behaviours such as decision-making, learning, and reasoning are some of the most important. Lemaignan, Warnier, Sisbot, Clodic, \& Alami, (2017)recognize the strides that have been made in the field of human-like behavioural modelling and human-aware decision-making. Pleskac, Dougherty, Busemeyer, Rieskamp, \& Tenenbaum, (2007)argue that modern robots should have 
cognitive abilities that are similar to that of the human mind, along with cooperation abilities. Terziyan et al., (2018)suggest that the industry adopts a Pi-Mind concept that responds well to the most crucial requirements of the Industry 4.0 which can be observed from figure 6 . This concept will ensure that the frequent vision and understanding of industry gets conveyed into a particular technology with its industrial application. Yet, Pi-Mind cannot be used in the industry, unless this new technology received a proper place and role in the industry's value chain.

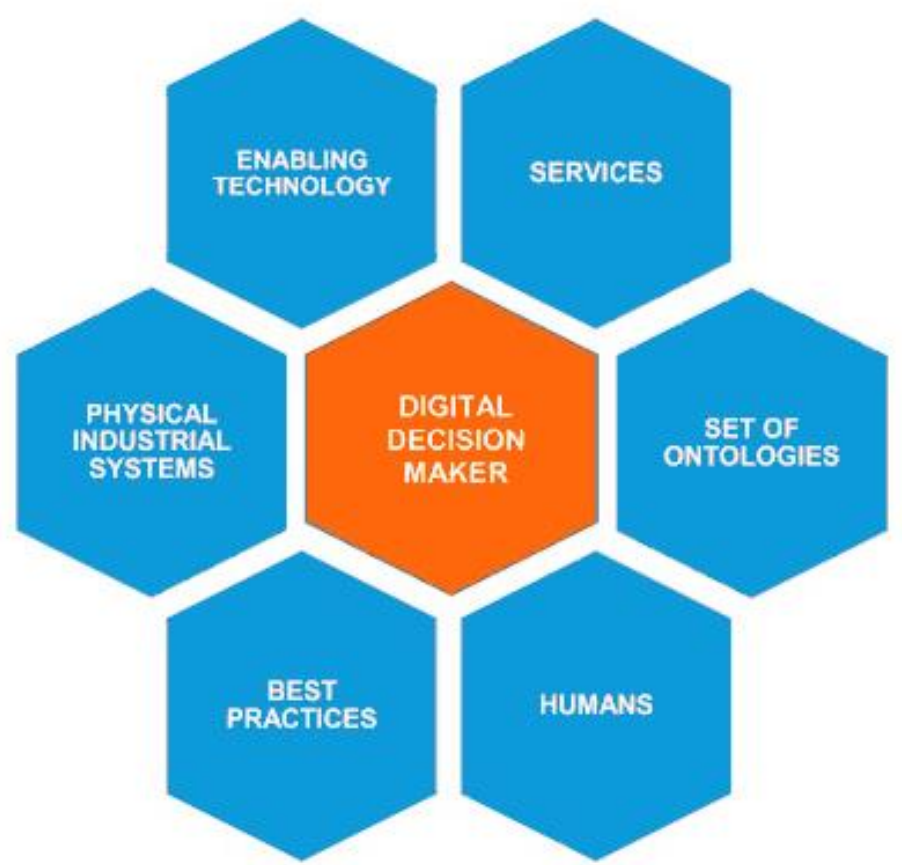

Figure 6: Smart factory system design. Adapted from Terziyan et al., (2018)

Roda-Sanchez, Garrido-Hidalgo, Hortelano, Olivares, \& Ruiz, (2018), introduced a Bluetooth Low Energy (BLE) wearable proposal called OperaBLE with the sole goal to create better working environment and competency in Industry 4.0 workplace. OperaBLE consists of two original algorithms programmed to focus on power awareness as it is the most eminent aspect to reach success. Table 3 displays 
the main differences in Technical attributes of a smart factory compared to that of a traditional factory Wang et al., (2016).

Table 3: Technical features comparison of smart and traditional factories.

\begin{tabular}{|l|l|l|}
\hline Feature & Smart production line & Conventional production line \\
\hline Resources & $\begin{array}{l}\text { Various resources: Extra } \\
\text { resources for different kinds } \\
\text { have to exist in the system to } \\
\text { make several types of } \\
\text { product. }\end{array}$ & $\begin{array}{l}\text { Limited prearranged resources: } \\
\text { Resources are planned ahead } \\
\text { carefully for a fixed mass } \\
\text { production line to a specific } \\
\text { product. }\end{array}$ \\
\hline Routing & $\begin{array}{l}\text { Effective routing: Settings for } \\
\text { configuring the machine to } \\
\text { produce various types of } \\
\text { products are automatically } \\
\text { done as machine is still } \\
\text { operating. }\end{array}$ & $\begin{array}{l}\text { Static routing: Settings for } \\
\text { configuring the machine to } \\
\text { produce various types of } \\
\text { products is done manually by } \\
\text { the workers with machine off } \\
\text { operation. }\end{array}$ \\
\hline Communication & $\begin{array}{l}\text { Dynamic connections: } \\
\text { Operators, machines, } \\
\text { products and information } \\
\text { system are all connected and } \\
\text { interacting together in a rapid } \\
\text { network framework. } \\
\text { Comprehensive convergence: } \\
\text { Industrial wireless network } \\
\text { and the cloud are connected } \\
\text { with the Cyber-Physical } \\
\text { systems making Internet of } \\
\text { Things. }\end{array}$ & $\begin{array}{l}\text { Shopfloor controlled-network: } \\
\text { Operators, machines and } \\
\text { products are weekly connected } \\
\text { together. } \\
\text { Disconnected system design: } \\
\text { Upper level information } \\
\text { systems and shop floor } \\
\text { machines are disconnected. }\end{array}$ \\
$\begin{array}{l}\text { Self optimization: Different } \\
\text { sections of the manufacturing } \\
\text { system communicate together } \\
\text { for optimal organization for } \\
\text { the system. }\end{array}$ & $\begin{array}{l}\text { Unconventional control: Each } \\
\text { entity in the manufacturing } \\
\text { system has a specific } \\
\text { programming for a specific } \\
\text { function. One error in any } \\
\text { section of the factory can stop } \\
\text { the entire production line. }\end{array}$ \\
\hline Optimization & $\begin{array}{l}\text { Big Data: Smart devices } \\
\text { produce huge data and its } \\
\text { stored in Big Data after being } \\
\text { transferred through high } \\
\text { bandwidth network. }\end{array}$ & $\begin{array}{l}\text { Separated data: Machines } \\
\text { produce data which is only } \\
\text { stored in the machine system } \\
\text { and such data are rarely used } \\
\text { by operators. }\end{array}$ \\
\hline
\end{tabular}




\subsubsection{Smart Operators in Smart Factories}

Longo et al., (2017)suggested a framework that amalgamates new methods with traditional methods to support operators' in manufacturing systems. The suggested framework passes through every single building block to detect the solutions and methods that align the operators' capabilities with the new necessities stemming from the intelligent factory context. The commencement of this framework is depicted in the 5C architecture in figure 1. 


\section{Chapter 3}

\section{HUMAN FACTORS IN THE INDUSTRY}

As the development of Industry 4.0 continues, human operators are required to adapt quickly, be highly flexible and perform intricate daily tasks seamlessly in this dynamic workplace. This new work environment necessitates tools and methods that can be incorporated into daily activities while also being able to combine intricate methodologies with high usability needs.

\subsection{Humanware}

Human ware can be defined as the mutual interconnection of leadership concept which refers to the leader's desire to maintain team work and complete work tasks, and followership concept which is about the follower's free wish to work according to leader's rules to complete the task. The advancement concerning Industry 4.0 will also be noticeable in the social plant since Social Operator 4.0 will be equipped by advanced tools such as smart wearable devices whose sole purpose will be to encourage cooperation with other social operators, social software systems and social machines. According to Woźniak, Graña, \& Corchado, (2014), continuous observation of the Social Operator 4.0 will occur by utilizing Advanced Trained Classifiers (ATCs) and by implementing various other detecting and error preventing methods concurrently with technology in the social factor. Under these circumstances, the aim of adaptive automation, based on active interface software, is to minimize unwanted acts of the human ware and avert mistakes. This will be achieved by safeguarding a sufficient level of situation awareness and mental 
workload and simultaneously grant the social operator a crucial perception of understandingRomero et al., (2017).

Kaare \& Otto, (2015)have extensively examined human factors especially as it pertains to the suggested human cantered worker performance analysis system which is depending on a couple of parameters accumulated from clinical and available sensors and smart mobiles dataLongo et al., (2017).

\subsection{Ergonomics}

Ergonomics is the scientific discipline responsible for comprehending human connection with other constituents of a system by applying theory and design approaches to enhance human wellbeing and system performance. Ergonomics maintains a harmonious balance in the interaction of humans and things, especially concerning people's needs, limitations and abilities.

Ergonomics consists of three categories, physical, cognitive and organizational ergonomics.

\subsubsection{Physical Ergonomics}

According to Macleod, (2008), physiological and biomechanical elements pertaining to physical activity. (i.e. materials handling, musculoskeletal disorders of work, postures, workshop layout, safety and repetitive movements.) Table 4 displays the most prominent concepts of physical ergonomics. 
Table 4: 10 main principles of physical ergonomics. Adapted from Macleod, (2008)

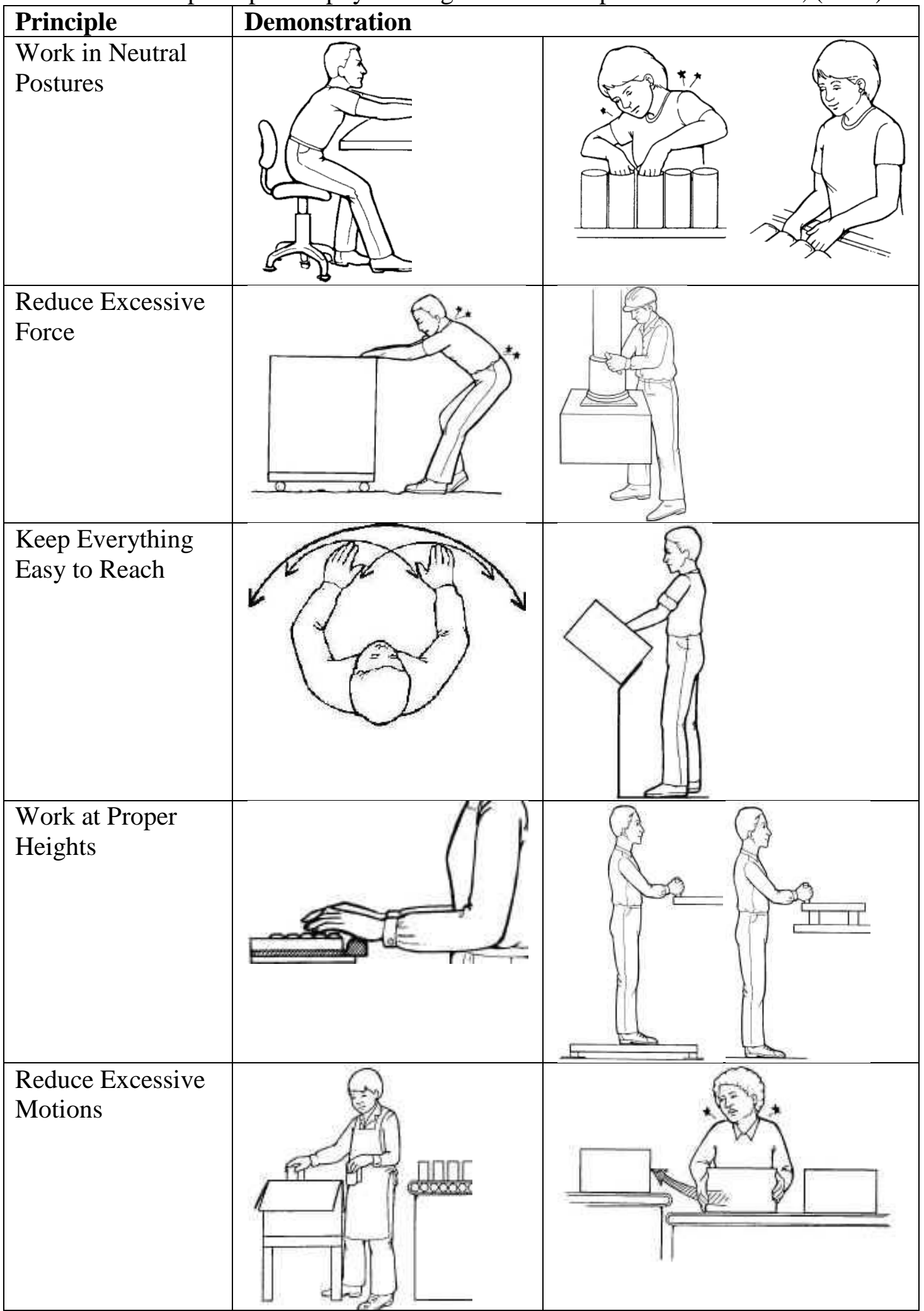




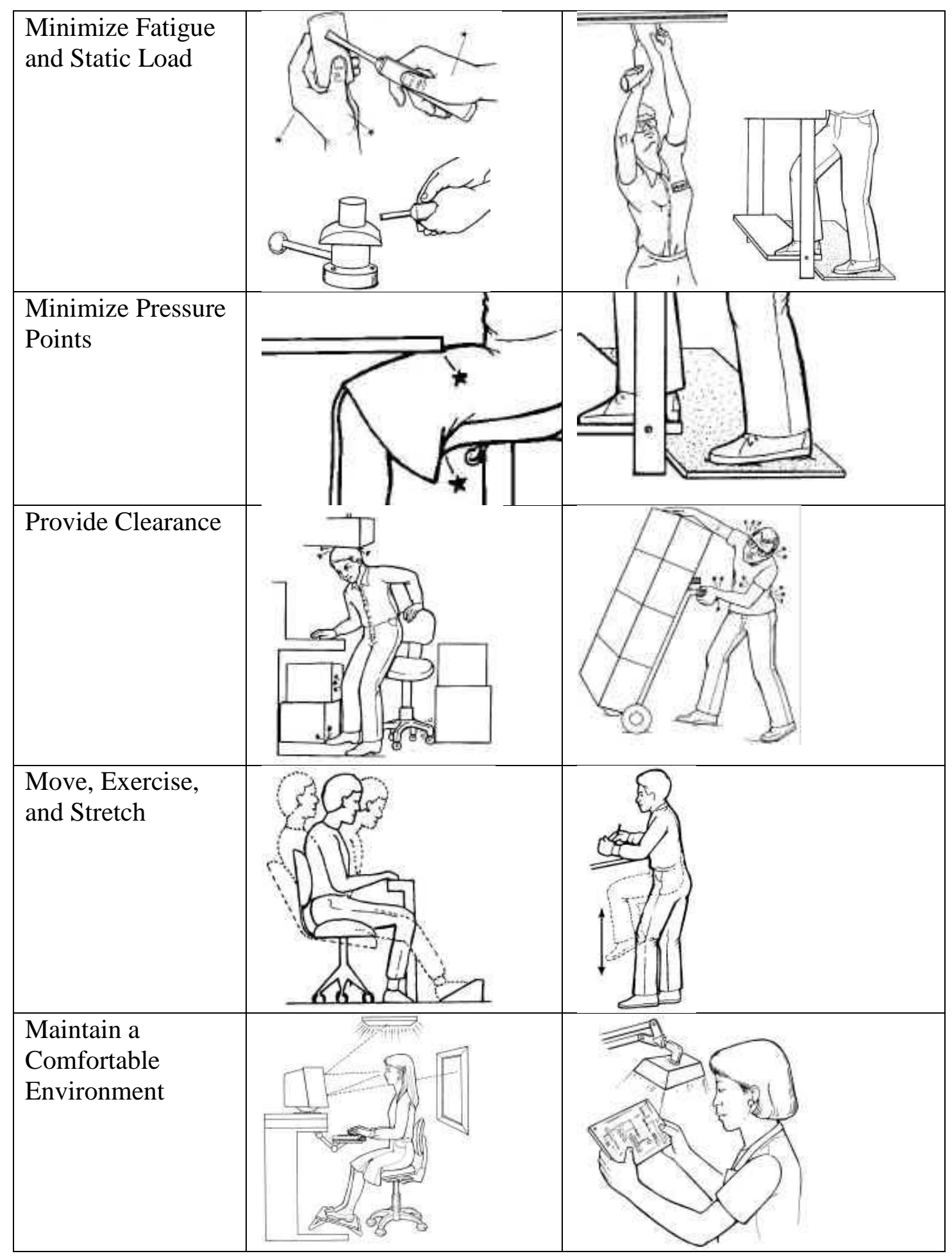

\subsubsection{Cognitive Ergonomics}

Cognitive ergonomics covers mental processes, including reasoning, observation, memory, and reaction, hence cognitive ergonomics influences human exchange with other elements and systems; (important topics on cognitive ergonomics include 
skilled performances, human reliability, human-computer interactions, decisionmaking, working stress, mental workload, and trainings. All these can have a connection with human-system design.) Iea.com, (2019).

\section{Cognitive Ergonomics}

Neuro Ergonomics

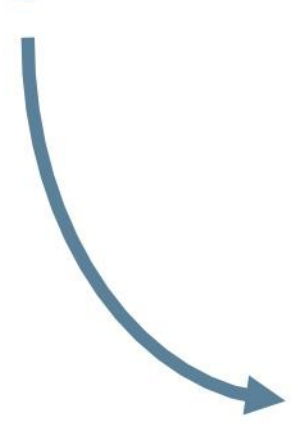

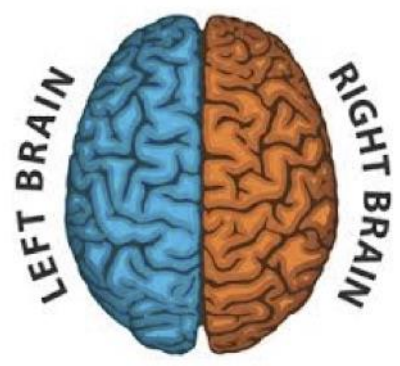

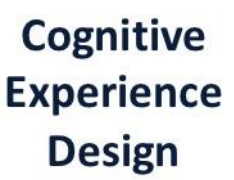

Human-Centered Design

User-Centered Design

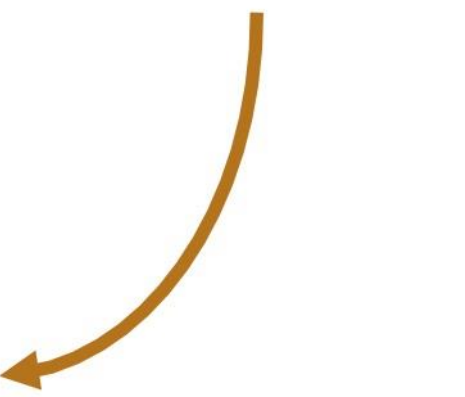

Figure 7: Human-cantered design and Cognitive Ergonomics. Adapted from Customerinnovations.com, (2018)

\subsubsection{Organizational Ergonomics}

This type of ergonomics covers the improvement of sociotechnical systems, which involves policies of an organization, processes, and structures; (Important topics include, teamwork, communication among team members, participatory design, and telework.) Iea.com, (2019).

\subsection{Physical Workload}

Neumann, Kolus, \& Wells, (2016)claims that the existence of a link between weak ergonomics and mistakes or poor eminence in anmanufacturing structure for example inspection, fabrication, manufacturing or assemblage can lead to worker fatigue. Various studies recognize that fatigue is the result of other factors, yet only a few have measured fatigue. Measuring fatigue can occur through well-controlled evidence-based laboratory studies on the fatigue aspect in productivity and product 
quality. Yung, Manji, \& Wells, (2017)also discuss the effect of cognitive reduction on error commitment based on laboratory studies. However, the measurements vary as some studies counted how many errors volunteers made while they were conducting visual search trials.

\subsection{Mental Workload}

Examining and measuring mental work springs from humans' natural interest for comprehending cognition from a fundamental theoretical point of view. One action that challenges our comprehension of brain activity is the act of computing the cost of neurocognitive operations. Therefore, MWL examinations are part of both the topical developments in neuroergonomics and the cognitive revolution of psychology. According to Young, Brookhuis, Wickens, \& Hancock, (2015)designers and ergonomists both show interest in the prediction of increased supply which results in performance decline. Other factors includes establishing workload standards, comprehending and modelling the task overload management approaches utilized such as task shedding, and can utilize various remedies in case this overload occurs. For this matter, separate resources may be used. In addition it may cover the reduction of the working memory load or automatic parts of the task to decrease the resource demands of the task, it may also mean that certain tasks may get assigned to other operators, provide substantial training to gain expertise or significantly altering the process to allow synchronous operations to be performed in sequence. These solutions also come from single or multiple resource models. The multiple resource model enables developers to predict measures to decrease the multitask resource demand. 


\subsection{Cognitive Ergonomics}

Due to the increased necessity for resilience and adjustability of industrial frameworks, factories of the future will surely be highly dynamic working environments. As a result, this will require the upgraded shop-floors (Factory 4.0) to receive cognitive aid to assist operators in performing operations related to mental cognition like augmented reality(AR) technologies or smart Human-Machine Interfaces (HMI) . These technologies will aid in the performance of the elevated cognitive workload (e.g.decision- making, planning, situational understanding, etc.) of the future operator. Romero, Bernus, Noran, Stahre, \& Fast-Berglund, (2016)expects that this assistance will increase human dependability on the job, especially when both the production system's performance and the operator's wellbeing are taken into account.

Cognitive ergonomics is an amalgamated dual notion where cognition focuses on the human brain activities such as processing, delivering information and observing. Mehta, (2016)believes that these activities necessitate human capabilities to convert, rehearse, preserve and recall information, which relies on the task at hand to sustain the work environment.

As a dual, Cognition and Ergonomics are connected to human exchange with machine constituents in an industrial unit. Cognitive ergonomics typically affect mental activities e.g. memory, reasoning, perception and response which occurs as a result of the exchange between humans, and diversebasics ofthe system. The exchange between humans and machines, combined with humans cognitive capabilities and limitations assure that proper communication occurs on human needs, abilities, works, products, environments Kim, (2016). 
A study by Moray, Groeger, and Stanton, (2017) on the concept of cognitive ergonomics proves that it can decrease unnecessary workload and increase efficiency for operators doing their jobs. It also decreases faults and misinterpretations due to the basic awareness of the principles of righteous cognitive design.

Bligård \& Osvalder, (2014) provides an illustrated examination of the kind of human capabilities and restrictions that are deemed practical to ensure proper development of work environment and operators safety and behaviors while averting workloads and stress.

\subsubsection{Cognition at Work for I4.0}

Pearson \& Sahraie, (2003)believe that numerous conditions can function as a distraction e.g. moving objects and flashing lights can easily distract one from visually focusing and maintaining information in visuospatial working memory.

\subsubsection{Perception and Attention at Work for I4.0}

For operators in I4.0 environment to gain perception, the following practices must undergo careful consideration:

- Improve text, symbols lighting and the contrast between objects and background.

- Have the ability to recognize a small number of background objects, groups of targets, targets, the modification of important stimulus.

- Minimize auditory and visual clutter.

\subsubsection{Memory at Work for I4.0}

Limiting the information needed to be remembered, unneeded visual information and limited noise are all aspects that could be averted to avoid limitations of working memory. Unnecessary loading of working memory can occur in cases where the system or job necessitates active maintenance and processing of details such as codes. 
- The amount of information or object to be memorized is fair,

- Reducing visual information, interruptions and background noises that serves no purpose,

- Utilize external visualizations and memory techniques.

- Decreases the need to do multiple tasks at the same time and the cost of task switching.

\subsubsection{Learning at Work for I4.0}

Even though favourable, long-term memory is not without its downside as it relates to slow processing when acquiring new skills and information. It also limits remembering work procedures and information rapidly, and it can cause one to easily forget information that has not been properly rehearsed. Dunlosky, Rawson, Marsh, Nathan, \& Willingham, (2013) found the most efficient learning techniques to be distributed practice and testing of the skill. The current articles and news on best practices for learning at work consist of the following:

- Provide a sufficient amount of space to learn skills and remember knowledge.

- Utilize the assistance of check and lists at work to circumvent forgetting of crucial information and skills.

- In case occupational training is chosen, these efficient learning techniques must be incorporated.

- Make detailed reports on important and decisions and information.

\subsubsection{Cognitive Ergonomic Design for Software User Interface}

During the process of designing a software interface, great consideration must be placed on how "easy to use" the software must be. Other visual cues including icons are also important as they help people to comprehend and act accordingly. Cognitive ergonomic design for the software user interface Dubey, (2015). 
Based on Harish, (2009), a software's ease of use is defined by the following crucial elements:

- Unrelated objects must be kept segregated and logically related screen elements must be kept together.

- Tasks should follow a natural flow to ensure easy navigation between tasks. Besides, applications must have the flexibility to enable users to accomplish operations in their specific order.

- The software must be designed with shortcut keys and advanced functionality to assist both novice and experienced users.

- Icons should only be used if their meanings are immediately obvious. Refrain from using an obscure icon, use text instead.

\subsection{Human Centered Manufacturing}

Collective-Intelligence-as-a-Service, as studied by Terziyan et al., (2018), is a mechanism that enables human's decision models to be cloned with the sole purpose of approaching automatic decision making while still requiring the assistance of humans. Its main focus is on finding ways to evaluate, share, appreciate, digitize and utilizeprofessional decision making expertise and experience; finding ways to incorporate the cognitive sides of problem solving anddecision making into the current sketches of the industrial operation; finding ways to ameliorate the cooperation between humans and machines and finding ways to make cognizant decisions. 


\section{Chapter 4}

\section{OPERATOR 4.0}

\subsection{Definition}

Operator 4.0 is a smart worker that works through H-CPS (human cyber-physical systems), which allows it to collaborate with robots and aided machines when needed. To accomplish this, it also uses progressive human machine interaction technology as well as adaptive Automation.Rabelo, Romero, and Zambiasi, (2018) claim that Operator 4.0 was created to forge balanced exchanges between humans and machines.

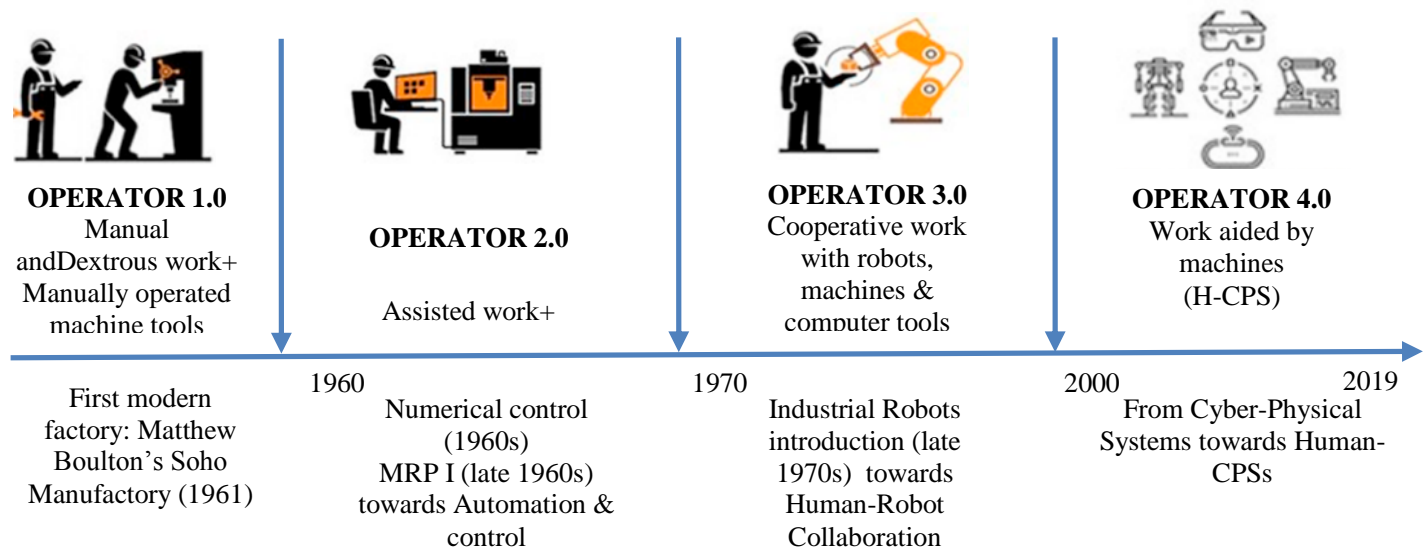

Figure 8: Industrial revolutions and operators' role. Adapted from Zolotová, Papcun, Kajáti, Miškuf, \& Mocnej, (2018)

Figure 8 displays the changes in the roles and duties of operators in the last decades. This new concept of Industry 4.0 determines various forms of operator 4.0. Rabelo et al., (2018) discusses that the types of Operator 4.0 will be depending on 
the job and tasks of the operator. Table 5 showcases the classification of Operator 4.0 .

Table 5: Different classifications of Operator 4.0.

\begin{tabular}{|c|c|}
\hline Operator Type & Characterization/Duty \\
\hline Analytical & $\begin{array}{l}\text { Detailed analysis of Big Data information in advanced } \\
\text { industrial production. }\end{array}$ \\
\hline Augmented & $\begin{array}{l}\text { Ameliorate the manufacturing plant condition through } \\
\text { augmented reality such as data trade-offs between the } \\
\text { physical world and the technologically advanced world. }\end{array}$ \\
\hline Cooperative & $\begin{array}{l}\text { Cooperation between operators to and cooperative } \\
\text { automation (CoBots) perform daily non-ergonomic } \\
\text { operations. }\end{array}$ \\
\hline Hygienic & $\begin{array}{l}\text { Wearable trackers to estimate well being and compute } \\
\text { performance, pulse and other individual information. }\end{array}$ \\
\hline Intelligent & $\begin{array}{l}\text { Intelligent Personal Assistant (IPA) which uses } \\
\text { ArtificiallIntelligence (AI) . }\end{array}$ \\
\hline Social & $\begin{array}{l}\text { Enterprise Social Network Services (E-SNS) whose aim is } \\
\text { to use easily adaptable and social collective approaches to } \\
\text { align intelligent Operators with smart industrial facility } \\
\text { assets in the workplace. }\end{array}$ \\
\hline Powerful & $\begin{array}{l}\text { Wearable exoskeletons that are light, motorized and can act } \\
\text { as versatile biomechanical devices. }\end{array}$ \\
\hline Virtual & $\begin{array}{l}\text { Virtual Reality (VR) is known as an intelligent computer } \\
\text { simulation which can copy a realistic digital layout, assembly } \\
\text { or production line while enabling the operator to virtually } \\
\text { work with and try out the replicated work environment. }\end{array}$ \\
\hline
\end{tabular}

Novak, Beyeler, Omlin, \& Riener, (2014) all concluded that three workload scales exists: the physical, the mental and the temporal. These scales can sometimes correlate with each other making it burdensome to separate them in a physical human-robot exchange. Young et al., (2015)argues that MWL and physical workload are both known to affect the heart rate. 


\subsection{Operator 4.0 and Cognitive Ergonomics}

Badri, Boudreau-Trudel, and Souissi, (2018)agrees that if the development of technologies leading to Industry 4.0 continues without considering operators' role then, the risk will multiply and it will negatively affect the Occupational Health and Safety (OHS) principles and this is all due to the big modifications and changes that are implemented, which puts all former improvements in precautionary management for the workplace safety and health at risk.

Valdeza, Braunera, Schaara, Holzingerb, and Zieflea, (2015) discusses different methods to reduce complexity of multidimensional data through the following:

- Reducing measurement: Filtering, factual strategies, collapsing, arrange illustrations, Andrews bends, parallel axes representations.

- Pattern recognition: Low pass channel, Entropy discovery.

- Interaction strategies: Rotation of information as a third measurement, drill down, suggestion, peruse, instrument tips, gadget turn, diversion-based methodologies

- Natural mapping of perception and association strategies.

- From the literature it was found that the methods used to reduce multidimensional data complexity have to match the future worker's field of knowledge and the available data. It is found out that complex mental models have to take shape along with the interaction process, which makes interaction by interrogative methods very useful in shaping an appropriate mental model.

\subsection{Operator 4.0 Qualifications Needed for I4.0}

Benešová \& Tupa, (2017) listed some of the key skills for operators in the smart factory in table 6 and table 7. 
Table 6: Production related operator figuration.

\begin{tabular}{|c|c|c|}
\hline Job/Role & Competence & Expertise \\
\hline $\begin{array}{l}\text { Electronics } \\
\text { Technician }\end{array}$ & $\begin{array}{l}\text { - Secondary school } \\
\text { degree } \\
\text { - Practical experience } \\
\text { within the field of dealing } \\
\text { with innovation and } \\
\text { mechanical hardware } \\
\text { - Ability to make } \\
\text { assessments services }\end{array}$ & $\begin{array}{l}\text { - Manual skills } \\
\text { - Ability to preserve modern } \\
\text { machines } \\
\text { - Adaptability } \\
\text { - Independence and obligation } \\
\text { - Fundamental information of } \\
\text { hardware }\end{array}$ \\
\hline $\begin{array}{l}\text { Automation } \\
\text { Technician }\end{array}$ & $\begin{array}{l}\text { - Secondary school } \\
\text { degree } \\
\text { - Practical experience } \\
\text { within the field of dealing } \\
\text { with machine preserving } \\
\text { and manufacturing plants }\end{array}$ & $\begin{array}{l}\text { - Information of security guidelines } \\
\text { - Language skills } \\
\text { - Adaptability } \\
\text { - Independence and responsibility }\end{array}$ \\
\hline $\begin{array}{l}\text { Production } \\
\text { Technician }\end{array}$ & $\begin{array}{l}\text { - Secondary school } \\
\text { degree }\end{array}$ & $\begin{array}{l}\text { - Language skills } \\
\text { - Smart reasoning } \\
\text { - Adaptability } \\
\text { - Independence and responsibility } \\
\text { - Ability and eagerness to memorize } \\
\text { unused things }\end{array}$ \\
\hline $\begin{array}{l}\text { Manufacturin } \\
\text { g Engineer }\end{array}$ & $\begin{array}{l}\text { - Secondary school + } \\
\text { higher education degree in } \\
\text { electrical and electronics } \\
\text { engineering }\end{array}$ & $\begin{array}{l}\text { - Technical abilities } \\
\text { - Language skills } \\
\text { - Independence } \\
\text { - Obligation and inventiveness } \\
\text { - Information of specialized } \\
\text { documentation } \\
\text { - Capacity and eagerness to } \\
\text { memorize unused things } \\
\text { - Organizational abilities } \\
\text { - Participation Media abilities } \\
\text { - Communication aptitudes }\end{array}$ \\
\hline
\end{tabular}

Benešová \& Tupa, (2017)Divided future operator's tasks into two main categories. Jobs related with production and jobs related with Information Technology. Based on the findings of their research, they were able to highlight the main academic competence and expertise required for future workers. 
Table 7: Information Technology related operator figuration.

\begin{tabular}{|c|c|c|}
\hline Job/Role & Competence & Expertise \\
\hline $\begin{array}{l}\text { Informatics } \\
\text { Specialist }\end{array}$ & $\begin{array}{l}\text { - High school degree }+ \text { higher } \\
\text { education degree in IT } \\
\text { - Practical experience in the same } \\
\text { field } \\
\text { - Comprehension in large domains } \\
\text { and network management } \\
\text { - Fundamental information of } \\
\text { dealing with database, } \\
\text { virtualization and cloud services }\end{array}$ & $\begin{array}{l}\text { - Language skills } \\
\text { - Independence } \\
\text { - Obligation } \\
\text { - Adaptability } \\
\text { - Communicativeness } \\
\text { - Reliability } \\
\text { - Planning experience } \\
\text { - Team leader } \\
\text { - Organizational aptitudes }\end{array}$ \\
\hline $\begin{array}{l}\text { PLC } \\
\text { Programmer }\end{array}$ & $\begin{array}{l}\text { - High school degree } \\
\text { - Practical experience in PLC and } \\
\text { PLC programming. } \\
\text { - Proof of experience in machine } \\
\text { programming }\end{array}$ & $\begin{array}{l}\text { - Language skills } \\
\text { - Experience in } \\
\text { BeckhoffTwinCAT } \\
\text { - Obligation } \\
\text { - Adaptability } \\
\text { - Communicativeness } \\
\text { - Reliability } \\
\text { - Capacity and eagerness to } \\
\text { memorize unused things }\end{array}$ \\
\hline $\begin{array}{l}\text { Robot } \\
\text { Programmer }\end{array}$ & $\begin{array}{l}\text { - High school degree }+ \text { higher } \\
\text { education degree in automation } \\
\text { - Comprehension in programming } \\
\text { online and offline robots } \\
\text { - Experience with essential robot } \\
\text { parameters and settings } \\
\text { - Project } \\
\text { administration,adjustment of robot } \\
\text { software engineer group and } \\
\text { knowledge with PLC programmers } \\
\text { - Installation of the gadget into } \\
\text { operation }\end{array}$ & $\begin{array}{l}\text { - Language skills } \\
\text { - Analytical and logic } \\
\text { reasoning } \\
\text { - Obligation } \\
\text { - Adaptability } \\
\text { - Communicativeness } \\
\text { - Reliability } \\
\text { - Experienced in simulation } \\
\text { process } \\
\text { - Ability to solve problems }\end{array}$ \\
\hline $\begin{array}{l}\text { Software } \\
\text { Engineer }\end{array}$ & $\begin{array}{l}\text { - High school degree }+ \text { higher } \\
\text { education degree in IT } \\
\text { - Comprehension of programming } \\
\text { C and C++ } \\
\text { - Practical experience in the same } \\
\text { field } \\
\text { - Fundamental information of } \\
\text { dealing with database such as SQL }\end{array}$ & $\begin{array}{l}\text { - Language skills } \\
\text { - Autonomy } \\
\text { - Inventiveness } \\
\text { - Adaptability } \\
\text { - Analytical and logic } \\
\text { reasoning } \\
\text { - Ability to solve problems }\end{array}$ \\
\hline Data Analyst & $\begin{array}{l}\text { - High school degree }+ \text { higher } \\
\text { education degree in mathematics } \\
\text { and/or statistical analysis } \\
\text { - Experienced with PL, SQL and } \\
\text { UML }\end{array}$ & $\begin{array}{l}\text { - Language skills } \\
\text { - Autonomy } \\
\text { - Inventiveness } \\
\text { - Adaptability } \\
\text { - Analytical and logic } \\
\text { reasoning } \\
\text { - Ability to make excel }\end{array}$ \\
\hline
\end{tabular}




\begin{tabular}{|c|c|c|}
\hline & & $\begin{array}{l}\text { sheets } \\
\text { - Ability to solve problems } \\
\text { - Comprehensive statistical } \\
\text { knowledge } \\
\text { - Ability to solve problems }\end{array}$ \\
\hline $\begin{array}{l}\text { Cyber } \\
\text { security }\end{array}$ & $\begin{array}{l}\text { - High school degree }+ \text { higher } \\
\text { education degree in IT }\end{array}$ & $\begin{array}{l}\text { - Language skills } \\
\text { - Autonomy } \\
\text { - Inventiveness } \\
\text { - Adaptability } \\
\text { - Analytical and logic } \\
\text { reasoning } \\
\text { - Capacity and eagerness to } \\
\text { memorize unused things } \\
\text { - Aware of security and } \\
\text { communication } \\
\text { - Awareness of servers } \\
\text { management level } \\
\end{array}$ \\
\hline
\end{tabular}

\subsection{Physical Tasks in I4.0}

Physical tasks in I4.0 are much less than physical tasks before, due to the technological improvements and especially human operators and robots will form a never before seen relation in the workplace which will allow operators to utilize their superbcapabilities tocreate, participate and adapt with new conditions.

According to Thorsten Wuest, (2017) future operators will have technical support and have the optimum level of strength, awareness, safety and constantly connected. Many types of improvements are available, and those can be either used on a personal level or combined so that humans can be fully utilizing the technological revolution.

\subsubsection{Powerful Operator}

One of the most undemanding ways to enhance workers strengths is to have them wear exoskeleton. One way to achieve this is through a "super-strength operator" as this allows humans to control large robots. This can reduce the high risk of injury and exhaustion that workers experience lifting heavy objects in construction sites and 
warehouses. Depending on the tasks, workers are sometimes forced to use rigid tools such as a forklift to lift heavy objects.

These robotic advancements for workers have numerous benefits e.g. powered robotic suits provide workers with the strength to handle extremely heavy objects while also making it possible that the worker retains natural human flexibility. Also, these powered robotic suits prevent severe injuries from accidents or overwork.

\subsubsection{Safety}

Most manufacturing plants contain caustic chemicals and heavy equipment that incapacitate or even cause death to human workers. For this reason, providing wearable sensors that can track pulse rate, chemical exposure, body temperature, and other risk-of-injury indicators is a great approach to minimize risk.

\subsection{Mental Workload in I4.0}

"Analytical operators" will receive monitors as well. These will display current data and analytics on pollutants at an incinerator or chemicals in a sewage treatment plant. "collaborative operators" may receive assistant from co-bots such as YuMi, the assembly assistant and "smarter operators", may receive help from a virtual assistant such as an advanced version of Siri or Alexa.

Humans do not have to live in fear of machines taking their jobs and leaving them unemployed as this will only cause conflicts between the two. Collaboration must be at the forefront of new technological advancement for organizations and workers to capitalize on the strengths of machines and humans. With the flexibility that Operator 4.0 provides, work environments of the future will be changeable and adaptable. Which means that with the introduction of new technologies the workplace will also become safer and more efficient. 


\subsection{Virtual Reality}

According to Heinonen, (2017), normally cases for VR fall into three classifications: simulations and training, designing for product development and visualization for sales and marketing.

VR establishes an artificial world and creates experiences in a non-physical form. The most prevalent and advanced hardware providing users with VR experiences is the Head Mounted Display (HMD) . Due to it being the most contemporaneous it has become the most talked about. An HMD is a technological type of helmet or pair of goggles used for the VR experience.

Table 8: Current applications of VR/AR technologies. Adapted from Heinonen, (2017)

\begin{tabular}{|l|l|}
\hline Application & Application example \\
\hline Engineering & $\begin{array}{l}\text { With VR engineers can test processes, products or facility } \\
\text { designs before producing them in physical form. Also, } \\
\text { engineers can detect errors and defects early in the process } \\
\text { and thus circumvent costly drawbacks in the future. }\end{array}$ \\
\hline $\begin{array}{l}\text { Industry and } \\
\text { Manufacturing }\end{array}$ & $\begin{array}{l}\text { Both AR and VR are prominent for skills training, operations } \\
\text { and maintenance as they both can add to a highly effective } \\
\text { daily operations and maintenance routine. }\end{array}$ \\
\hline $\begin{array}{l}\text { Architecture, } \\
\text { Ronstruction and }\end{array}$ & $\begin{array}{l}\text { VR/AR could be beneficial to the architecture industry as it } \\
\text { could significantly improve designs, construction, and } \\
\text { communication in archaeology. Also, it allows one to } \\
\text { virtually visit the estate. Architects }\end{array}$ \\
\hline Retail & $\begin{array}{l}\text { VR/AR could abet in the demonstration of large products } \\
\text { such as cars and furniture and other high end markets and be } \\
\text { beneficial to lower end markets in the research and marketing } \\
\text { department as efficient store design is crucial in lower end } \\
\text { markets. }\end{array}$ \\
\hline
\end{tabular}




\begin{tabular}{|l|l|}
\hline Healthcare & $\begin{array}{l}\text { Surgeons have used VR to plan operations. Today VR can } \\
\text { also be used for post-traumatic stress disorders, } \\
\text { rehabilitation, phobia treatment, surgery designing, creating a } \\
\text { visual of a 3D image and provide training on how to perform } \\
\text { complex surgeries. }\end{array}$ \\
\hline $\begin{array}{l}\text { Military and } \\
\text { Aerospace }\end{array}$ & $\begin{array}{l}\text { Aerospace training can be expensive as pilots training occurs } \\
\text { in expensive simulations. VR can create a similar simulation } \\
\text { for a significantly reduced price. HMDs. However, VR is not } \\
\text { limited to pilot training in the military as it can serve many } \\
\text { other purposes in the military as well. }\end{array}$ \\
\hline Entertainment & $\begin{array}{l}\text { VR/AR technology was introduced to the entertainment } \\
\text { industry through gaming, but now media companies have } \\
\text { adopted it for their live-events and videos. }\end{array}$ \\
\hline
\end{tabular}

\subsubsection{Applications of VR in Manufacturing}

Based on a study that is conducted by Aniruddha Talekar, (2017) virtual reality has many applications related to manufacturing as demonstrated in table 9.

Table 9: VR applications in manufacturing systems

\begin{tabular}{|l|l|}
\hline VR Application & Details \\
\hline Virtual prototyping & $\begin{array}{l}\text { VR prototyping is a method used to test } \\
\text { different product designs before } \\
\text { manufacturing. This way is much cheaper } \\
\text { than making a physical prototype. }\end{array}$ \\
\hline Virtual Assembly (VA) & $\begin{array}{l}\text { Virtual assembly facilitates design faults } \\
\text { allocation process for designers as they } \\
\text { are able to take a closer look at product } \\
\text { parts during the assembly process. }\end{array}$ \\
\hline Virtual Manufacturing (VM) & $\begin{array}{l}\text { VR has also proven to be beneficial in the } \\
\text { detailed documentation of a product as } \\
\text { the usage of the Virtual Manufacturing } \\
\text { techniquesare gaining prominence. This } \\
\text { Virtual Manufacturing technique utilizes } \\
\text { processes for manufacturing a desktop } \\
\text { VR system for Computer Aided Desing } \\
\text { (CAD) of product parts. }\end{array}$ \\
\hline
\end{tabular}




\begin{tabular}{|l|l|}
\hline Virtual training & $\begin{array}{l}\text { Virtual training is used instead of } \\
\text { traditional training with simulation } \\
\text { technology which makes it easier to } \\
\text { disconnect the machine engineering and } \\
\text { production process so each type of } \\
\text { operator can focus on their own field } \\
\text { comfortably Ordaz, Romero, Gorecky, \& } \\
\text { Siller, (2015). }\end{array}$ \\
\hline \multirow{2}{*}{$\begin{array}{l}\text { Virtual reality approach in immersive } \\
\text { design }\end{array}$} & $\begin{array}{l}\text { The combination between VR tools an } \\
\text { CAD softwares facilitates the work for } \\
\text { path planning }\end{array}$ \\
\hline Virtual reality approach for hierarchical to make immersive designs. \\
\hline $\begin{array}{l}\text { For this to commence, a tool capable of } \\
\text { swiftly testing the product throughout the } \\
\text { PLM using VR is needed. Currently, there } \\
\text { exist two paths planning part: immersive } \\
\text { path planning and automatic path } \\
\text { planning which encompasses the usage of } \\
\text { robots and exchanges between human } \\
\text { workers and computers Cailhol, }\end{array}$ \\
Fillatreau, Fourquet, \& Zhao, (2015).
\end{tabular}

According to Dépincé, Chablat, \& Woelk, (2007) one of the main applications of VR is Virtual Manufacturing (VM) and table 10 demonstrates the main tasks used in VM.

Table 10: Main tasks of Virtual Manufacturing technique. adapted from Dépincé et al., (2007)

\begin{tabular}{|l|l|}
\hline Task & Details \\
\hline Production classification & $\begin{array}{l}\text { Capture, calculate and investigate the } \\
\text { factors which impact raw materials } \\
\text { transformation throughout production. }\end{array}$ \\
\hline Designing and presentation methods & $\begin{array}{l}\text { Various versions of models and designs } \\
\text { are provided and the needed technologies } \\
\text { are able to represent the information that } \\
\text { are related with the manufacturing and } \\
\text { design such that these information are } \\
\text { sharable with all software applications. }\end{array}$ \\
\hline Visualization technologies & $\begin{array}{l}\text { Present the information to operators such } \\
\text { that it is useful and easy to understand } \\
\text { throughout VR technologies, Graphical }\end{array}$ \\
Validation, verification and calculation & $\begin{array}{l}\text { Metrics and decision tools are examples } \\
\text { of the necessary methods and equipments } \\
\text { to assist the validation and verification of }\end{array}$ \\
\hline
\end{tabular}




\begin{tabular}{|l|l|}
\hline & VM system. \\
\hline \multirow{3}{*}{ Multi discipline optimization } & VM and simulation are normally not \\
independent research disciplines as they \\
are oftenly combined with traditional \\
manufacturing research.
\end{tabular}

Often, Agile manufacturing is mentioned together with virtual manufacturing. Agile manufacturing is viewed as a structure that encompasses three primary resources to achieve agility through integration. These resources are people, organization and technologies. By amalgamating flexible and advanced technology, organizations and unconventional management structures and skillful and empowered workers, one can achieve Agile manufacturing.

To accomplish this, creative management frameworks, skilled and knowledged people, and resilient technologies are the way to do so. Novak-Marcincin, (2011), states that virtual manufacturing differs from agility because it provides a means to forge swift changes in commodities and processes using only the customer's voice, while the focal point of agility is the ability to make these changes.

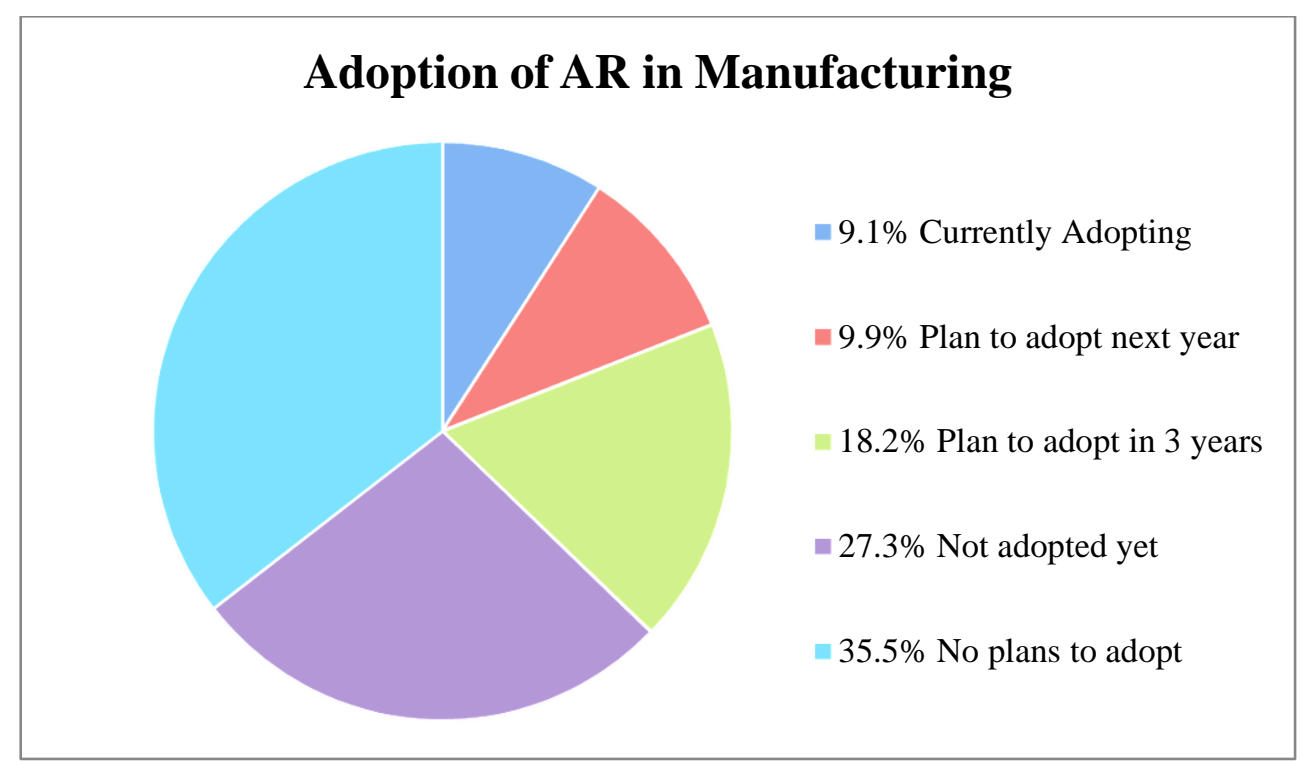

Figure 9: Adoption of AR technology in manufacturing industry. Adapted from PWC, (2015) 
According to a study that was conducted in the United States by PWC, (2015), 120 manufacturing plants were asked the whether their company has no intention to use, planning to or currently using VR/AR technologies at the shop floor and the results are demonstrated in figures 9 and 10.

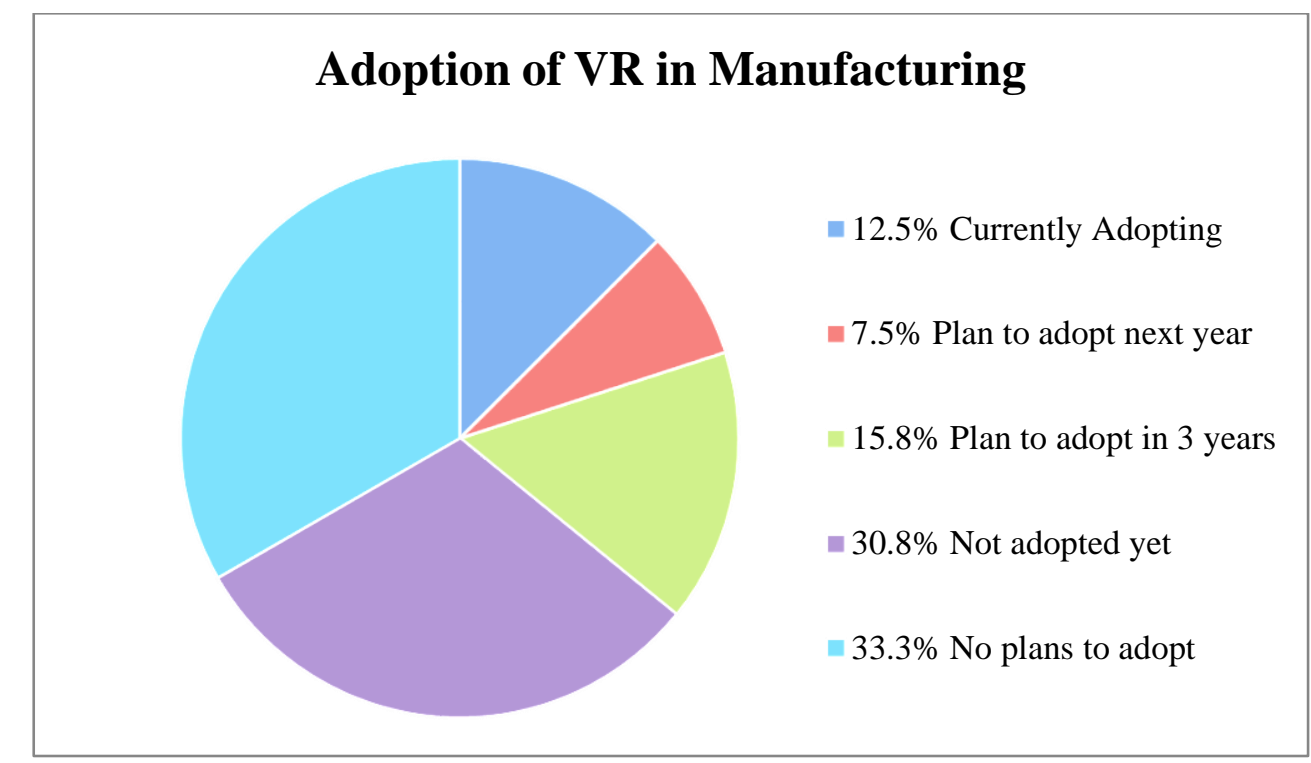

Figure 10: Adoption of VR technology in manufacturing industry.Adapted from PWC, (2015)

The same study that was conducted by the PWC asked a question regarding the importance of these technologies in the industrial section and as s result, $4.2 \%$ of the same 120 respondents agrees that such technologies are extremely important, $18.3 \%$ see them as very important, $50 \%$ fairly important and $27.5 \%$ sees they are not important at all.

\subsubsection{Benefits of VR in the Modern Industrial World}

VR is beneficial to constructive learning since it gives students the ability to practically learn the subjects as in "real-life". For participative learning to occur, a crowd of learners must be present in the same place together. With virtual reality, the students are not obliged to be in the same physical location, however, they do need to 
be present during the same time simultaneously. VR contains the settings of real classrooms while allowing online (distance) learning.

According to research that was conducted by Stadnicka, Litwin, \& Antonelli, (2019) where they estimated how much the brain can remember through body senses and their results are stated in table 11.

Based on PWC, (2015) the main current applications of VR/AR technologies in the manufacturing industry are categorized in figure 12 as a result of a 98 US based manufacturing plants.

$38.8 \%$ Product design and development

17.3\% Virtual assembling and advanced process planning

27.6\% Learning production skills and safety

$19.4 \%$ Conservation of maintenance of tools and equipment

19.4\% Data accessibility

$19.4 \%$ Remote controlling

13.3\% Client communication and interaction

7.1\&Communication with the supply chain

Figure 11: Main applications of VR/AR technologies in industry

\subsubsection{VR/AR and Cognitive Ergonomics}

- The execution of VR takes significant effort.

- VR is a magnificent tool, however, it does necessitate more cognitive effort when communicating as opposed to talking face to face Stadnicka et al., (2019). 
- VR allows operators to fully involve themselves, experience and interact with cyberspace that provides insightswithin virtual and augmented reality or directly communicates with a personal digital assistant on topics such as man and machine interactions must fulfil safety standards.

- Fully utilize AR and virtual technology resources to provide introductory training for operators on high-risk tasks.

- Provide operators training as well as supportive information that usually cannot be found in the work environment to operators such as expected maintenance activities, warnings on unexpected dangers, machine productivity, unforeseen risks that might happen, suggestions for increasing productivity, etc) .

- Provide detailed warnings on the results of unprofessional operations (i.e. That which occurs if a repairtask does not perform well or if it is a fail etc.) Longo et al., (2017).

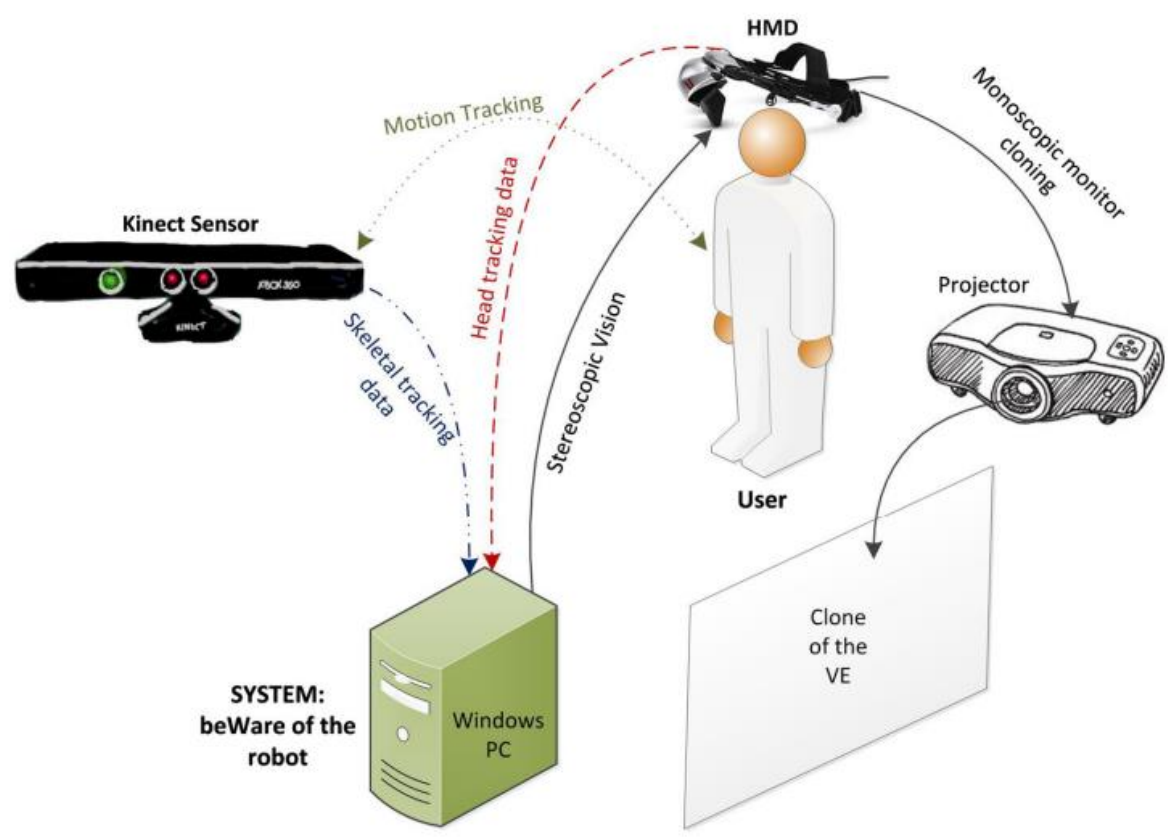

Figure 12: How VR/AR works. Adapted from Matsas \& Vosniakos, (2017) 


\subsubsection{Cognitive Requirements for VR/AR Technologies}

According to Grewe et al., (2013), the modification of cognitive functions occur by age this necessitates a vital need for rehabilitation programs in this aging society. VR can ameliorate the trustworthiness of neuropsychological analysis by placing intricate test stimuli under constant manipulation and accurately measure of participants reactions. The legitimacy of the measurement of different cognitive areas could increase due to the capability of the VR technology to quantify responses more discreetly. These cognitive domains comprise of visuospatial abilities, executive processes and an enhanced level for problem solving,attention, and memory. A second approach to this is to directly analyse performance in a simulated human environment. Thus, VR provides the possibility for cognitive analysis within a simulation of a real world practical testing spaces whose sole goal is to enhance the ecological legitimacy of neuropsychological analysis.

The required cognitive skills for operators for using VR technology are demonstrated in table 12 and 13.

Rizzo \& Buckwalter, (1997) agrees that the first important aspect in cognitive skills is attentional abilities and the reason is that attentional problems are mostly known as the main deficiency with brain injured workers. Attentional abilities have been categorized by Sohlberg \& Mateer, (1989) into 5 different categories.

Table 11: Attention and cognitive abilities.

\begin{tabular}{|l|l|}
\hline Attention type & Explanation \\
\hline Focused & $\begin{array}{l}\text { The fundamental ability to react to a } \\
\text { particular event at the early stages of } \\
\text { coma }\end{array}$ \\
\hline Sustained & $\begin{array}{l}\text { Referred to as concentration and it is the } \\
\text { ability to consistently respond in } \\
\text { repetitive performance and activities. (i.e. } \\
\text { visual quality control) }\end{array}$ \\
\hline
\end{tabular}




\begin{tabular}{|l|l|}
\hline Selective & $\begin{array}{l}\text { The capacity to remain behavioral and } \\
\text { cognitive setting during distractions. }\end{array}$ \\
\hline Alternating & $\begin{array}{l}\text { The mental ability to switch focus and } \\
\text { alertness among tasks requiring different } \\
\text { needs. (i.e. writing notes and listen to a } \\
\text { laecture at the same time) }\end{array}$ \\
\hline Divided & $\begin{array}{l}\text { The ability for doing multiple different } \\
\text { tasks at the same time (i.e. driving and } \\
\text { listening to music) }\end{array}$ \\
\hline
\end{tabular}

Other required cognitive skills for using VR in industrial environment are demonstrated in the below table.

Table 12: Cognitive skills required by Operator 4.0 within VR

\begin{tabular}{|l|l|}
\hline Skill & Explanation \\
\hline Memory & $\begin{array}{l}\text { The individual is requested to gradually } \\
\text { remember responses occurring at a specific } \\
\text { time, settings on gauges, locations of tools } \\
\text { and behavioural patterns to accomplish } \\
\text { several duties. }\end{array}$ \\
\hline Sensory Processing: Visual and Auditory & $\begin{array}{l}\text { touch, taste, and smell are extremely crucial } \\
\text { senses to humans, and difficulties pertaining } \\
\text { to audition and vision are relevant in day to } \\
\text { day operations. A VR space would be } \\
\text { beneficial when addressing these } \\
\text { difficulties. }\end{array}$ \\
\hline Higher Cognitive Functions & $\begin{array}{l}\text { the ability to solve problems, conceptual and } \\
\text { organization thinking, executive functioning } \\
\text { and critical thinking and more. }\end{array}$ \\
\hline
\end{tabular}

\subsubsection{Digital Twin}

The Digital-Twin is a direct result of Visual Computing. Services such as simulations are only effective when supported by an actual real-life 2D-3D visual 
illustration of the object. The amalgamation of real-time production data and Visual representation of simulation outcomes can be used as a magnificent tool for Visual analysis to ameliorate decision making. According toP. Xu, Mei, Ren, \& Chen, (2016), Initialising Industry 4.0 in combination with the strong connectionof production entities creates an unmatched integration of control, computing and sensing Segura et al., (2018).

The Robotic Digital Twin for Virtual Operators portrays how operators can learn how to utilize collaborative robotics exchange (technically and psychologically) to be able to cooperate with machines and robots Segura et al., (2018).

\subsection{Augmented Operator}

On machines, AR can offer analytical intelligence obtained from real time data sensors to determine the repair equipment or maintenance of machines. AR also enables factory managers to gain a clear view of Key Performance Indicators (KPIs). Besides, AR also provides managers with a real-time overview of the different sections of a factory. This allows managers to immediately identify, analyse, diagnose, monitor and resolve flaws (e.g. alerting on deviations) for manufacturing processes to keep occurring efficiently. Furthermore, serving as 'tag reader' may cause original human-product exchanges through QR codes, GPS, OCR, barcodes, RFID and NFC technologies which provides the smart operator with topical and historical information on a product. This also allows the smart operator to monitor and configure data and settings about that product Romero, Stahre, et al., (2016).

Augmented Reality (AR) on the other hand enhances real-life events and experiences with virtual replicated characters. It consists of three basic constituents: an integration and re-collocation of real and virtual objects, working with interaction in real-time and an amalgamation of actual and virtual objects in the actual work 
environment Chimienti, Iliano, Dassisti, Dini, \& Failli, (2010). Latest VR tools are demonstrated in figure 11.

An augmented operator is dependent on Augmented reality technology which could be seen as the other side of the coin and that is because of the developed generated computer views, pictures, sound effects and other useful data which is integrated within the real working environment and presented on a display. Dictionary.com, (2017).

Smith, (2002) argues that AR forges a virtual reality that enables the user to experience the sensation of actually being present within it.

Augmented Reality decreases the cognitive load in cases where technical reporting occurs. AR belongs to the group of nine enabling technologies, therefore, utilizing it is an exceptional way for making technical documentation of factory instruments or products, suitable for Industry 4.0, Fiorentino, Uva, Gattullo, Debernardis, \& Monno, (2014). AR can form a new appearance of reality due to its advanced manufacturing. This allows users to feel like they are present within it.

Fiorentino et al., (2014)argues that novel computer graphics interfaces such as Virtual and Augmented Reality can remarkably alter how technical information is conveyed to the its users. Currently, high-resolution Head-mounted displays (HMD) and onboard 3D real world synchronizations well as voice and body movements recognition are being commonly used and decreasing in price (e.g. HTC Vive) .

In any factory, maintenance of machines and equipments can be achieved through Augmented Reality (AR) through the concept of "Diagnostic Intelligence" which is done by real time sensors. This concept is about collecting performance related data for a whole machine or particular part while operating. The AR also allows factory 
managers to monitor the production lines to analyze, diagnose, and solve flaws. This makes production operations more efficient Romero, Stahre, et al., (2016).

According to Uva et al., (2018)AR technology is the reason for the maintenance and assembly work. Graphics and other visual objects have proven to be exceptionally effective in delivering the task the operator must accomplish and how the task must be accomplished Fiorentino et al., (2014).

The visual characters of AR can aid operators in two particular tasks:

- Identifying elements, for example, using strong clear colours and text labels in ARMAR inside a military vehicle.

- The actual performance of the process, for example, utilizing an animated 3D model such as bolts, and an operation description like a text referring to unscrew the bolt in an automotive task Gattullo et al., (2019). 


\section{Chapter 5}

\section{DESIGN AND METHODOLOGY}

This chapter discusses the research methodology and outlines the strategy of the study, research method, approach, data collection method, data analysis and the research limitations. The total cost of the application is specified in table 13.

\subsection{Design}

Based on the importance of Virtual Reality in manufacturing especially in training workers and operators, this research focuses on a VR simulation of a manufacturing system and its importance for understanding workers interaction with machines and their cognition abilities inside the VR environment. Currently, various industries consider and use VR application as anhighly developedscheme to train employees on manufacturing skills and processes.

The first step for such an application is to build a virtual reality environment which fully includes all the little details a manufacturing plant would have for the purposed application. For VR to work, the following steps must be followed:

- Programming of the open simulation script.

- Design of 3D representation.

- Generate a virtual environment in a simulator.

- Upload the 3D representationinto the virtual environment.

- A detailed assessment of its part in the industrial process. 
Further requirements for better VR experience:

- Make the virtual world and physical plant compatible.

- Update the open simulation script.

- Update the controller.

- Continuous testing and validating.

A built model was used from Game4automation company which is specialized in making 3D Simulation shareware frameworksof automated systemsbased on Unity game designing software. Game4automation provides all required elements which will power up a digital twin with Unity software - software that is needed in the creation and animation/programming of $2 \mathrm{D}, 3 \mathrm{D}, \mathrm{VR}$, and $\mathrm{AR}$ environments. This application uses CAD interfaces (CAD-Live-Link), interfaces for industrial automation systems, sensors, and drives. In operating systems such as Windows, IOS, and Android, the digital twin merges as a unity module.

\subsection{Simulation Engine}

The platform used to create/edit the $3 \mathrm{D}$ workspace is Unity engine. This software is mainly commonly used for game making within Integrated Development Environment (IDE). In a Unity project, it is important to include the needed resources such as models, textures, sounds, etc. 


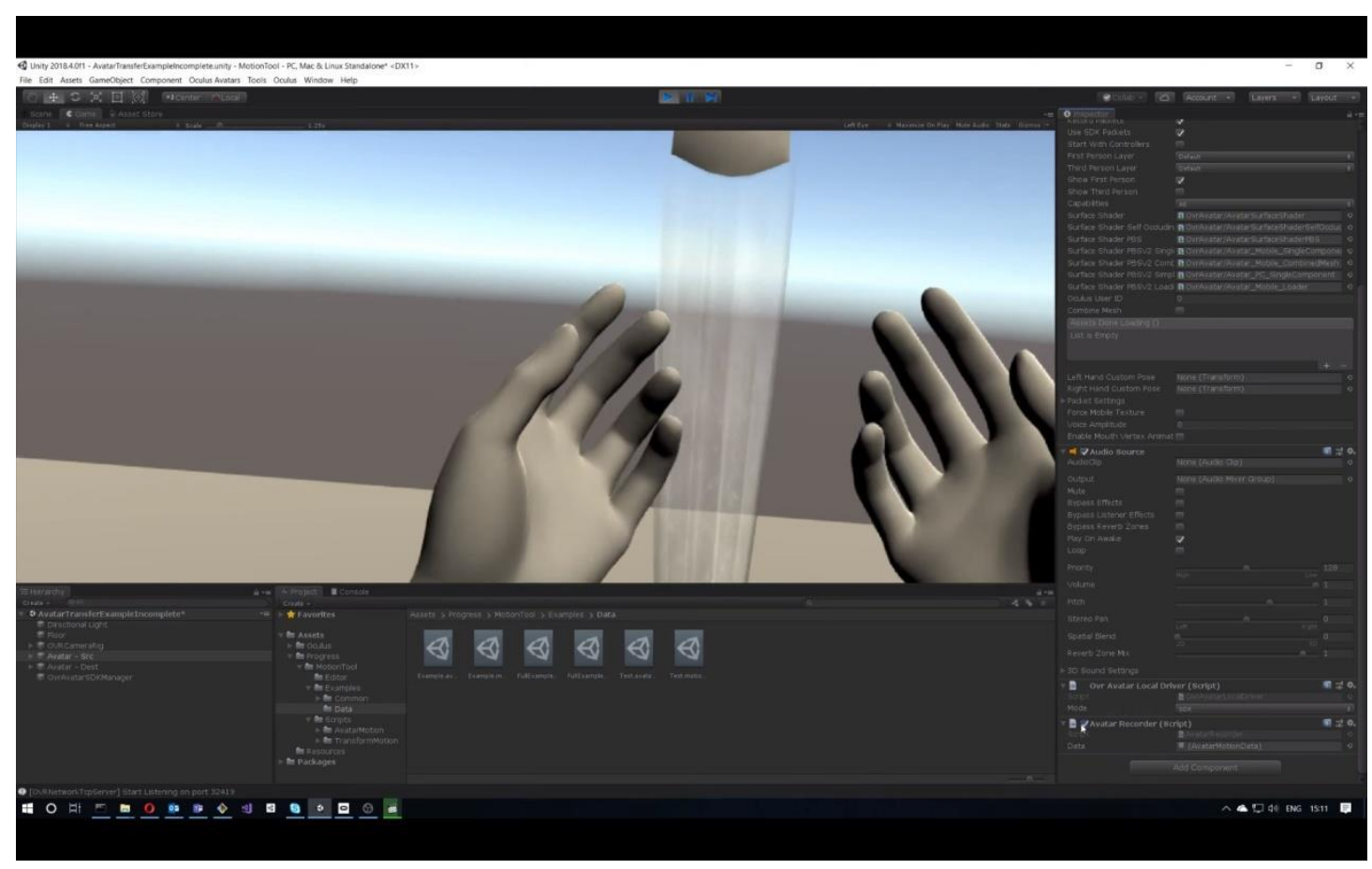

Figure 13: VR modeling inside Unity engine. Adapted from Medium.com, (2019)

\subsection{D Environment}

The 3D animated model was bought from Game4automation company. The application includes 5 main sections, control box, conveyor belt, sorting machine, container and a 5-axis robot. The control box is mainly a power supply which is used to power up the production line. The Conveyor belt is used mainly to move the product to a specific position so the sorting machine can move and sort the product from the conveyor belt to the blue container. Lastly, once the blue container is full, the 5-axis robot holds the container and empty's it. 


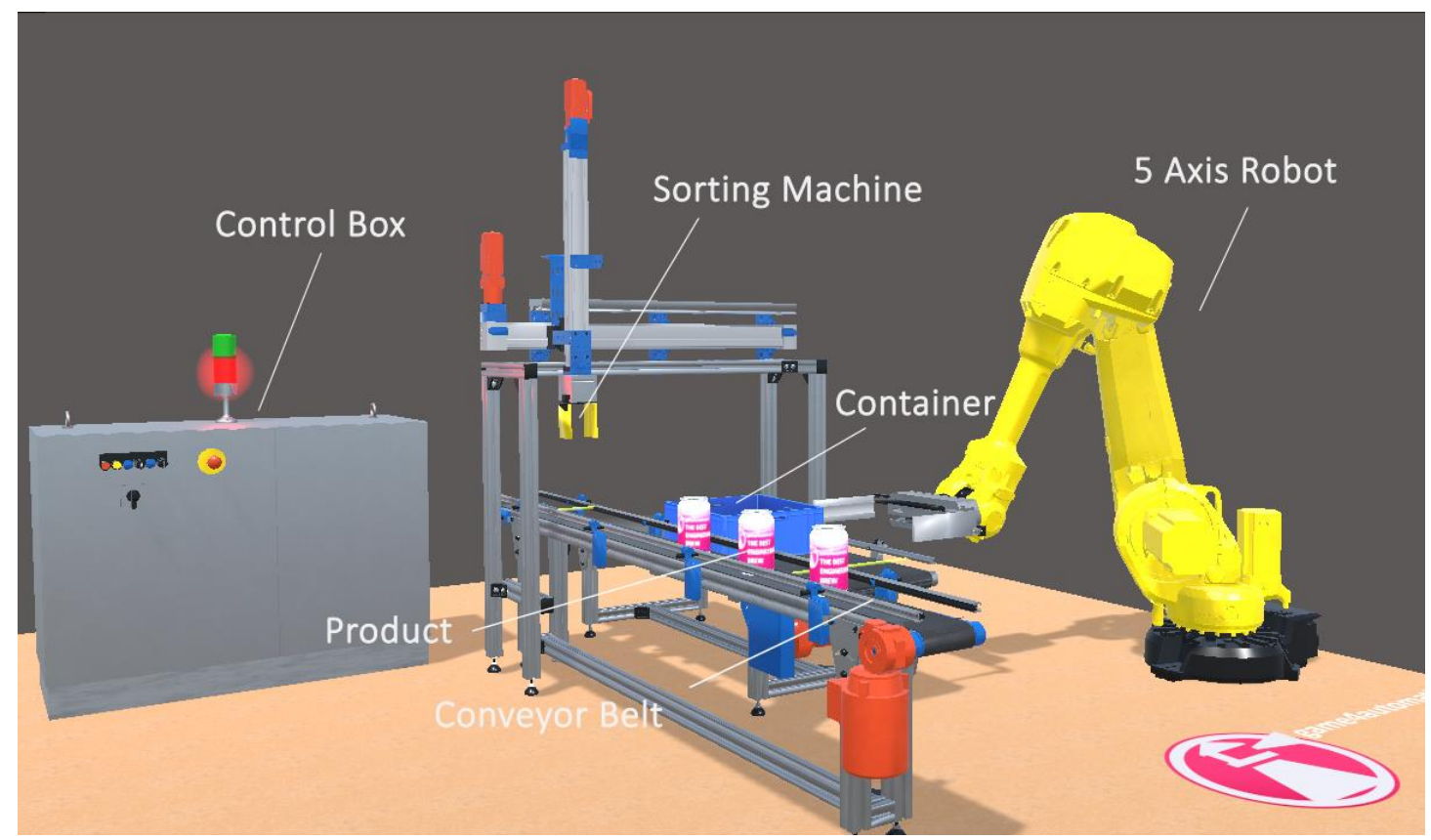

Figure 14: Game4automation 3D simulation

As the machines are communicating with each other as it is in I4.0 Smart factory, the Operator 4.0 job is to only observe and control the machines once necessary. Basic on/off controllers are available for all the machines so it facilitates the worker's ability to understand the relation between the machines.

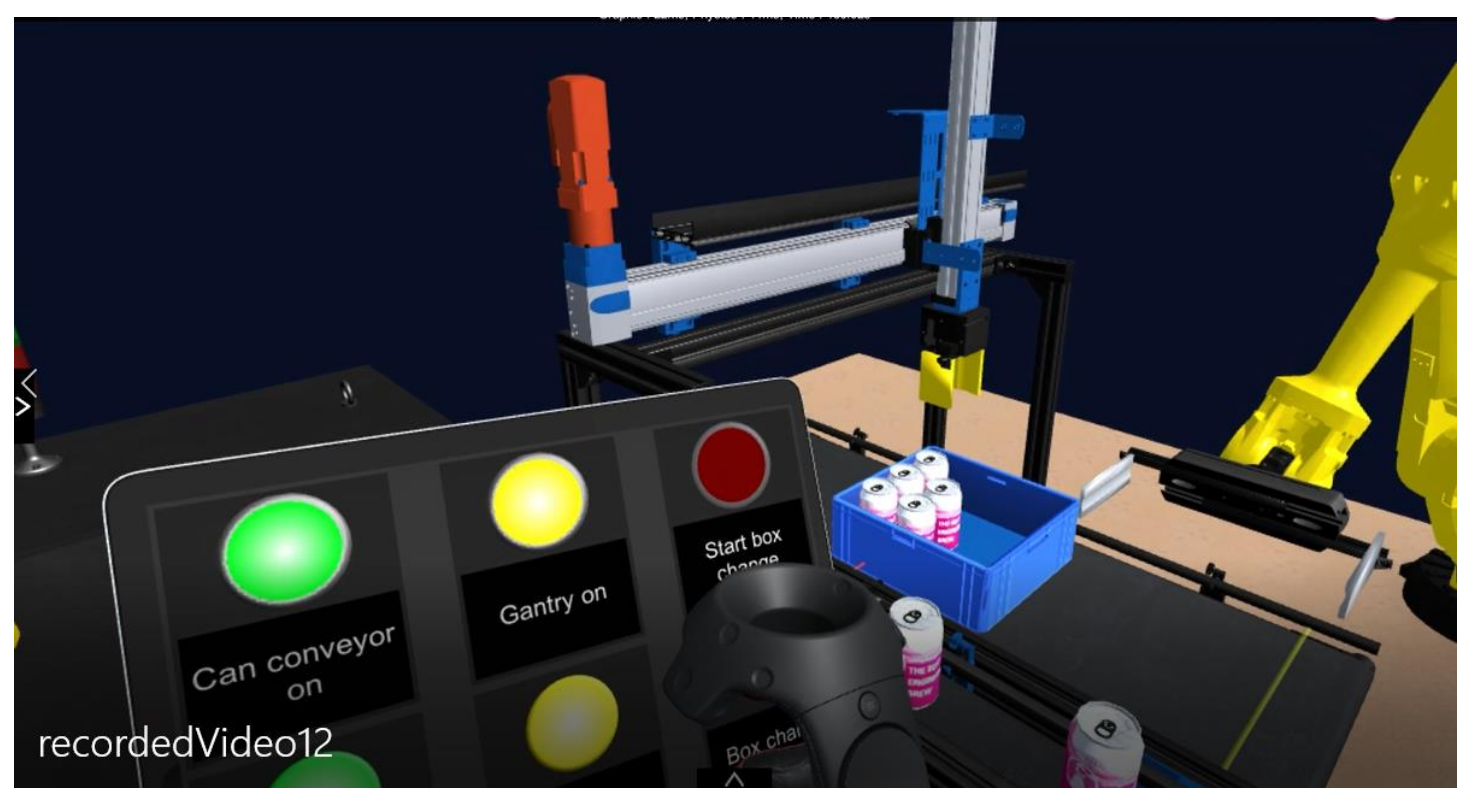

Figure 15: Virtual Reality simulation 


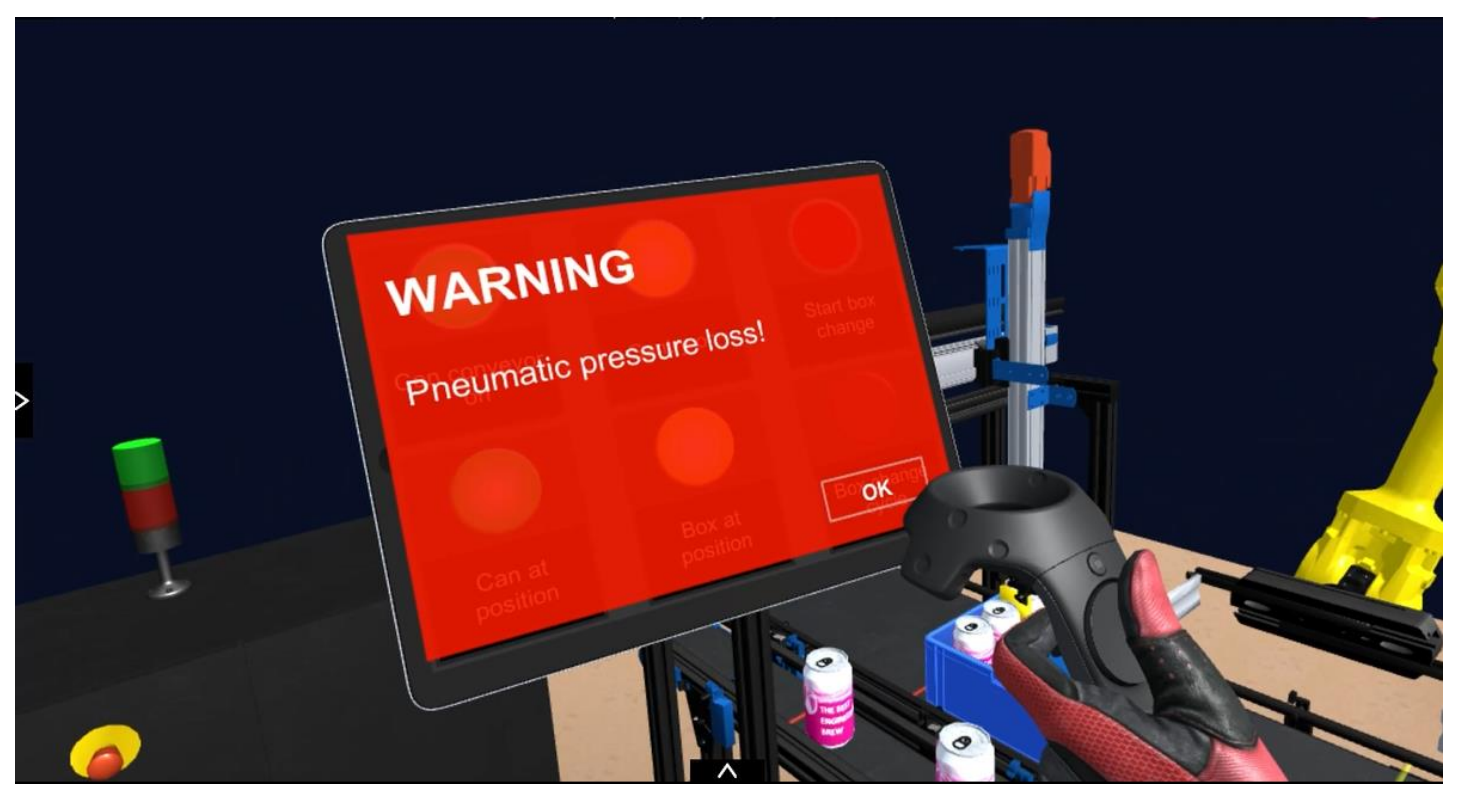

Figure 16: Unplanned change in Virtual Reality simulation

\subsection{Survey Design}

The survey was planned based on the CompleXity Index method (CXI). This method aims to assist production companies to identify and reduce working complexities that could affect operators' performance. Mattsson et al., (2012). The survey is presented in Appendix A. The questionnaire includes 10 questions which are presented using the Likert scale. The scale range is from 1 (Do not agree at all) to 5 (Totally agree).

The questionnaire was divided into 2 main sections. The first section has questions related to the task and operation. First question was related to the time limit given to participants to do the task, three questions related to the warning message (unplanned change), and a question related to whether participants felt any stress during the task.

The second section of the questionnaire was mainly related to the software design of the tablet controller, starting from the icon shapes and functionality to the general design of the software. 


\subsection{Experiment and Task}

- Step 1: A participant is required to wear the VR apparatus and confirm that the vision of 3D simulation is clear. Then it is confirmed that the participant is ready for the next step.

- Step 2: In this step, the participant has become the operator of the virtual factory, and he is required to move inside the VR environment to observe the factory and the machines.

- Step 3: Operator is required to hold the tablet which controls all machines, from inside the 3D simulation and see if there are any notifications or warnings.

- Step 4: A warning appears on the tablet (unplanned change) for one of the machines about pressure loss, and the operator is required to turn off all machines and visually observe if anything is wrong.

- Step 5: After concluding that machines are in good working conditions the operator is required to turn on all machines.

\subsection{Design Goals}

This research aims to find out the results of interactions between 3D Virtual environment and workers. The goal here is to train operators on the factory and allow them to explore the design of the factory prototype before launching it. The feedback and responses of participantscan assist future designers to avoid GUI issues such as the software faults such as the software used to control the machines and to improve the quality of such application for a better and more convenient experience in such a way that they keep their focus on the tasks given to them and keeping them immersed in reality. 


\subsection{Technical Requirements}

Some technical requirements are necessary to make and work with Virtual Reality environment. Main needs for VR can be listed as follows:

- Advanced computer system: MSI gaming computers or any similar system.

- Virtual Reality kit:HTC Vive or Oculus Rift for VR simulations.

- Programming skills: C\#, C++, Javascript.

- Designing skills: Unity 3D, Sketchup or any similar software.

HTC Vive VR system has a minimum required computer specifications with a CPA of at least Core i5 equivalent or higher, 4 GB or more RAM, HDMI 1.4, graphics card with a DisplayPort 1.2 (HDMI) or higher, one USB 2.0 port or higher and an operating system Windows 7 or later. The computer system that was used for this study is MSI GFTRVR 7RF, figure 18.

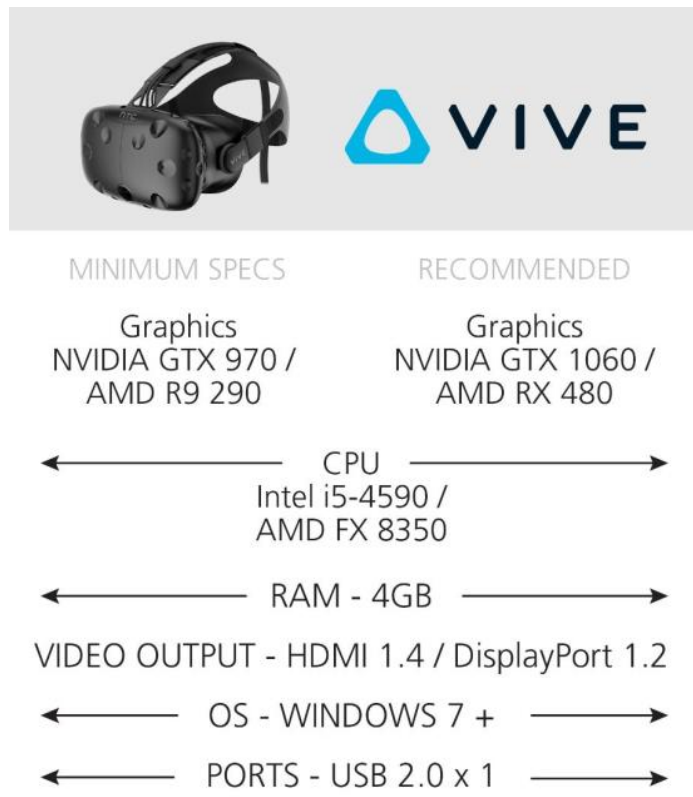

Figure 17: Computer system requirement by HTC Vive VR kit. Adapted from Vive.com, (2019) 


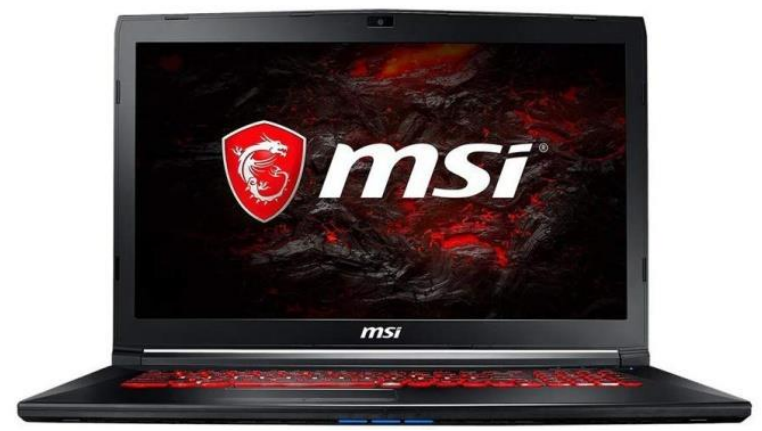

Figure 18: MSI high performance computer system. Adapted from Msi.com, (2018)

Table 13:Total cost of the application.

\begin{tabular}{|l|l|l|}
\hline \multirow{2}{*}{ Utility } & \multicolumn{2}{|c|}{ Cost \$ } \\
\cline { 2 - 3 } & Buy & Rent \\
\hline Computer system & 1200 & - \\
\hline HTC Vive & 700 & 10 per day \\
\hline Game4automation (Basic model) & 35 & - \\
\hline Programming and animation & - & $20-100$ per hour \\
\hline
\end{tabular}

\subsection{Application and Methodology}

A 360 degree VR production line was displayed through Virtual Reality kit. Participants (prospective operator 4.0) had to observe the working environment and had to understanding how machines operate and how they can control them using the tablet. The time limit given to participants was approximately 5 minutes. Participants had to memorize which buttons control which section of the production line.

The VR software that was used in this application enables participants or future Operator 4.0 to do real movements within the simulation (moving in a specifically designed area) and freely turning around and rotating as they would do in real world. The application allows participants to reach out for things (tablet) in the VR environment allowing for more convenient interaction through the arm controllers. A real hand model simulation was visible on the high resolution VR kit for more convenience. 


\subsection{VR Apparatus}

VR environment was presented using HTC Vive 360 degrees VR system figure 18, which is a software, hardware, and a creative platform to form imaginative creations with a Sub-millimeter-precise tracking technology from SteamVR (an environment for innovation and High-fidelity hardware). This combination forms a strong superlative experience that cannot be paralleled. It creates a future of art, gaming, enterprise, storytelling, and entertainment.

\subsection{Components of HTC Vive VR System}

- Vive Headset: It contains a 110-degree field of view and a refresh rate of $90 \mathrm{~Hz}$. It has two panels for the eyes with a display resolution of $1080 * 1200$.

- Vive Controllers: They come equipped with multiple input methods, such as grip buttons, dual-stage trigger, a trackpad, and about 6 hours of usage time. 24 infrared sensors are around the ring of the controller that detects the base stations to determine the location of the controller.

- Vive Base Stations: This is sometimes referred to as the Lighthouse tracking system. The Vive Base Stations are two black boxes that form a 360-degree virtual environment within a $15 \times 15$ foot radius. They release 60 infrared pulses per second which the headset and controllers with sub-millimeter precision pick up.

- Vive Tracker: This is a motion-tracking device that must be attached to a physical device or controller for it to track these devices via the Lighthouse system. These trackers come equipped with a connector that enables communication between the tracker and the device it is attached to.

- Vive Deluxe Audio Strap: This device distributes weight easier hence it enhances the HMD's comfort and includes integrated over-ear headphones. 


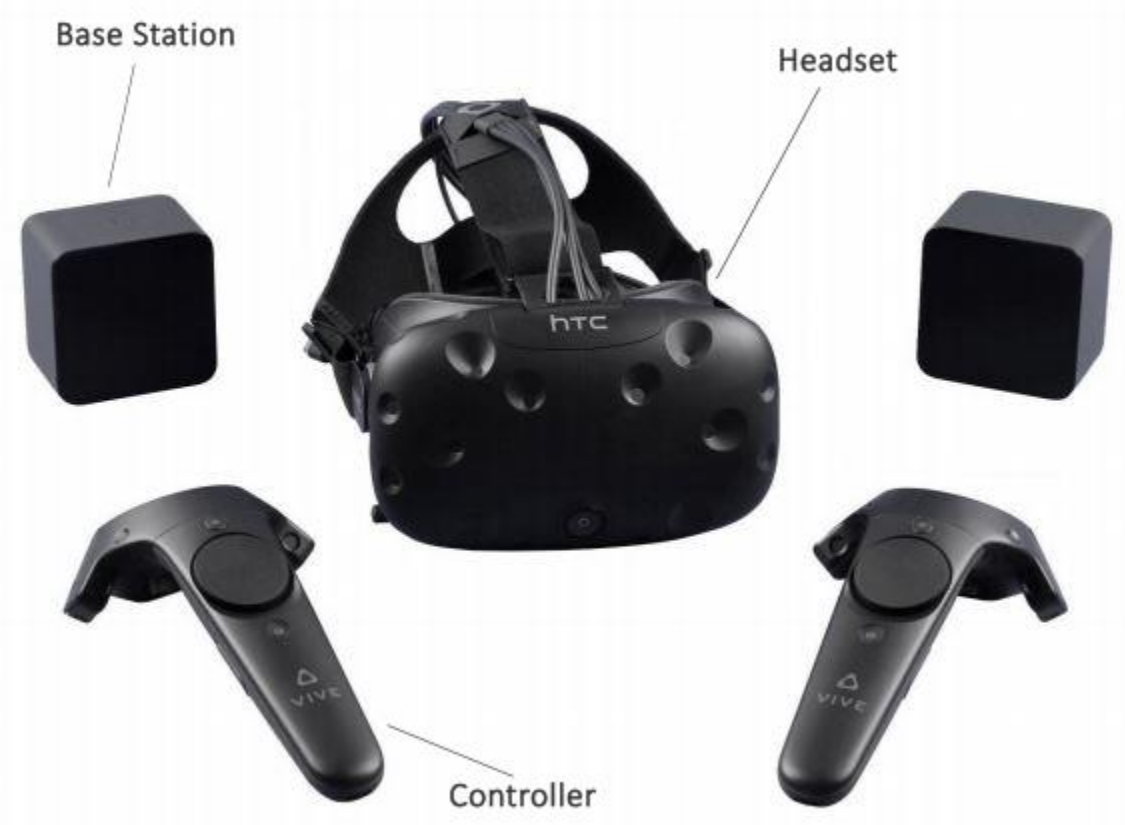

Figure 19: HTC Vive VR Kit. Adapted from Bhphotovideo.com, (2018)

\subsection{Data Collection}

Testing with a real-time experiment was selected for the purpose of the study. The experiment's aim is to understand future worker's feelings, reasoning abilities and most importantly their opinions on how to improve similar application for future purposes. Volunteers who had any injuries, physical or mental were excluded for the purpose of the research and to avoid any further injuries and having uncertainties in the results. As far as data collection tool is concerned, the study includes a semi structured questionnaire.

\subsection{Participants}

Participants were divided into 3 groups, bachelor, masters and PhD. 10 participants of each group participated which made 30 participants in total. The age range was between 20 and 40 years (average of 30 years). To ensure the validity of 
the survey, prior to making the experiment, participants were asked if they had any medical injury that might affect their ability to participate such as physical or mental injuries. Half of the participants were below or equal to 25 years old, and the other half were above 25 years old.

Table 14: Participants classification table

\begin{tabular}{|l|l|l|}
\hline Degree level & Age range & VR Experience \\
\hline Bachelor & $20-26$ & $60 \%$ gaming experience in VR. \\
& & $40 \%$ no previous experience in VR. \\
\hline Masters & $22-31$ & $30 \%$ gaming experience in VR. \\
& & $70 \%$ no previous experience in VR. \\
\hline PhD & $28-40$ & $20 \%$ gaming experience in VR. \\
& & $80 \%$ no previous experience in VR. \\
\hline
\end{tabular}

\subsection{Protocol}

All chosen volunteers had a verbal introduction about the experiment prior to the VR application. Later, volunteers were asked to do some tests and movements to make sure that the application was fully functional and to fulfill the criteria of making the experiment, for example, walking straight, walking in curves, turning around, reaching upwards and bending downwards. Participants were given 30 to 60 seconds to navigate in the VR production plant and to visually explore and walk through the VR factory environment till they confirm the comfortness of using our HTC Vive VR control system. Thereafter, the real experiment started when they 
were asked to do some tasks such as checking specific parts of machines and turning machines on and off using tablet controller.

\subsection{Data Analysis}

Statistical Package for the Social Sciences (SPSS) version 23 was used to analyze collected quantitative data. A total of 30 volunteers made the experiment and all of the participants answered all the questions. Excluding participants names from the data analysis part, the data analysis included mainly numerical values except for the last question which was related with any suggestions for future developments.

\subsection{Ethical Considerations}

The questionnaire of the study got approved by the Research and Publication Ethics Board of Eastern Mediterranean University on the $7^{\text {th }}$ of October 2019. As this study depends on the usage of Virtual Reality Apparatus, the risks of using it must be minimal. Therefore, some considerations to the place where the experiment took place were taken such as available moving space... etc. All selected volunteers were above 18 years old.

Any participant who has mental disabilities, eye sight weaknesses or any other physical disability that might affect the results of the research were excluded.

Using VR kit could make participants go through disorientation, dizziness and make them feel uncomfortable. Therefore, all volunteers had enough time to move around in the VR module till they feel relaxed using the kit.

Prior to the experiment, participants were given a brief presentation about the tasks they are going to make and in case participants had any concerns or questions, the researcher was giving all the related answers.

Throughout the experiment, the researcher was attendant in case participant mentioned any disturbances or any feel of dizziness the experiment would 
immediately pause to avoid injuries. Collected data from these participants was also excluded.

As for confidentiality, volunteers' privacy was preserved in all times. There was a buffer time in between sessions, in order for participants not to see each other. As for collected data, participants' names were not included with the data analysis process which keeps their personal details private. Lastly, if any volunteer asked for not taking his/her data into consideration for any reason/s their collected data is immediately eliminated. 


\section{Chapter 6}

\section{RESULTS}

Survey questionnaire was divided into two main sections. Section one, task and operation, which focuses on the task in general and has questions related to time limit and stress. Section two, tablet graphical user interface and this section focuses more on the software design and ergonomics of the tablet controller. In total there was 9 questions.

Question 1 in the survey asks about whether the given time for the task was enough or not. The results of this question are presented in figure 20.

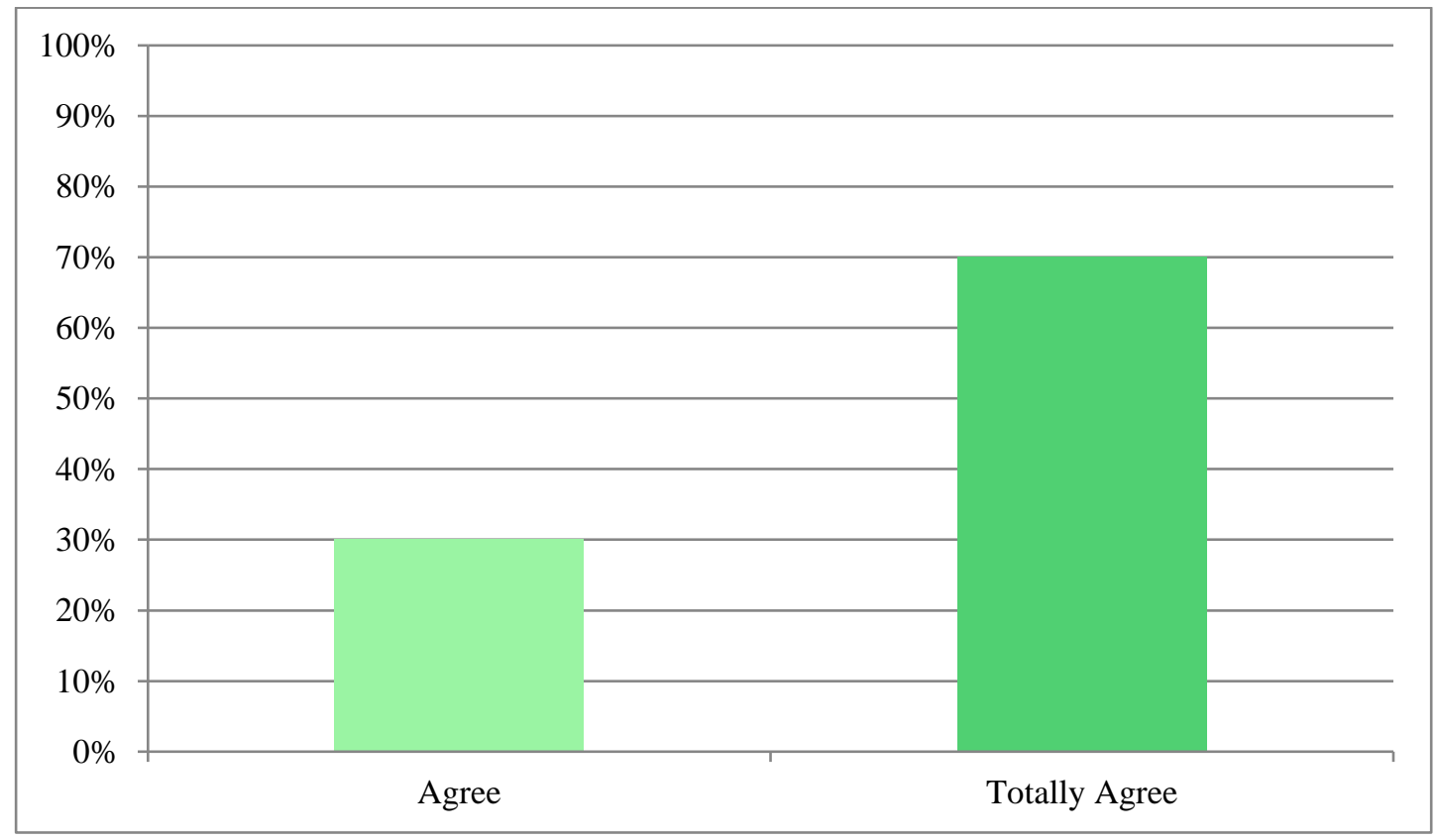

Figure 20: RQ 1 results 


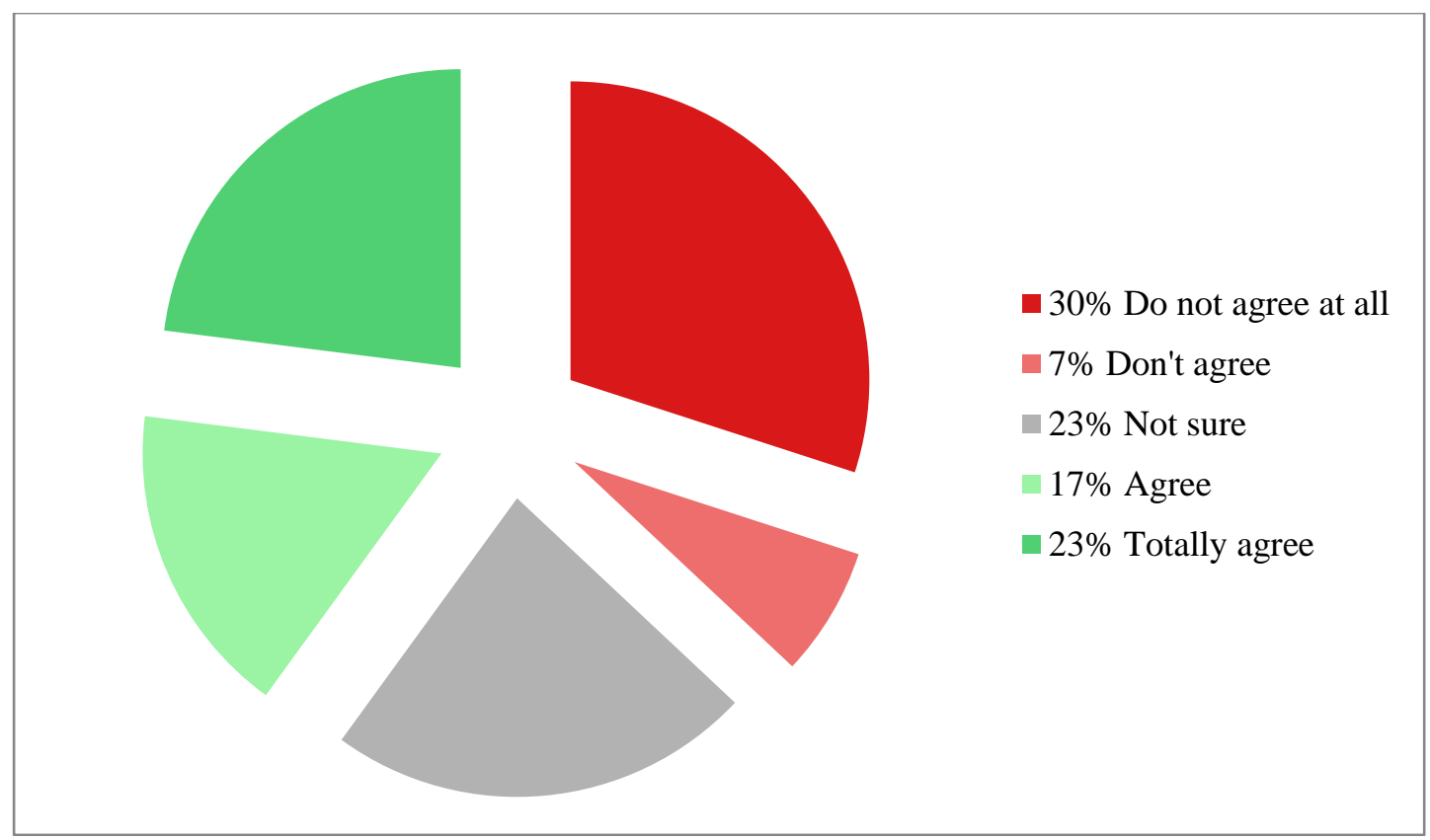

Figure 21: RQ 2 results

Regarding the second research question, figure21. Participants were asked whether the task/operation was affected by any unplanned changes. Around $41 \%$ agreed that the task was affected by unplanned changes. $23 \%$ of participants were not sure and $36 \%$ saw that the task was not affected by any change. 


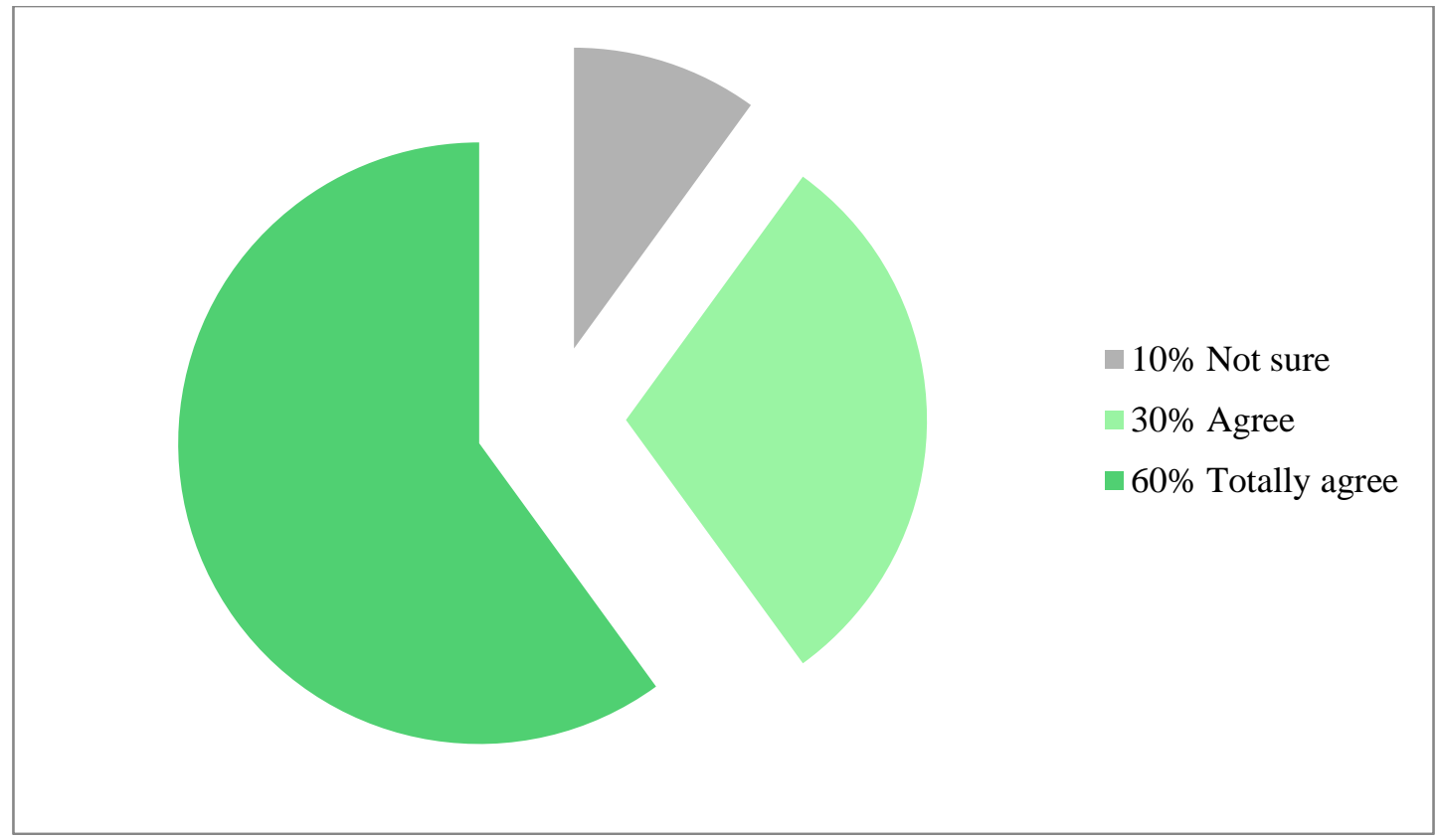

Figure 22: RQ 3 results

As for research question 3, figure $22,90 \%$ of the participants agreed that there was enough time for them to deal with the unplanned changes in case any occurred.

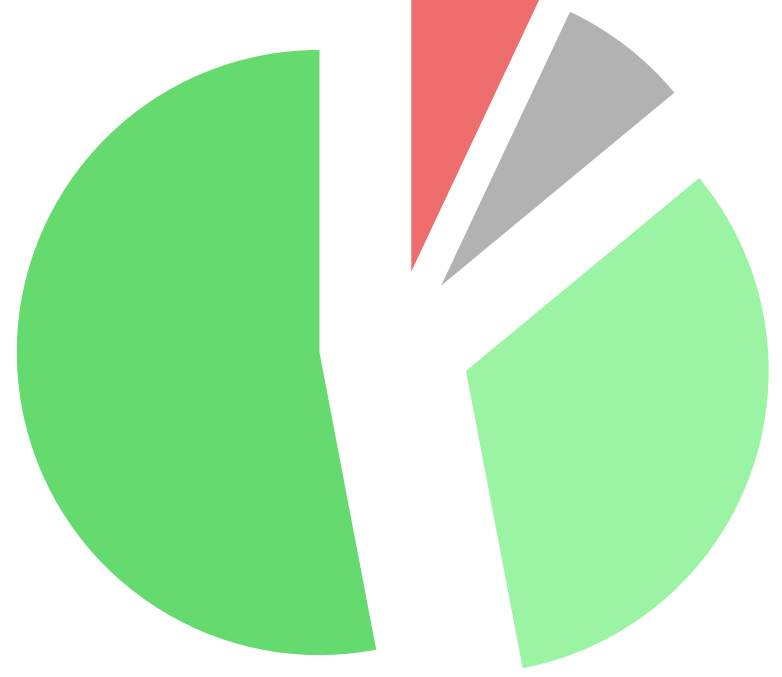

$\square 7 \%$ Don't agree

$7 \%$ Not sure

$33 \%$ Agree

$\square 3 \%$ Totally agree

Figure 23: RQ 4 results 
When participants were asked about whether it was easy for participants to find the information or instruction during any unplanned changes in research question 4, the majority of participants agreed that it was easy to find. Figure 23.

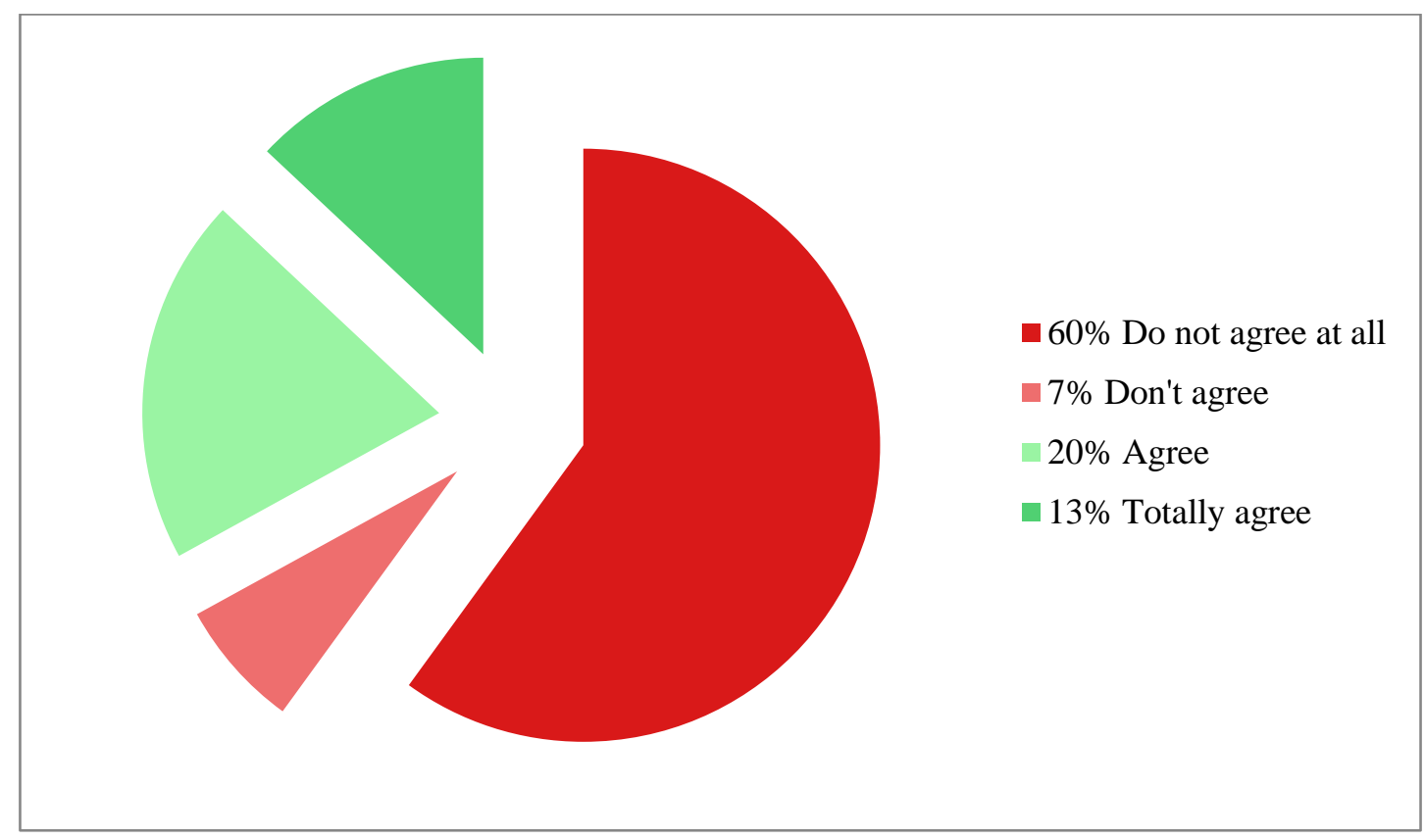

Figure 24: RQ 5 results

$66 \%$ of participants did not feel stressed while making the experiment while $33 \%$ felt stressed about it according to research question 5. Figure 24. 


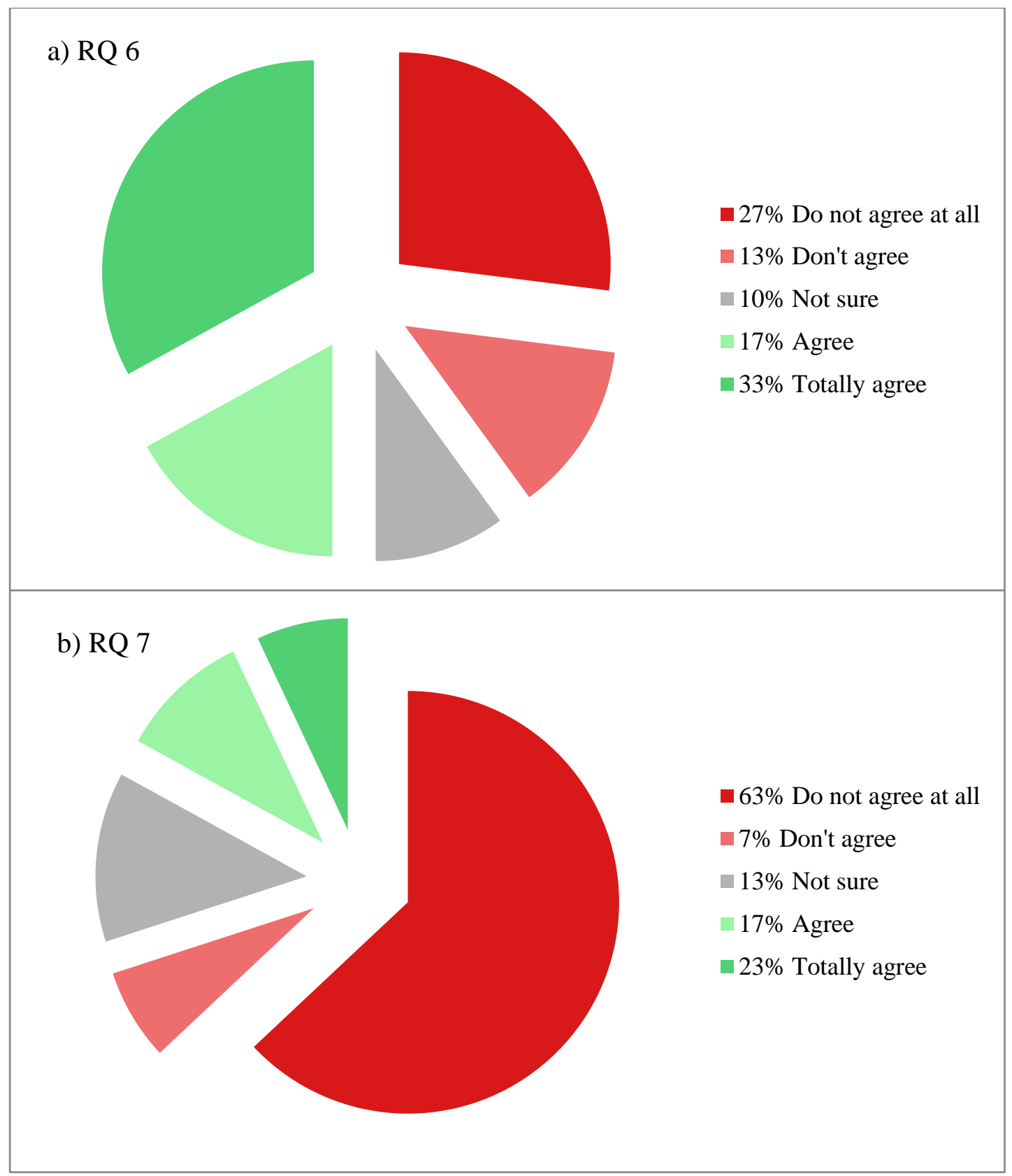

Figure 25: Survey results for, a) RQ 6, b) RQ7

Based on the results of research questions 6 and 7 in figure 25a and figure 25b, majority of the participants chose that the tablet user interface had many different icons and icons are not similar to one another in function. 


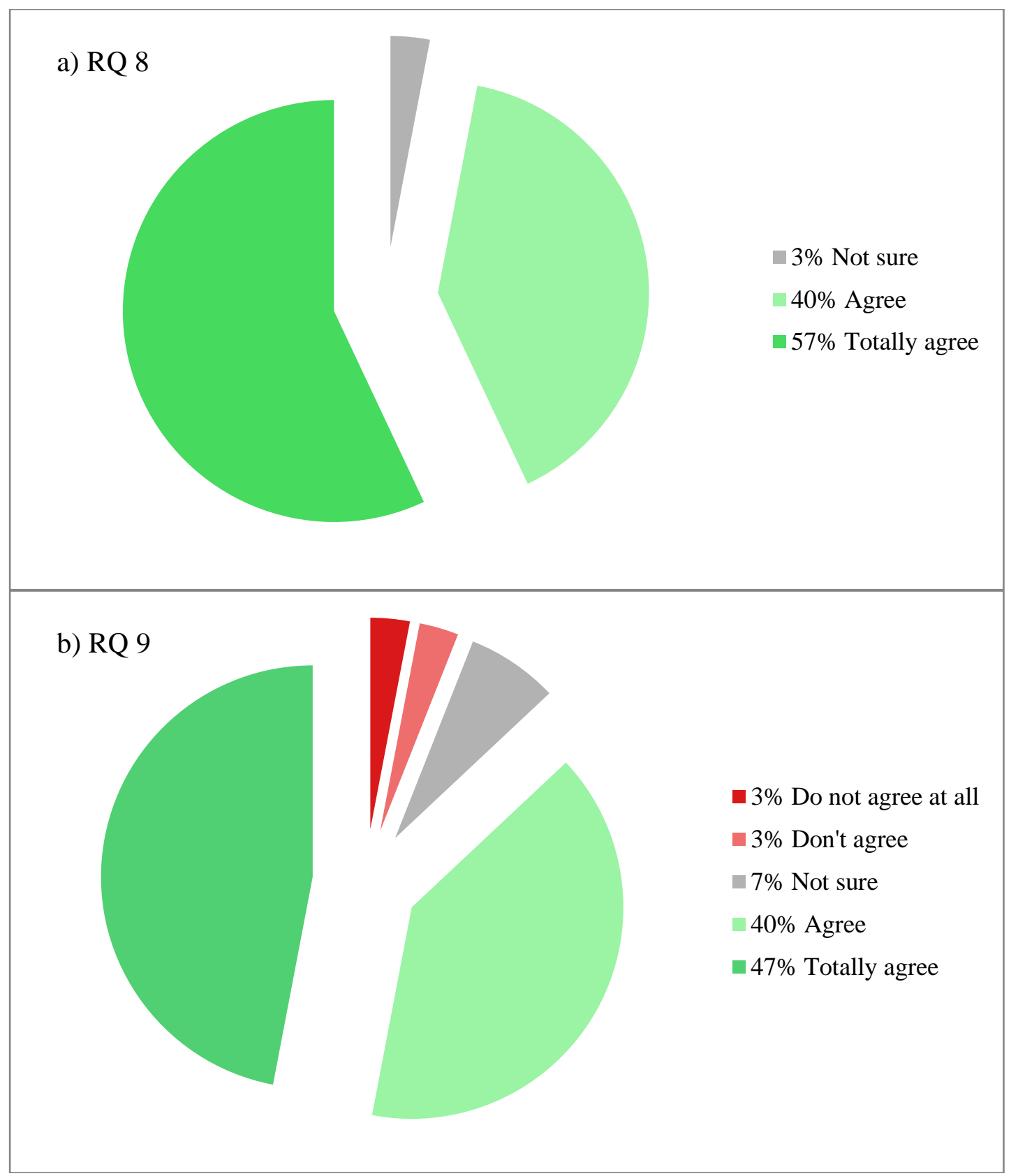

Figure 26: Survey results for, a) RQ 8, b) RQ 9

More than $80 \%$ of participants agreed that the software user interface in the tablet was generally well designed and well ergonomically designed. 


\section{Chapter 7}

\section{DISCUSSION}

According to the survey results, all of participants agreed that the considered time (5 minutes) for the given task was enough for them to learn and complete the task. However, some participants exceeded the time limit given to them. In figure 27 , an analysis of the effect of unplanned changes to participants' stress and time duration to complete the task was made. The word stress here refers to the participant not knowing how to deal with the warning message. Although a brief tutorial was given to all participants regarding the task. Only $25 \%$ of all participants who agreed that their task was affected by the warning message highlighted that they felt stressed. Amongst the ones who highlighted they have been stressed. Nearly $65 \%$ of them required more time to complete the task. This gives an idea on how stress could affect the operator's learning ability and cognition at the working place. 


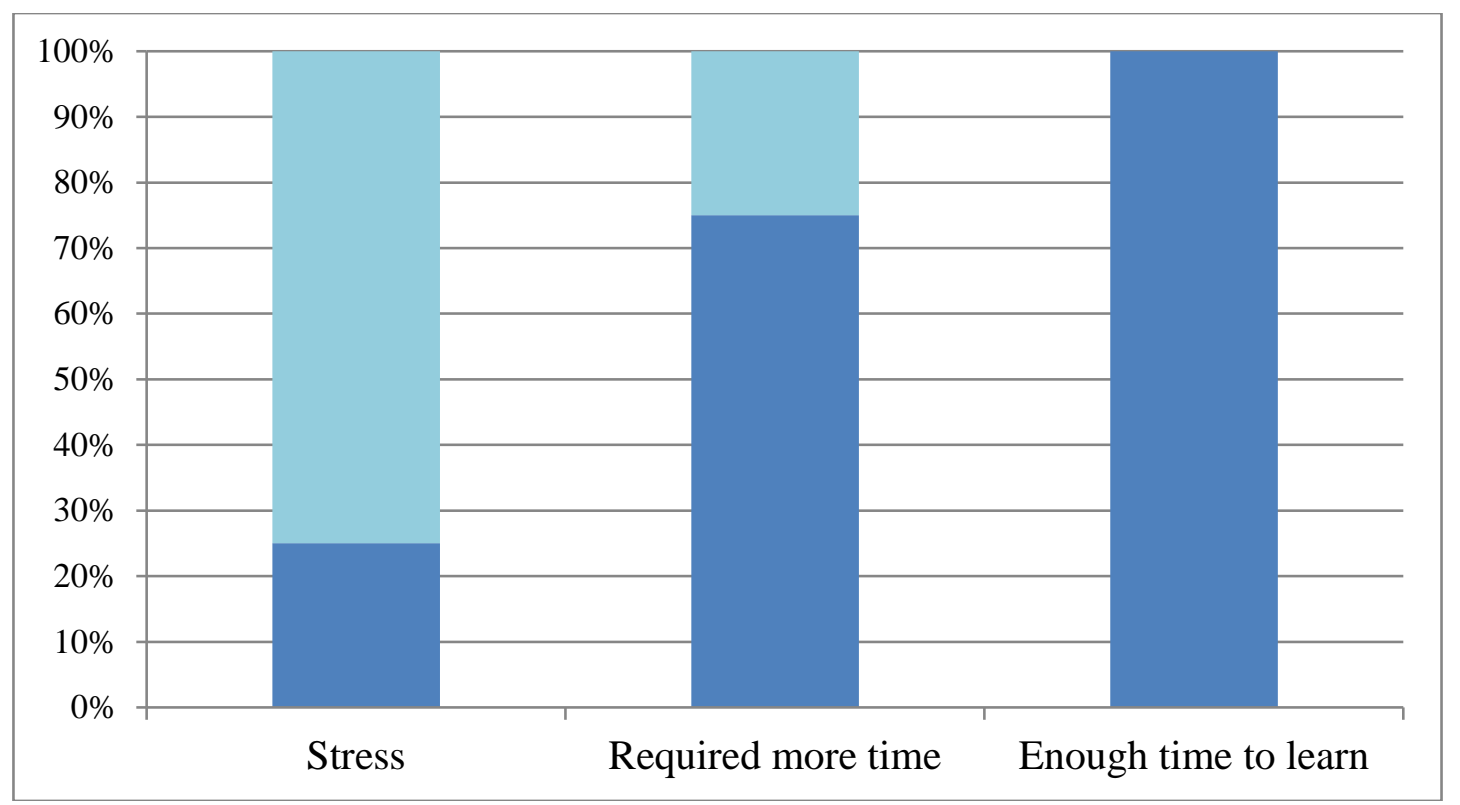

Figure 27: Unplanned changes and stress analysis

Less than $50 \%$ of participants who were above 25 years old highlighted that theyfelt stressed while performing the task as shown in figure 28. These participants required more time to complete the required task as well. Whereas more than $50 \%$ of participants who were less than or equal to 25 years old highlighted that they were stressed. But took less time to finish the task.

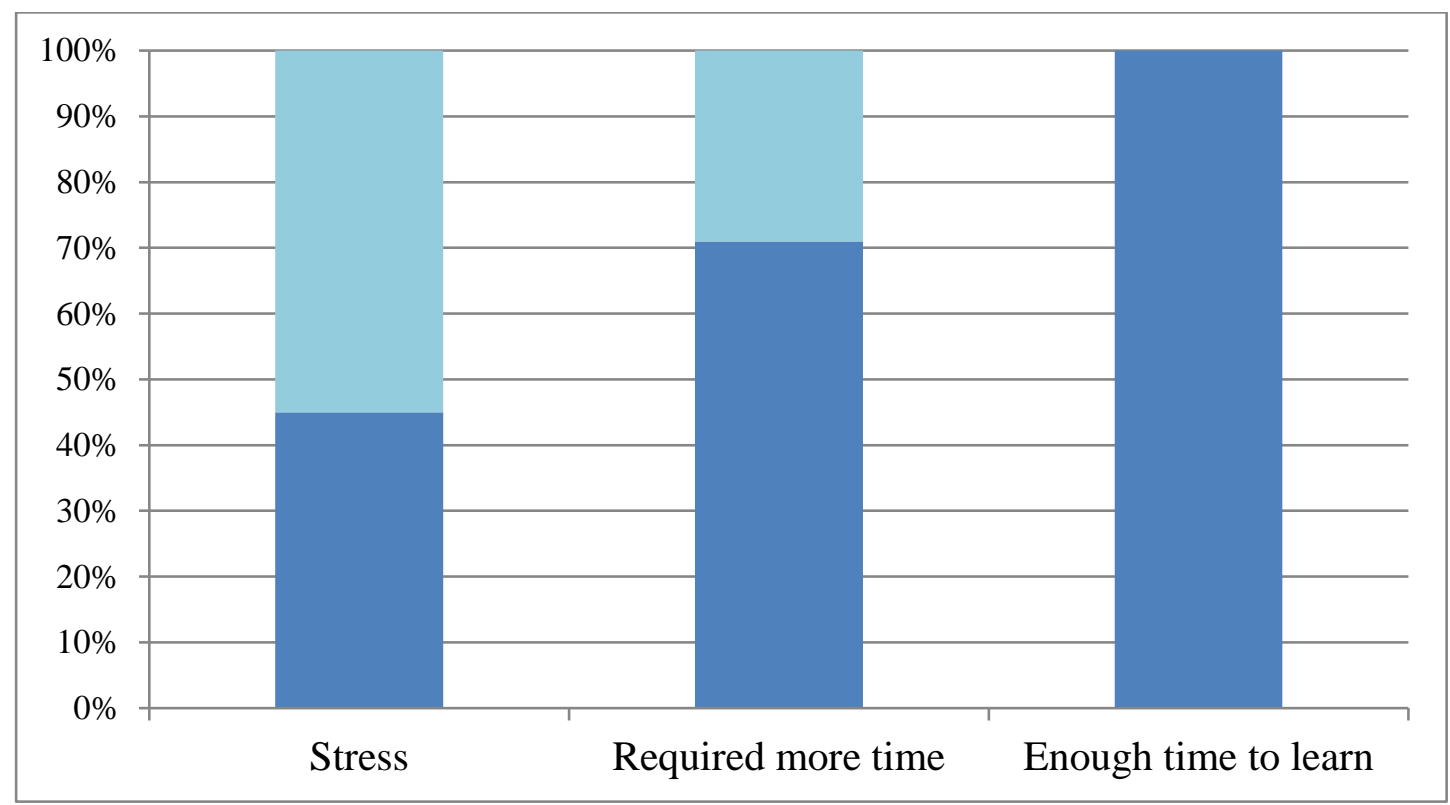

Figure 28: Age analysis for participants above 25 years old 
Although some of the participants could have used VR before. This did not show a major effect to the time duration a participant required to complete the task. The stress in this task can come from the warning message, tablet software design where participants could not remember which button controls which machine, or the 3D environment.

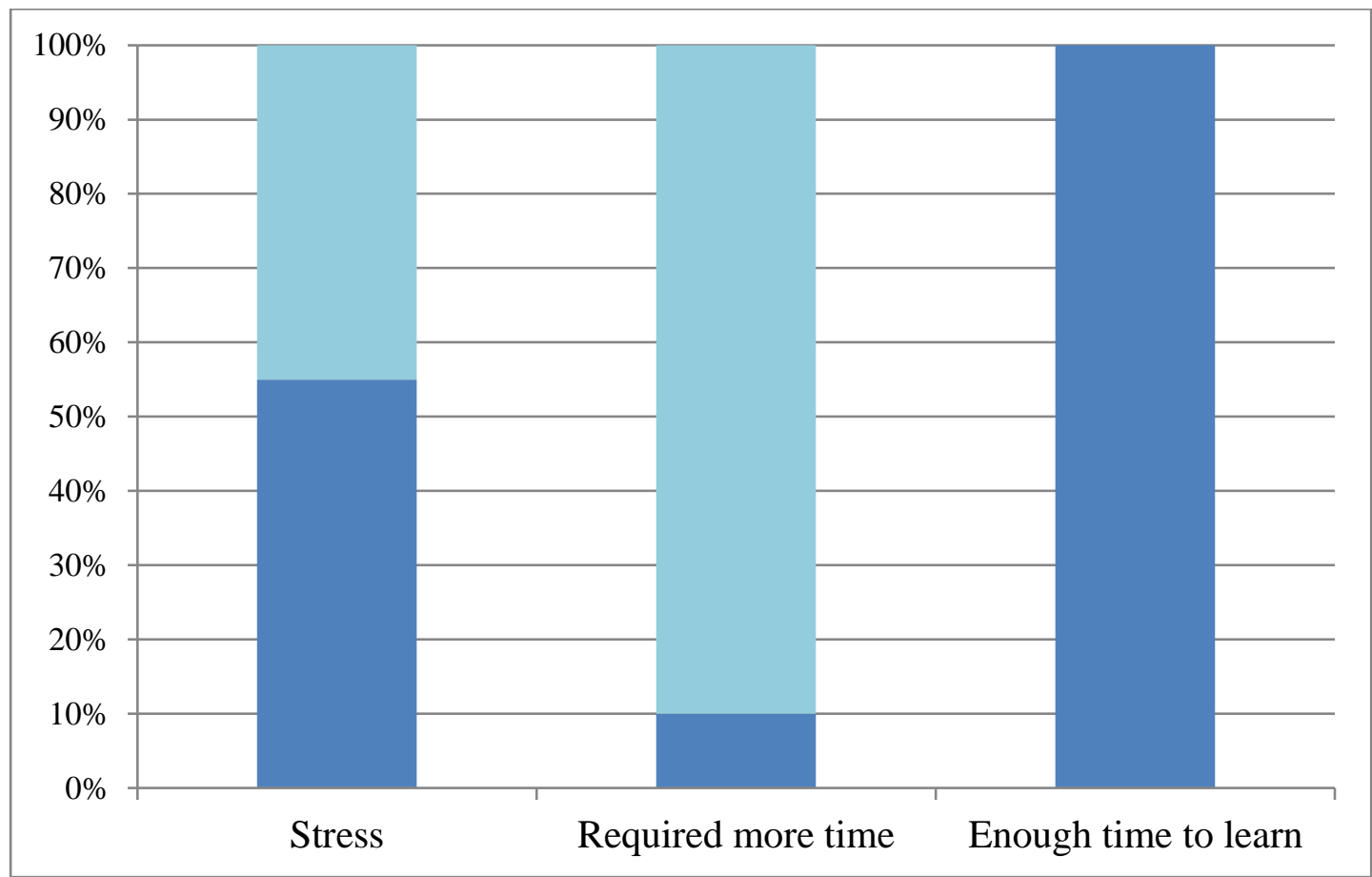

Figure 29: Age analysis for participants below or equal to 25 years old

In general, all of participants agreed that such application is a useful method to teach future workers on how to perform their tasks in a smart factory. As for the survey question that asked about any comments and future proposal on how to improve this application the list below sums up important comments by participants:

- Adding visual assistance such as comments on the screen for better instructions.

- Audio assistance for better understanding.

- Extend it to a complete production line. 
- Adding a seat for better physical ergonomics.

Positive comments by participants:

- Such technology can be implemented by Cypriot factories to improve the industrial movement.

- Workers can have their training before starting their jobs.

- Can be implemented in the education system.

\subsection{Limitations of the Study}

The main limitation in this survey is programming. The VR application could have been made more complex and visual and auditory assistances could have been added. However, professional programming is required to achieve this. 


\section{Chapter 7}

\section{CONCLUSION}

The concept of smart factory systems can be easily presented through innovative techniques that are manifested in simulation, learning in action, and the VR. Moreover, these innovative techniques can further promote future development in the field.

The first research objective was to identify the required skills for future Operator 4.0 and these skills were classified in the literature in chapter 3 and chapter 4.

The second objective was to see how can VR be used to train future Operator 4.0 in a smart factory environment. For this objective, a VR experiment was made and 30 students from the faculty of engineering participated in the survey. Participants' feedback on the survey questions showed important findings. One of those findings is that age had indeed its effect in the learning duration of participants. However, at the end, all of the participants were successfully able to complete the given task. This shows that older workers can have equal chances to be hired in the future if they had sufficient training.

Furthermore, participants feedback regarding the experiment helped in finding out the required improvements to the application model regarding VR environment, user interface and task instructions. Hence, the application used was useful to analyze how VR in manufacturing could be progressed to make similar applications more convenient particularly that the experiment needed workers' physical and mental interaction with the machines and tools required to control the machines. 
According to participants responses, the experiment reinforced thesis goals in the following:

- Design a manufacturing environment which assists Operator 4.0 to learn and have a visual based training on a 3D based production line.

- Search on different methods Opartor 4.0 would interact with a VR training program and study the ergonomics of software user interface.

- Observe the type of communication that can be acheived between Operator 4.0 and machines through technologies like IoT and CPS.

The new model of Industry 4.0 has received a great recognition, hence leading to some questions about its developments, effects to operators, and the concepts it holds beneath. Thus, the current study provided an overview of the related literature, to present the latest applications of the Operator 4.0, and the way this concept, when related to cognitive ergonomics, can help both researchers and professionals in the future.

The results of the study showed that there is a focus on the manufacturing endeavour, which aims to meet the I4.0 level and but limited research to improve different operator types for this purpose. Moreover, since the Industry 4.0 will still have to develop more technological and human features, the study mainly focused on human features and the way they are involved in the I4.0 paradigm. The main key point of this study would serve cognitive ergonomics researchers to perceive human strengths, abilities, and limitations.

\subsection{Future Recommendations}

- Implement vocal and visual assistance within similar VR applications to assist workers while training in the virtual environment. 
- Future factory's human resources sectors must be involved with the improvement of human asset through teaching, learning and qualifying worker, rather than just being responsible for recruiting workers.

- Higher education cirriculumns especially in engineering departments must improve to reach I4.0 level. Such improvements can be done by adding more practical applications that involves AR, VR, CPS and more. 


\section{REFERENCES}

Alam, K. M., Saini, M., \& El Saddik, A. (2015). Toward social internet of vehicles: Concept, architecture, and applications. IEEE access, 3, 343-357.

Alami, R. (2013). On human models for collaborative robots. Paper presented at the 2013 International Conference on Collaboration Technologies and Systems (CTS).

Aniruddha Talekar, S. P., Prashant Thakre, Rajkumar E. (2017). Virtual reality and its applications in manufacturing industries Journal of Chemical and Pharmaceutical Sciences (JCHPS), 10(1), 151.

Badri, A., Boudreau-Trudel, B., \& Souissi, A. S. (2018). Occupational health and safety in the industry 4.0 era: A cause for major concern? Safety Science, 109, 403-411.

Benešová, A., \& Tupa, J. (2017). Requirements for Education and Qualification of People in Industry 4.0. Procedia Manufacturing, 11, 2195-2202. doi:10.1016/j.promfg.2017.07.366

Bligård, L.-O., \& Osvalder, A.-L. (2014). CCPE: Methodology for a Combined Evaluation of Cognitive and Physical Ergonomics in the Interaction between Human and Machine. Human Factors and Ergonomics in Manufacturing \& Service Industries, 24(6), 685-711. doi:10.1002/hfm.20512 
Cailhol, S., Fillatreau, P., Fourquet, J.-Y., \& Zhao, Y. (2015). A hierarchic approach for path planning in virtual reality. International Journal on Interactive Design and Manufacturing (IJIDeM), 9(4), 291-302.

Chimienti, V., Iliano, S., Dassisti, M., Dini, G., \& Failli, F. (2010). Guidelines for implementing augmented reality procedures in assisting assembly operations. Paper presented at the International Precision Assembly Seminar.

Customerinnovations.com. (2018). The Dawn Of Cognitive Experience Design. Retrieved from http://customerinnovations.com/the-emergence-of-cognitiveexperience-design/

Delen, D., \& Demirkan, H. (2013). Data, information and analytics as services. In: Elsevier.

Dépincé, P., Chablat, D., \& Woelk, P.-O. (2007). Virtual Manufacturing: Tools for improving Design and Production. arXiv preprint arXiv:0708.0495.

Dictionary.com. (2017). Augmented reality. Retrieved from https://www.dictionary.com/browse/augmented-reality

Dubey, N. (2015). A Study on Cognitive Ergonomics. Retrieved from https://www.slideshare.net/NamitaDubey2/cognitive-ergonomics 
Dunlosky, J., Rawson, K. A., Marsh, E. J., Nathan, M. J., \& Willingham, D. T. (2013). Improving students' learning with effective learning techniques: Promising directions from cognitive and educational psychology. Psychological Science in the Public Interest, 14(1), 4-58.

Epicor. (2019). What is Industry 4.0 - the Industrial Internet of Things (IIoT)? Retrieved from https://www.epicor.com/en-us/resource-center/articles/whatis-industry-4-0/

Fawzi, H., Tabuada, P., \& Diggavi, S. (2014). Secure estimation and control for cyber-physical systems under adversarial attacks. IEEE Transactions on Automatic control, 59(6), 1454-1467.

Fielding, R. T., \& Taylor, R. N. (2002). Principled design of the modern Web architecture. ACM Transactions on Internet Technology (TOIT), 2(2), 115150.

Fiorentino, M., Uva, A. E., Gattullo, M., Debernardis, S., \& Monno, G. (2014). Augmented reality on large screen for interactive maintenance instructions. Computers in Industry, 65(2), 270-278.

Gattullo, M., Scurati, G. W., Fiorentino, M., Uva, A. E., Ferrise, F., \& Bordegoni, M. (2019). Towards augmented reality manuals for industry 4.0: A methodology. Robotics and Computer-Integrated Manufacturing, 56, 276-286. 
Grewe, P., Kohsik, A., Flentge, D., Dyck, E., Botsch, M., Winter, Y., . . Piefke, M. (2013). Learning real-life cognitive abilities in a novel $360^{\circ}$-virtual reality supermarket: a neuropsychological study of healthy participants and patients with epilepsy. Journal of NeuroEngineering and Rehabilitation, 10(1), 42. doi:10.1186/1743-0003-10-42

Gubbi, J., Buyya, R., Marusic, S., \& Palaniswami, M. (2013). Internet of Things (IoT): A vision, architectural elements, and future directions. Future generation computer systems, 29(7), 1645-1660.

Harish, N. (2009). Social and Ethical Issues in Software Design \& Development. Retrieved from http://web1.arthurphilh.schools.nsw.edu.au/tas/Multimedia/Website/Term1/Resources/HARISH_N armada/Ergonomic\%20issues\%20in\%20Software\%20Desgin.html

Heinonen, M. (2017). Adoption of VR and AR technologies in the enterprise.

Iea.com. (2019). Definition and Domains of Ergonomics. Retrieved from https://www.iea.cc/whats/

Jałowiecki, A., Kłusek, P., \& Skarka, W. (2017). Skeleton-based Generative Modelling method in the context of increasing functionality of virtual product assembly. Procedia Manufacturing, 11, 2211-2218. 
Kaare, K. K., \& Otto, T. (2015). Smart health care monitoring technologies to improve employee performance in manufacturing. Procedia Engineering, $100,826-833$.

Kaasinen, E., Schmalfuß, F., Özturk, C., Aromaa, S., Boubekeur, M., Heilala, J., . . . Walter, T. (2019). Empowering and engaging industrial workers with Operator 4.0 solutions. Computers \& Industrial Engineering. doi:10.1016/j.cie.2019.01.052

Kim, I. J. (2016). Cognitive Ergonomics and Its Role for Industry Safety Enhancements. Journal of Ergonomics, 6(4). doi:10.4172/2165$7556.1000 \mathrm{e} 158$

Kinzel, H. (2017). Industry 4.0-Where does this leave the Human Factor? Journal of Urban Culture Research, 15, 70-83.

Kopetz, H. (2011). Real-time systems: design principles for distributed embedded applications: Springer Science \& Business Media.

Kyoung-Dae, K., \& Kumar, P. R. (2012). Cyber-Physical Systems: A Perspective at the Centennial. Proceedings of the IEEE, 100(Special Centennial Issue), 1287-1308. doi:10.1109/jproc.2012.2189792

Kyriazis, D., \& Varvarigou, T. (2013). Smart, autonomous and reliable Internet of Things. Procedia Computer Science, 21, 442-448. 
Leitao, P., Karnouskos, S., Ribeiro, L., Lee, J., Strasser, T., \& Colombo, A. W. (2016). Smart Agents in Industrial Cyber-Physical Systems. Proceedings of the IEEE, 104(5), 1086-1101. doi:10.1109/jproc.2016.2521931

Lemaignan, S., Warnier, M., Sisbot, E. A., Clodic, A., \& Alami, R. (2017). Artificial cognition for social human-robot interaction: An implementation. Artificial Intelligence, 247, 45-69.

Li, S., Da Xu, L., \& Zhao, S. (2018). 5G Internet of Things: A survey. Journal of Industrial Information Integration, 10, 1-9.

Longo, F., Nicoletti, L., \& Padovano, A. (2017). Smart operators in industry 4.0: A human-centered approach to enhance operators' capabilities and competencies within the new smart factory context. Computers \& Industrial Engineering, 113, 144-159. doi:10.1016/j.cie.2017.09.016

Lucia, W., Sinopoli, B., \& Franze, G. (2016). A set-theoretic approach for secure and resilient control of cyber-physical systems subject to false data injection attacks. Paper presented at the 2016 Science of Security for Cyber-Physical Systems Workshop (SOSCYPS).

Macleod, D. (2008). 10 Principles of Ergonomics. Retrieved from https://www.danmacleod.com/ErgoForYou/10_principles_of_ergonomics.ht $\mathrm{m}$ 
Matsas, E., \& Vosniakos, G.-C. (2017). Design of a virtual reality training system for human-robot collaboration in manufacturing tasks. International Journal on Interactive Design and Manufacturing (IJIDeM), 11(2), 139-153.

Mattsson, S., Gullander, P., Harlin, U., Bäckstrand, G., Fasth, ̊̊., \& Davidsson, A. J. P. C. (2012). Testing complexity index-a method for measuring perceived production complexity. 3, 394-399.

Mehta, R. K. (2016). Integrating Physical and Cognitive Ergonomics. IIE Transactions on Occupational Ergonomics and Human Factors, 4(2-3), 8387. doi:10.1080/21577323.2016.1207475

Miorandi, D., Sicari, S., De Pellegrini, F., \& Chlamtac, I. (2012). Internet of things: Vision, applications and research challenges. Ad Hoc Networks, 10(7), 14971516.

Molano, J. I. R., Lovelle, J. M. C., Montenegro, C. E., Granados, J. J. R., \& Crespo, R. G. (2018). Metamodel for integration of internet of things, social networks, the cloud and industry 4.0. Journal of Ambient Intelligence and Humanized Computing, 9(3), 709-723.

Monostori, L., Kádár, B., Bauernhansl, T., Kondoh, S., Kumara, S., Reinhart, G., . . . Ueda, K. (2016). Cyber-physical systems in manufacturing. CIRP Annals, 65(2), 621-641. doi:10.1016/j.cirp.2016.06.005 
Moray, N., Groeger, J., \& Stanton, N. (2017). Quantitative modelling in cognitive ergonomics: predicting signals passed at danger. Ergonomics, 60(2), 206-220. doi:10.1080/00140139.2016.1159735

Muhuri, P. K., Shukla, A. K., \& Abraham, A. (2019). Industry 4.0: A bibliometric analysis and detailed overview. Engineering Applications of Artificial Intelligence, 78, 218-235. doi:10.1016/j.engappai.2018.11.007

Neumann, W. P., Kolus, A., \& Wells, R. W. (2016). Human factors in production system design and quality performance-a systematic review. IFACPapersOnLine, 49(12), 1721-1724.

Novak-Marcincin, J. (2011). Selected Applications of Virtual Reality in Manufacturing. Journal for Technology of Plasticity, 36(1), 25-34. doi:10.2478/v10211-011-0002-3

Novak, D., Beyeler, B., Omlin, X., \& Riener, R. (2014). Workload estimation in physical human-robot interaction using physiological measurements. Interacting with computers, 27(6), 616-629.

Ordaz, N., Romero, D., Gorecky, D., \& Siller, H. R. (2015). Serious games and virtual simulator for automotive manufacturing education \& training. Procedia Computer Science, 75, 267-274. 
Özdemir, V. (2019). Not all intelligence is artificial: Data science, automation, and AI meet HI. Omics: a journal of integrative biology, 23(2), 67-69.

Pearson, D., \& Sahraie, A. (2003). Oculomotor control and the maintenance of spatially and temporally distributed events in visuo-spatial working memory. The Quarterly Journal of Experimental Psychology Section A, 56(7), 10891111.

Pereira, A., \& Romero, F. (2017). A review of the meanings and the implications of the Industry 4.0 concept. Procedia Manufacturing, 13, 1206-1214.

Perera, C., Liu, C. H., \& Jayawardena, S. (2015). The emerging internet of things marketplace from an industrial perspective: A survey. IEEE Transactions on Emerging Topics in Computing, 3(4), 585-598.

Peres, R. S., Dionisio Rocha, A., Leitao, P., \& Barata, J. (2018). IDARTS - Towards intelligent data analysis and real-time supervision for industry 4.0. Computers in Industry, 101, 138-146. doi:10.1016/j.compind.2018.07.004

Pleskac, T. J., Dougherty, M. R., Busemeyer, J., Rieskamp, J., \& Tenenbaum, J. (2007). Cognitive decision theory: Developing models of real-world decision behavior. Paper presented at the Proceedings of the Annual Meeting of the Cognitive Science Society. 
PWC. (2015). How virtual and augmented reality technologies are reimagining America's factory floors. Disruptive Manufacturing Innovations Survey.

Rabelo, R. J., Romero, D., \& Zambiasi, S. P. (2018). Softbots Supporting the Operator 4.0 at Smart Factory Environments. 536, 456-464. doi:10.1007/9783-319-99707-0_57

Ramírez, O. A. I., Khambhaita, H., Chatila, R., Chetouani, M., \& Alami, R. (2016). Robots learning how and where to approach people. Paper presented at the 2016 25th IEEE international symposium on robot and human interactive communication (RO-MAN).

Rizzo, A., \& Buckwalter, J. (1997). Virtual reality and cognitive assessment and rehabilitation: The State ofthe Art. Psycho-neuro-physiological assessment and rehabilitation in virtual environments: cognitive, clinical and human factor $s$ in advanced human computer interactions.

Roda-Sanchez, L., Garrido-Hidalgo, C., Hortelano, D., Olivares, T., \& Ruiz, M. C. (2018). OperaBLE: an IoT-based wearable to improve efficiency and smart worker care services in Industry 4.0. Journal of Sensors, 2018.

Romero, D., Bernus, P., Noran, O., Stahre, J., \& Fast-Berglund, A. (2016). The operator 4.0: human cyber-physical systems \& adaptive automation towards human-automation symbiosis work systems. Paper presented at the IFIP International Conference on Advances in Production Management Systems. 
Romero, D., Stahre, J., Wuest, T., Noran, O., Bernus, P., Fast-Berglund, Å., \& Gorecky, D. (2016). Towards an operator 4.0 typology: a human-centric perspective on the fourth industrial revolution technologies. Paper presented at the Proceedings of the International Conference on Computers and Industrial Engineering (CIE46), Tianjin, China.

Romero, D., Wuest, T., Stahre, J., \& Gorecky, D. (2017). Social factory architecture: social networking services and production scenarios through the social internet of things, services and people for the social operator 4.0. Paper presented at the IFIP International Conference on Advances in Production Management Systems.

Segura, Á., Diez, H. V., Barandiaran, I., Arbelaiz, A., Álvarez, H., Simões, B., . . . Ugarte, R. (2018). Visual computing technologies to support the Operator 4.0. Computers \& Industrial Engineering.

Sénéchal, O., \& Trentesaux, D. (2019). A framework to help decision makers to be environmentally aware during the maintenance of cyber physical systems. Environmental Impact Assessment Review, 77, 11-22. doi:10.1016/j.eiar.2019.02.007

Shen, W., Hao, Q., Yoon, H. J., \& Norrie, D. H. (2006). Applications of agent-based systems in intelligent manufacturing: An updated review. Advanced engineering INFORMATICS, 20(4), 415-431. 
Smith, J. M. (2002). Advanced manufacturing. European Management Journal, 9(1), 114-115. doi:10.1016/0263-2373(91)90067-z

Sohlberg, M. M., \& Mateer, C. A. (1989). Introduction to cognitive rehabilitation: Theory and practice: Guilford Press.

Stadnicka, D., Litwin, P., \& Antonelli, D. (2019). Human factor in intelligent manufacturing systems - knowledge acquisition and motivation. Procedia CIRP, 79, 718-723. doi:10.1016/j.procir.2019.02.023

Terziyan, V., Gryshko, S., \& Golovianko, M. (2018). Patented intelligence: Cloning human decision models for Industry 4.0. Journal of Manufacturing Systems, 48, 204-217. doi:10.1016/j.jmsy.2018.04.019

Thorsten Wuest, D. R., Johan Stahre. (2017). Introducing 'Operator 4.0,' a techaugmented human worker. THE CONVERSATION( ).

Uva, A. E., Gattullo, M., Manghisi, V. M., Spagnulo, D., Cascella, G. L., \& Fiorentino, M. (2018). Evaluating the effectiveness of spatial augmented reality in smart manufacturing: a solution for manual working stations. The International Journal of Advanced Manufacturing Technology, 94(1-4), 509521. 
Valdeza, A. C., Braunera, P., Schaara, A. K., Holzingerb, A., \& Zieflea, M. (2015). Reducing complexity with simplicity-usability methods for industry 4.0. Paper presented at the Proceedings 19th triennial congress of the IEA.

Voet, H., Altenhof, M., Ellerich, M., Schmitt, R. H., \& Linke, B. (2019). A Framework for the Capture and Analysis of Product Usage Data for Continuous Product Improvement. Journal of Manufacturing Science and Engineering, 141(2), 021010.

Wang, S., Wan, J., Li, D., \& Zhang, C. (2016). Implementing smart factory of industrie 4.0: an outlook. International Journal of Distributed Sensor Networks, 12(1), 3159805.

Woźniak, M., Graña, M., \& Corchado, E. (2014). A survey of multiple classifier systems as hybrid systems. Information Fusion, 16, 3-17.

Xu, L. D., \& Duan, L. (2018). Big data for cyber physical systems in industry 4.0: a survey. Enterprise Information Systems, 13(2), 148-169. doi:10.1080/17517575.2018.1442934

Xu, P., Mei, H., Ren, L., \& Chen, W. (2016). ViDX: Visual diagnostics of assembly line performance in smart factories. IEEE transactions on visualization and computer graphics, 23(1), 291-300. 
Young, M. S., Brookhuis, K. A., Wickens, C. D., \& Hancock, P. A. (2015). State of science: mental workload in ergonomics. Ergonomics, 58(1), 1-17.

Yung, M., Manji, R., \& Wells, R. P. (2017). Exploring the relationship of task performance and physical and cognitive fatigue during a daylong light precision task. Human factors, 59(7), 1029-1047.

Zolotová, I., Papcun, P., Kajáti, E., Miškuf, M., \& Mocnej, J. (2018). Smart and cognitive solutions for Operator 4.0: Laboratory H-CPPS case studies. Computers \& Industrial Engineering. 
APPENDIX 
Faculty / Department:

Degree (Current Level):

Age:

Please consider how well the following statements fit with the task you did.

The scale range is $\mathbf{1 - 5}$, with $\mathbf{1}$ as "I do not agree at all" and 5 as "I totally agree".

\section{Task and Operation}

1. The considered time is generally enough for me to perform my tasks.

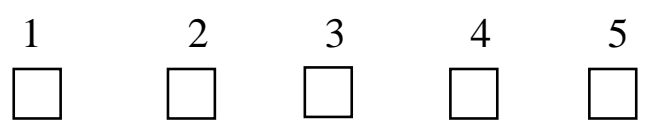

Do not

Totally

Agree at all

Agree

2. My task operationwas affected by unplanned changes/uncertainties such as (new instructions/variants, or machine disturbances)

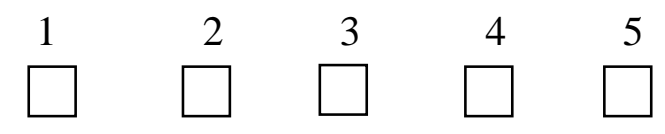

Do not Totally

Agree at all Agree

3. During unplanned changes/uncertainties, there is enough time for me to perform my task.

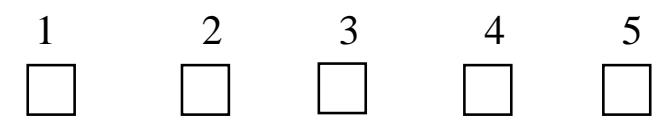
Do not
Agree at all
Totally
Agree

4. During unplanned changes/uncertainties (new instructions/variants, or machine disturbances), it was still easy to find the information needed to continue the task.

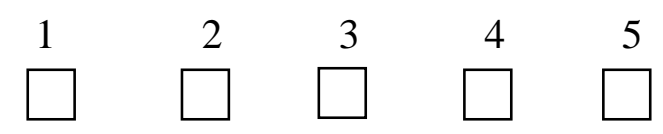

$\begin{array}{ll}\text { Do not } & \text { Totally } \\ \text { Agree at all } & \text { Agree }\end{array}$

5. During my task performance, Ifelt stressed and/or frustrated.

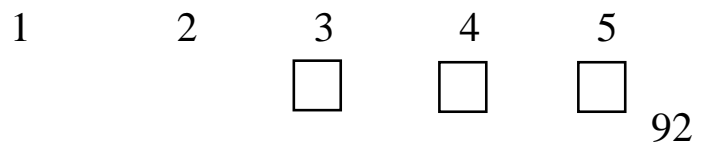




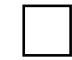

Do not

Agree at all

Totally

Agree

\section{Control tablet software and User Interface}

6. There are many different icons in the interface

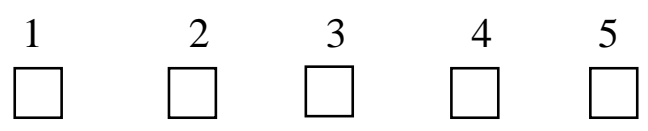

Do not

Totally

Agree at all

Agree

7. Many icons are similar to one another in function.

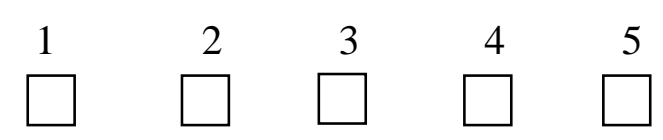

Do not

Totally

Agree at all

Agree

8. This user interface is well-designed regardingthe given task.

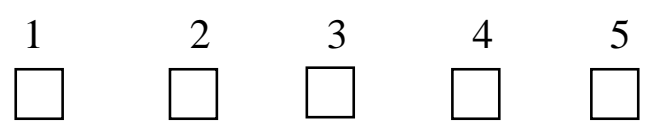

Do not

Agree at all

Totally

Agree

9. This software interface is well ergonomically designed for the specified task. (such as chosen colors, button shapes/icons, buttons distances).

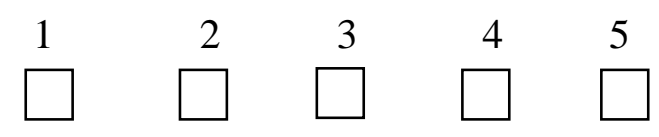

Do not

Totally

Agree at all

Agree

10. Please write your comments for any suggestion of improvement (optional) 
Thank you for your kind participation for answering the survey. Your answers are very much appreciated.

Please feel free to contact me for any details.

Mohamad Fallaha

Email: muhamed.fallaha@gmail.com 